This is the final peer-reviewed accepted manuscript of:

Musiani, F.; Gioia, D.; Masetti, M.; Falchi, F.; Cavalli, A.; Recanatini, M.; Ciurli S. (2017) J. Chem. Theory Comput., 13:2322-2331. "Protein tunnels: the case of urease accessory proteins".

The final published version is available online at:

http://dx.doi.org/10.1021/acs.jctc.7b00042

Rights / License:

The terms and conditions for the reuse of this version of the manuscript are specified in the publishing policy. For all terms of use and more information see the publisher's website.

This item was downloaded from IRIS Università di Bologna (https://cris.unibo.it/)

When citing, please refer to the published version. 


\section{Protein tunnels: the case of urease accessory proteins}

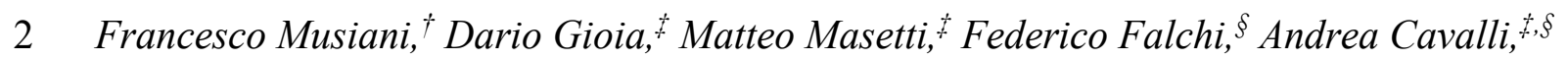

3 Maurizio Recanatini, ${ }^{*}$ and Stefano Ciurli ${ }^{\dagger * *}$

4

5 'Laboratory of Bioinorganic Chemistry, Department of Pharmacy and Biotechnology, University

6 of Bologna, Viale G. Fanin 40, I-40127, Bologna, Italy.

7 Laboratory of Computational Medicinal Chemistry, Department of Pharmacy and

8 Biotechnology, University of Bologna, Via Belmeloro 6, I-40126, Bologna, Italy.

$9 \quad{ }^{\S}$ Compunet, Istituto Italiano di Tecnologia, Via Morego 30, I-16163, Genova, Italy.

11 ABSTRACT

12 Transition metals are both essential micronutrients and limited in environmental availability. The

$13 \mathrm{Ni}(\mathrm{II})$-dependent urease protein, the most efficient enzyme known to date, is a paradigm for

14 studying the strategies that cells use to handle an essential, yet toxic, metal ion. Urease is a

15 virulence factor of several human pathogens, in addition to decreasing the efficiency of soil

16 organic nitrogen fertilization. $\mathrm{Ni}(\mathrm{II})$ insertion in the urease active site is performed through the

17 action of three essential accessory proteins: UreD, UreF, and UreG. The crystal structure of the

18 UreD-UreF-UreG complex from the human pathogen Helicobacter pylori (HpUreDFG) revealed

19 the presence of tunnels that cross the entire length of both UreF and UreD, potentially able to 
1 deliver $\mathrm{Ni}(\mathrm{II})$ ions from UreG to apo-urease. Atomistic molecular dynamics simulations

2 performed on the $H p$ UreDFG complex in explicit solvent and at physiological ionic conditions

3 demonstrate the stability of these protein tunnels in solution and provide insights on the

4 trafficking of water molecules inside the tunnels. The presence of different alternative routes

5 across the identified tunnels for $\mathrm{Ni}(\mathrm{II})$ ions, water molecules and carbonate ions, all involved in

6 urease activation, is highlighted here, and their potential role in the urease activation mechanism

7 is discussed.

\section{INTRODUCTION}

10 Transition metal ions are needed by all living organisms as essential micronutrients. ${ }^{1-2}$ Their

11 essentiality, coupled with their limited environmental availability and toxicity, has stimulated all

12 life forms to develop mechanisms for selective metal ions accumulation and utilization. ${ }^{3}$

13 Accordingly, all organisms possess metal homeostasis networks that ensure the availability and

14 the correct localization of metal ions in metallo-proteins and sub-cellular compartments. ${ }^{4}$ In

15 parallel, intracellular metal trafficking mechanisms maintain the concentration of free metal ions

16 in the cytoplasm under the physiological limits. ${ }^{5-7}$ Despite their biological and biophysical

17 relevance, metal trafficking processes in the cell and inside the proteins are still poorly

18 understood..$^{5-6}$

$19 \mathrm{Ni}(\mathrm{II})$ ions are essential for the survival of several and often deadly pathogenic strains of

20 Helicobacter, Staphylococcus, Clostridium, Vibrio, Mycobacterium, Yersinia, Escherichia,

21 Proteus, Ureaplasma, Klebsiella, Pseudomonas, Corynebacterium, Providencia, Morganella,

22 and Cryptococcus. These ureolytic bacteria rely on the activity of the enzyme urease (urea 
1 amidohydrolase; EC 3.5.1.5) to colonize and survive the host organism. ${ }^{8-9}$ Urease catalyzes urea

2 degradation to yield ammonia and bicarbonate and causing a local $\mathrm{pH}$ increase to values suitable

3 for bacterial survival. This is especially true in the case of Helicobacter pylori, a spiral-shaped

4 neutrophilic bacterium able to survive in the highly acidic gastric niche. ${ }^{10}$ The Center for Disease

5 Control and Prevention estimates that approximately two-thirds of the world's population

6 harbors H. pylori, whose infection can lead to stomach cancer and cause gastric mucosa-

7 associated lymphoid tissue lymphoma. ${ }^{11}$ In 1994, the International Agency for Research on

8 Cancer classified H. pylori, uniquely among bacteria, as a class-I carcinogen in humans. The

9 importance of this bacterium has been emphasized by the award of the Nobel Prize in Medicine

10 to Marshall and Warren in 2005, for their studies on the link between H. pylori infection with

11 gastritis and peptic ulcers. Moreover, the rising antibiotic resistance that affects the most

12 commonly used H. pylori eradication treatments requires the identification of new drug targets. ${ }^{12-}$

14 The knowledge of the activation mechanisms that lead from the inactive apo-urease to its active

15 holo-form, with the insertion of two essential $\mathrm{Ni}(\mathrm{II})$ ions in the active site of the enzyme, is thus

16 essential for the development of new drugs able to eradicate H. pylori infections. In particular, it

17 is fundamental to understand, at the molecular detail, the structure-function relationships for the

18 proteins that play key roles in this mechanism. The available crystal structures of ureases from

19 several bacteria and higher plants show a typical quaternary structure formed by a functional

20 minimal trimeric assembly. ${ }^{8-9}$ Each monomer is in turn composed by a single chain in ureases

21 from higher plants, as in the cases of jack bean (Canavalia ensiformis) $)^{14}$ and pigeon pea

22 (Cajanus cajan), ${ }^{15}$ by two chains in the case of $H$. pylori,${ }^{16}$ and by three chains in the cases of

23 Sporasarcina pasterurii and Klebsialla aerogenes ${ }^{8-9}$. The minimal trimeric assembly eventually 
1 forms dimers in higher plants or nearly spherical tetramers in H. pylori (Fig. 1A) ${ }^{16}$. Each

2 trimeric assembly hosts three conserved active sites, each containing two Ni(II) ions (Fig. 1B). ${ }^{9}$

3 Urease is produced in vivo in an inactive form, and its activation necessitates the carbamylation

4 of a key lysine in the active site to render this residue able to bind and bridge the two $\mathrm{Ni}(\mathrm{II})$

5 through the carbamate moiety, and the delivery of Ni(II) into the active site, two steps that

6 apparently require GTP hydrolysis and $\mathrm{CO}_{2}$ uptake. ${ }^{8}$ This activation process is carried out

7 through the action of four accessory proteins, named UreD (called UreH in H. pylori), UreF,

8 UreG, and UreE. ${ }^{8}$ UreD appears to be the first protein that binds apo-urease, although little is

9 known about its functional properties. ${ }^{17}$ UreF is proposed to bind the urease-UreD complex

10 through a direct interaction with $\mathrm{UreD},{ }^{18}$ facilitating the formation of the complex between apo-

11 urease and the UreD-UreF-UreG complex (UreDFG hereafter). ${ }^{19}$ UreG is a GTPase proposed to

12 couple GTP hydrolysis to the process of urease activation, and its putative role has been

13 proposed to be linked to the formation, in the presence of $\mathrm{CO}_{2}$, of carboxyphosphate, an

14 excellent carbamylation agent for the conserved metal-binding lysine in the enzyme active site. ${ }^{19}$

15 UreG is the first reported case of an intrinsically disordered enzyme,${ }^{20}$ which can retain

16 enzymatic activity because of the rigidity of the GTP binding site region while possessing

17 disordered regions involved in protein-protein recognition mechanisms, prodromal to a disorder-

18 to-order transition. ${ }^{21}$ UreF has also been proposed to act as a GTPase-activating protein (GAP) to

19 regulate the folding and the function of UreG.$^{22}$ Finally, UreE is known to be the metallo-

20 chaperone $\mathrm{e}^{23}$ in charge of delivering and transferring $\mathrm{Ni}(\mathrm{II})$ ions to the apourease-UreDFG

21 complex in a GTP-dependent activation process. ${ }^{24}$ The urease activation mechanisms proposed

22 so far involve either the sequential binding of UreD, UreF, and UreG to apo-urease ${ }^{8}$ (Fig. 1C), or

23 the direct interaction of a preformed UreDFG protein complex to the inactive form of the 
1 enzyme, to build a pre-activation complex that prepares apo-urease for nickel binding. $\mathrm{Ni}$ (II)

2 ions were suggested to be directly delivered by UreE to apo-urease in the final step of the

$3 \operatorname{process}^{24}$ (Fig. 1C). However, a recent study indicated the occurrence of a preliminary step of

$4 \mathrm{Ni}$ (II) translocation from $\mathrm{UreE}$ to $\mathrm{UreG}$ when the latter is not yet bound to the UreF and UreD

5 accessory proteins. ${ }^{25}$ According to this scheme, UreG subsequently separates from UreE to join

6 the preformed UreD-UreF assembly and form the Ni(II)-bound UreDFG complex. The latter

7 would finally interact with apo-urease completing the insertion of two $\mathrm{Ni}$ (II) ions into the

8 enzyme following GTP hydrolysis and through activation by carbonate ${ }^{25}$ (Fig. 1C).

9 The recent publication of the apo-UreDFG crystal structure from H. pylori (HpUreDFG, Fig.

10 1D), ${ }^{26}$ devoid of metal ions, represents a crucial breakthrough for the understanding of $\mathrm{Ni}(\mathrm{II})$

11 ions delivery to the apo-urease active site. The $H p$ UreDFG structure features a central core

12 composed by $H p \mathrm{UreF}$ in the same dimeric form as previously observed for $H p \mathrm{UreF}$ itself. ${ }^{27} \mathrm{~A}$

13 monomeric chain of $H p \mathrm{UreD}$ is bound to each $H p \mathrm{UreF}$ monomer in the same arrangement found

14 in the UreD-UreF crystal structure from H. pylori (HpUreDF). ${ }^{28}$ In the HpUreDFG complex, the

$15 H p \mathrm{UreG}$ dimer is bound to the $H p \mathrm{UreDF}$ complex interacting with a large concave region

16 formed on the $H p \mathrm{UreF}$ dimer surface and flanked, on each side, by one $H p \mathrm{UreD}$ monomer. In

17 the crystal structure of this super-complex, a GDP molecule is bound to each $H p$ UreG monomer.

18 A recent study on the metal-binding properties of recombinant $H p \mathrm{UreF}$, determined using site-

19 directed mutagenesis and isothermal titration calorimetry, indicated that His 229 and Cys231 in

$20 H p$ UreF are involved in $\mathrm{Ni}(\mathrm{II})$ binding in vitro, and are critical for urease activation in vivo. ${ }^{29}$

21 This result prompted a detailed analysis of the structure of the $H p$ UreDFG complex, which

22 revealed the presence of a large cavity at the interface between $H p \mathrm{UreF}$ and $H p \mathrm{UreG}$, containing

23 several internal water molecules interconnected through a network aligned along the long 
1 horizontal axis of the UreD-UreF $2-U r e D$ portion of the structure (Fig. 1E) ${ }^{29}{ }^{29}$ This internal water

2 network encompasses two nearly identical and symmetric tunnels going from the central cavity

3 in the complex and exiting near the $H p \mathrm{UreD} C$-terminal, passing through $H p \mathrm{UreF}$ in the vicinity

4 of His229 and Cys231, located at the interface between $H p \mathrm{UreF}$ and $H p \mathrm{UreD} .{ }^{29}$ This observation

5 prompted the proposal for a role of UreF in the metal ion transport through these tunnels during

6 urease activation. ${ }^{29}$ In particular, this hypothesis entails that $\mathrm{Ni}$ (II) ions, known to bind to a

7 conserved Cys-Pro-His (CPH) motif on the surface of the $H p$ UreG dimer ${ }^{8,30-31}$ facing $H p$ UreF in

8 the $H p$ UreDFG complex structure, can proceed through the tunnels in order to reach the apo-

9 urease active site. ${ }^{29}$ This hypothesis has subsequently received support by in vivo assays using

10 site-directed mutagenesis coupled with bioinformatics and atomistic molecular dynamics (MD)

11 simulations on UreD from $K$. aerogenes (KaUreD), of. ${ }^{32}$

12 Here, we use atomistic $200 \mathrm{~ns}-$ long MD simulations in explicit solvent to extend the

13 investigation to the structural fluctuations and the stability of the full $H p$ UreDFG complex,

14 focusing the analysis on the dynamic behavior of the internal tunnels that encompass the entire

15 protein super-complex. Our findings indicate that the tunnels are persistent during the

16 investigated time of the MD simulation, further suggesting alternative routes for $\mathrm{Ni}(\mathrm{II})$ and

17 carbonate ions during the urease activation process. The results of this study represent the

18 starting point for atomistic simulations of $\mathrm{Ni}(\mathrm{II})$ permeation through the tunnels in the full

$19 H p$ UreDFG complex by using enhanced sampling algorithms. 
1 The $H p$ UreDFG crystal structure from H. pylori strain 26695 (PDB code: $4 \mathrm{HI} 0)^{26}$ was used. The

2 most probable protonation state of titratable amino acids, and the tautomeric state of histidine

3 residues at neutral $\mathrm{pH}$, were assigned through the Protein Preparation wizard tool of the

4 Schrödinger suite 2015.4. ${ }^{33}$ The complex was embedded into a truncated octahedron water box

5 using an 11-Å buffer zone of solvent around the protein complex. The resulting system consisted

6 of ca. 337,000 atoms. The Amber ff99SB force fields ${ }^{34}$ for the protein and the TIP3P model ${ }^{35}$ for

7 water were used, while known parameters were applied to the GDP molecule found in the crystal

8 structure. ${ }^{36}$ The systems were neutralized by adding $\mathrm{Na}^{+}$and $\mathrm{Cl}^{-}$ions using the genion program

9 of the GROMACS 4.6.2 package. ${ }^{37-39}$ Analogously, additional $\mathrm{Na}^{+}$and $\mathrm{Cl}^{-}$ions were placed in

10 the water box to achieve the physiological ionic strength $(150 \mathrm{mM})$. A total of $350 \mathrm{Na}^{+}$and 316

$11 \mathrm{Cl}^{-}$ions were added. The system was energy-minimized and then equilibrated at $300 \mathrm{~K}$ and $1 \mathrm{~atm}$

12 by performing $1 \mathrm{~ns}$ of gradual annealing using GROMACS 4.6.2. The geometry optimization

13 was performed in four cycles. In the first two cycles, which comprised 800 steps of steepest

14 descent followed by 3000 steps of conjugate gradient, the water molecules were relaxed while

15 the protein was constrained using a harmonic potential with a force constant of $1,000 \mathrm{~J} \mathrm{~mol}^{-1} \AA^{-2}$.

16 In the third and in the fourth cycles the procedure was repeated without applying any constraint.

17 During this equilibration phase, positional constraints were applied on the protein atoms and on

18 GDP (force constant of $1,000 \mathrm{~J} \mathrm{~mol}^{-1} \AA^{-2}$ ). The temperature and pressure was controlled using a

19 Berendsen thermostat and barostat, ${ }^{40}$ respectively. An integration step of $1 \mathrm{fs}$ was used, and the

20 structures were sampled every 0.1 ps. Periodic boundary conditions (PBC) were applied. The

21 Particle Mesh Ewald (PME) method was used to calculate electrostatic interactions. ${ }^{41}$ The cut-off

22 values for the real part of the electrostatic interactions and for the van der Waals interactions

23 were set to $10 \AA$. In the 200 ns-long production run, the temperature and pressure coupling was 
1 made using a Nose-Hoover thermostat ${ }^{42-43}$ and a Parrinello-Raman barostat, ${ }^{44-45}$ respectively.

2 The calculations were performed using the Eurora and the PLX supercomputers at CINECA 3 (Italy).

4 The program CAVER $3.0^{46}$ was used to calculate all pathways departing from the $H p U r e G \mathrm{CPH}$ 5 motif region within 2,000 superimposed MD snapshot of the $H p$ UreDFG complex. All water

6 molecules were removed before the tunnel calculation. The starting point of the tunnel search

7 was calculated as the average position between the $H p \mathrm{UreG} C y s 66 \mathrm{~S} \gamma$ atoms from each $H p \mathrm{UreG}$

8 monomer. The tunnel search was performed using a probe of $0.9-\AA$ radius. This probe was

9 selected for two reasons: i) it is the CAVER 3.0 default value for the determination of molecular

10 tunnels using molecular dynamics simulations, ${ }^{46}$ and ii) it provides a reasonable agreement with

11 the shape of the water density inside the tunnels (see below). The GDP molecules were

12 considered in the computation in order to avoid bias due to the $H p$ UreG GTP/GDP solvent

13 exposed cavity. Each tunnel is determined as an ensemble of beads of radii selected to fit the

14 tunnel diameter. The identified tunnels were clustered by hierarchical average link by calculating

15 the pairwise distances (i.e. dissimilarities) among the centers of the beads for all the computed

16 tunnels.

$17 \mathrm{H} p \mathrm{UreD}$ residue conservation was analyzed using the ConSurf server. ${ }^{47}$ The server calculates

18 conservation on the basis of a PSI-BLAST analysis ${ }^{48}$ that retrieved the best $150 \mathrm{UreD}$ sequences

19 with more than $15 \%$ and less than $90 \%$ sequence identity with respect to $H p U r e D$. Residue

20 conservation was mapped on the $H p \mathrm{UreD}$ structure found in the $H p \mathrm{UreDFG}$ complex (PDB

21 code: $4 \mathrm{HI} 0)^{26}$. Molecular graphics and analyses were performed using the UCSF Chimera

22 package $^{49}$ and VMD. ${ }^{50}$ 
1 Solvent molecules passing through or in the vicinity of the tunnel bottleneck characterized by

$2 H p$ UreD residues Arg95 and Asp140 (see Results and Discussion section below) were filtered

3 out from the remaining part of the solvent by selecting the water molecules passing within $3.2 \AA$

4 of the tunnel-facing atoms of Arg95 and Asp140 along the entire trajectory. The volumetric

5 density map of the selected water molecules was then created using the VolMap plugin in VMD.

6 VolMap replaced each oxygen atom of the selected water molecules with a normalized Gaussian

7 distribution of width corresponding to the oxygen atomic radius. The superimposition of all the

8 trajectory frames were used to compute the resulting density map. An in-house tcl script was

9 used to calculate the time spent inside the tunnels by the selected water molecules.

\section{RESULTS AND DISCUSSION}

12 To gain a deeper understanding of the structural and dynamic behavior of the $H p$ UreDFG

13 complex, we ran one $200 \mathrm{~ns}$-long MD simulation in explicit solvent, using an atomistic force

14 field. The root-mean-square-deviation (RMSD) of the $\mathrm{C} \alpha$ atoms of the complex from the initial

15 conformation stabilizes after ca. $25 \mathrm{~ns}$ and then oscillates around $2.0 \AA$ for the remaining time of

16 the simulation (Fig. 1-SI in the Supplementary Information). The RMSD of each protein forming

17 the complex stabilizes after a short period (less than $25 \mathrm{ns)}$ ) and remains stable around values of

18 ca. $1.0,1.0$ and $1.5 \AA$ for $H p \mathrm{UreF}, H p \mathrm{UreD}$, and $H p \mathrm{UreG}$, respectively (Fig. 2-SI). This

19 observation, together with the constant secondary structure content of the complex (Fig. 3-SI)

20 indicates that the simulation was long enough to relax and equilibrate each protein within the

$21 H p$ UreDFG complex. In particular, the $H p$ UreG dimer remains well-folded and stable along the

22 simulation (Fig. 4-SI), especially in those regions that were predicted to be intrinsically unfolded 
1 through bioinformatics predictions ${ }^{20}$ and MD calculations conducted on the $H p$ UreG model

2 structure before the release of the $H p U r e G$ crystal structure. ${ }^{21}$ Apparently, the interaction

3 between $H p \mathrm{UreF}$ and the predicted intrinsically unfolded region of $H p \mathrm{UreG}$ (residues 38-94,

4 128-137, and 155-176) stabilizes the latter in the simulation time scale, consistently with the

5 hypothesis that UreF acts as a GTPase activator (GAP) for UreG. ${ }^{22}$

6 Analysis of the tunnels. Following the assessment of the overall structure stability of the

7 HpUreDFG complex, the tunnels departing from the cysteine residues in the conserved CPH

8 motif of the $H p U r e G$ dimer, and able to pass through the entire complex in order to eventually

9 transport the $\mathrm{Ni}(\mathrm{II})$ ions needed for urease activation to $H p \mathrm{UreG}$ to $H p \mathrm{UreD}$, were then

10 examined. The software CAVER 3.0 was used for the analysis of 2,000 snapshots from the 200

11 ns-long trajectory of $H p$ UreDFG. In each snapshot, all possible pathways with a bottleneck

12 radius equal or larger than $0.9 \AA$ were identified, leading to a set of ca. 58,000 pathways along

13 the simulation. These pathways were clustered, using the average-link algorithm based on the

14 pairwise distances of the pathways, to yield 2,081 clusters. Considering the symmetry of the

$15 H p \mathrm{UreDFG}$ complex and the position along the major vertical axis of the starting point of the

16 tunnels (Fig. 2A), in principle each cluster of tunnels could have a symmetrically corresponding

17 tunnel. Moreover, considering further the symmetry of the system, each side of the $H p U r e D F G$

18 complex along the vertical axis can be considered independent from the other side. In other

19 words, by running $200 \mathrm{~ns}$ of simulation on the $H p$ UreDFG structure, we sampled a total of 400

20 ns of the tunnels dynamics. The analysis of the cluster of tunnels revealed that the largest portion

21 of the tunnels departing from the $\mathrm{CPH}$ motif passes through only $H p \mathrm{UreG}$ itself or $H p \mathrm{UreF}$ (Fig.

22 2A). On the other hand, it is possible to identify five pairs of symmetric clusters of tunnels

23 passing through both $H p \mathrm{UreF}$ and $H p \mathrm{UreD}$ (Table 1). Tunnels $1-3$ are present in about $30 \%$ of 
1 the analyzed frames, while tunnels 4 and 5 are closed for the large part of the simulation time.

2 We thus concentrate on tunnels 1-3 (Fig. 2B-D, Table 1 and 2), while tunnels 4 and 5 are 3 reported in the SI (Fig. 5-SI and Table 1-SI). From Table 1, it appears that the tunnels going

4 through the $H p$ UreDF monomer located on the left in Fig. 2B-D are more present and active 5 during the MD trajectory as compared to the tunnel on the $H p \mathrm{UreDF}$ monomer on the right. The 6 analysis of the tunnels' bottlenecks (i.e. the region of each tunnel showing the smallest tunnel 7 radius, Table 2 and Fig. 6,7,8-SI) revealed that the $H p$ UreD residues Arg95 and Glu140 are 8 among those more frequently found in a single bottleneck. Glu140 was also identified in a recent 9 study on $\mathrm{KaUreD}$ (Asp142 in K. aerogenes numeration) as one of the crucial residues in urease 10 maturation..$^{32}$ The analysis of the distance between $H p \mathrm{UreD}$ Arg95 $\mathrm{C} \zeta$ and Glu140 $\mathrm{C} \delta$ shows that 11 the side chains of these two residues are at different distances in the left and in the right $12 H p \mathrm{UreDF}$ monomer, respectively, as shown in Fig. 3A. In particular, in the $H p \mathrm{UreD}$ monomer

13 on the right side of the $H p$ UreDFG complex, the Arg95 C $\zeta$ - Glu140 C $\delta$ distance is less than $6 \AA$ 14 for the $95 \%$ of the simulation time, while in the monomer on the left side this happens only for 15 only $21 \%$ of the time. Consistently, $H p \mathrm{UreD}$ Arg95 and Glu140 side chains are involved in the 16 formation of a H-bond for $98 \%$ and $30 \%$ of the simulation time in the right and in the left $17 H p \mathrm{UreDF}$ monomer, respectively. When $H p \mathrm{UreD}$ Glu140 is not forming a H-bond with Arg95, 18 it can form a H-bond with the On atom of the $H p \mathrm{UreD}$ Tyr138 residue. The analysis of the H-

19 bonds formed by the side chains of $H p \mathrm{UreD}$ Tyr138 and Glu140 showed that one H-bond is 20 present between these residues for $54 \%$ and $5 \%$ of the simulation time in the left and in the right $21 H p$ UreDF monomer, respectively. A conservation analysis conducted using PSI-BLAST ${ }^{48}$

22 showed that Glu140 is conserved in $50 \%$ of the $H p$ UreD most similar sequences, while in the 23 remaining cases this residue is conservatively mutated with an aspartate. Arg95 is present in only 
$11 \%$ of the cases, while in $96 \%$ of the sequences it is mutated with a glutamine, which is

2 nevertheless able to form a H-bond with the residue in the position of Glu140 through its $-\mathrm{NH}_{2}$

3 group. Moreover, the residue in position 94 is not largely conserved, and is present as a tyrosine

4 in $36 \%$ of the cases, and as an arginine in $17 \%$ of the cases. Finally, in K. aerogenes UreD and

5 only in the $3 \%$ of the considered sequences, position 96 is again mutated with an arginine. ${ }^{32}$ In

6 the case of the model structure of $\mathrm{KaUreD}$ used for MD simulations, ${ }^{32}$ position 96 does not

7 correspond to an arginine because of possible misalignment between the structure of $\mathrm{KaUreD}$

8 and $H p U r e D$, for which the crystal structure has been experimentally determined. Tyr 138 is

9 present in $47 \%$ of the cases, while in the remaining sequences it is mostly mutated with a

10 glycine. On the other hand, $H p$ UreD Ser139 is frequently mutated with a tryptophan residue that

11 can ensure the formation of an H-bond with Glu140 through the nitrogen atom in the indole

12 group. Taken together, these results show that the formation of the Glu140-Tyr138 H-bond

13 opens the tunnels passing through $H p \mathrm{UreF}$ and $H p \mathrm{UreD}$ (Fig. 3B), while the presence of the

14 Arg95-Asp140 salt bridge closes the tunnels (Fig. 3C). In the present simulation, the Arg95-

15 Asp140 bottleneck in the left side of the structure is open for ca. $95 \%$ of the simulation time, but

16 only for ca. $70 \%$ of time on the right side. No correlation has been identified between the

17 open/close behaviour of the tunnels on the left with the respect of the tunnels on the right,

18 suggesting a completely stochastic situation.

19 Tunnels 1, 2 and 3 coincide from the starting $\mathrm{CPH}$ motif at the interface of the $\mathrm{HpUreG}$ dimer

20 until they reach the $H p$ UreD Arg95-Asp140 bottleneck (Fig. 2B-D). In this region, these three

21 most populated tunnels split to reach different regions on the $H p U$ reD surface. Tunnels 1 and 2

22 emerge in highly conserved region of the $H p$ UreD surface, while tunnel 3 flows into a less

23 conserved zone (Table 2). HpUreD is composed by $17 \beta$-strands and $2 \alpha$-helices. The structure is 
1 characterized by two mixed strand $\beta$-sheets with $\beta$-strands $\beta 1, \beta 2, \beta 5, \beta 8, \beta 11, \beta 13$, and $\beta 14$

2 forming $\beta$-sheet I and $\beta$-strands $\beta 3, \beta 4, \beta 6, \beta 7, \beta 9, \beta 10, \beta 12$, and $\beta 15$ - $\beta 17$ forming $\beta$-sheet II

3 (Fig. 4A). Helix $\alpha 1$ and $\alpha 2$ are packed against anti-parallel $\beta$-strands $\beta 15-\beta 17$ to form an $\alpha / \beta$-like

4 motif located at the $\mathrm{C}$-terminus of $\beta$-sheet II. The $\mathrm{C}$-terminal regions of both $\beta$-sheets I and II

5 constitute the interacting region with $H p$ UreF. Tunnel 1 passes through $\beta$-strand $\beta 9, \beta 10$ and $\beta 12$

6 in $\beta$-sheet II and emerges in the space between helix $\alpha 2$ and $\beta$-strand $\beta 6$ (Table 2 and Fig. 4A).

7 Tunnel 1 is characterized by a second bottleneck located at the $H p \mathrm{UreF}-H p \mathrm{UreD}$ interface and

8 involving Ala233, Val235, Lys237 and Asp238 on the $H p U r e F$ side together with $H p U r e D$

9 Asp174, Thr176, Tyr197 and Asn199 residues. In the vicinity of this bottleneck, the two $H p$ UreF

10 residues His229 and Cys231 were experimentally found to be involved in $\mathrm{Ni}(\mathrm{II})$ binding events

11 critical for urease activation in vivo. ${ }^{29}$ Indeed, all the most populated tunnels pass through this

12 region, and $H p \mathrm{UreD}$ Asp174 was among the identified residues in $\mathrm{KaUreD}$ to be crucial for

13 urease activation, ${ }^{32}$ while Asn199 mutation resulted only in a small but recognizable reduction of

14 urease activation. The mouth of tunnel 1 remains open for all the simulation time and is

15 stabilized by the formation of one salt-bridge between the side chains of $H p \mathrm{UreD} \operatorname{Arg} 76$ and

16 Glu251 (Fig. 4B). Tunnel 2 passes through the space between $\beta$-sheets I and II and emerges in

17 the vicinity of $\beta$-strands $\beta 1, \beta 3, \beta 4$, and $\beta 6$ (Table 2 and Fig. 4A). Also in this case, the exit

18 mouth of tunnel 2 remains open for all the simulation time and is stabilized by a dense $\mathrm{H}$ -

19 bonding network involving $H p$ UreD Ser54, Asp61, Gln63, and Glu83 (Fig. 4C). Among these

20 residues, $H p \mathrm{UreD}$ Asp61 and Glu83 are in the list of crucial residues for urease activation

21 identified in a mutagenesis/MD study on $\mathrm{KaUreD},{ }^{32}$ while Ala52, Met57, Gln63, and Lys84

22 mutations did not alter the $K$. aerogenes urease activity with respect of the level of active

23 enzyme obtained using the wild type $\mathrm{KaUreD}$. Moreover, the exit mouth of tunnel 2 is located in 
1 a highly conserved surface region of $H p \mathrm{UreG}$, and this region has been proposed to act as the

2 UreD/urease binding interface. ${ }^{32}$ Finally, tunnel 3 passes through the space between $\beta$-sheets I

3 and II, and crosses the entire length of the $H p U$ reDF complex exiting between $\beta$-strands $\beta 1$ and

$4 \quad \beta 2$ (Table 2 and Fig. 4A). The tunnel mouth is open for the largest part of the simulation time

5 even if some hydrophobic residues (HpUreD Ile24, Leu35, and Ala37) can close at times the

6 access to the bulk of the solvent (Fig. 4D). Indeed, these three residues are also found among the

7 most frequent bottleneck residues for tunnel 3 (Table 2 and Fig. 8-SI). As for the residues

8 identified in this region (Table 2), Leu35 mutation in $\mathrm{KaUreD}$ didn't produce large changes in

9 urease activation levels with respect to the wild type, while the mutation of Tyr40 resulted in a

10 small reduction. ${ }^{32}$ All the remaining mutated $\mathrm{KaUreD}$ residues that didn't show any relevant

11 activity on urease maturation (Asp44, Ala46, Glu47, His86, Asn87, Phe109, Thr126, Arg146,

12 Glu151, Lys161, Ser163, Glu167, and Arg213 in HpUreD numeration) are not involved in any of

13 the tunnels identified in the present study.

14 These results shows that the tunnels observed in the $H p$ UreDFG crystal structure and passing

15 through each $H p$ UreDF monomer are stable in the simulation time scale and can open and close

16 in the nanoseconds - tens of nanoseconds time scale. The three most present tunnels, observed

17 during the simulation, feature openings in different regions of the $H p \mathrm{UreD}$ structure. The exit of

18 tunnel 2 is found in a conserved region proposed to be in contact with apo-urease ${ }^{32}$ and thus

19 tunnel 2 should be the preferred pathway for $\mathrm{Ni}(\mathrm{II})$ ions during urease maturation. However, the

20 role of tunnel 1 and 3 has not been elucidated yet. Even when the $H p$ UreD Arg95-Glu140

21 bottleneck is closed, the tunnels mouths are open for the largest part of the simulation time and

22 can theoretically be navigated by water molecules coming from the tunnels or from the bulk of

23 the solvent. In order to gather additional information on the role of the three tunnels passing 
1 through the $H p U r e D F$ monomers, we analyzed the dynamic behavior of water molecules present

2 inside the tunnels.

3 Water molecules trafficking inside the tunnels. The presence and persistence of the identified

4 tunnels passing through each $H p$ UreDF dimer in the simulation time scale is not enough to

5 demonstrate the effective passage of water molecules together with $\mathrm{Ni}$ (II) ions through the

6 tunnels during the urease activation process. We thus focused our attention on the water

7 molecules passing at $\mathrm{H}-$ bond distance from the $H p \mathrm{UreD}$ Arg95-Asp140 bottleneck of tunnels 1-

83 . This analysis resulted in 511 out of the initial 108,896 water molecules. The density of water

9 molecules calculated from the trajectory of these 511 specimens retraces with very good

10 agreement the shape of the tunnels (Fig. 5A). We then concentrated only on those water

11 molecules that are able to enter in the tunnels from the bulk of the solvent or that escape from the

12 tunnels during the simulation. For this analysis we developed an in-house algorithm built on the

13 following assumptions/approximations: i) a total number of fourteen overlapping spheres of

14 radius equal to $15 \AA$ were used to encompass the water molecules density map contoured at

150.025 oxygen atoms $\AA^{-3}$ (Fig. 12-SI). This step allowed us to unambiguously define the edges of

16 the tunnels in a computationally efficient way; ii) a water molecule entering the tunnels was

17 defined as a molecule moving from the bulk of the solvent (i.e. from outside the spheres defined

18 above) to the interior of at least one of the spheres and spending no less than 5 consecutive ps

19 inside the tunnels; vice versa, a water molecule exiting the tunnels was defined when the same

20 movement occurred in the opposite direction; iii) in order to avoid artifacts due to the way the

21 spheres were defined, only water molecules with a persistence inside the tunnels greater than 1

22 ns were considered. This analysis allowed us to identify a subset of 370 water molecules moving

23 from or into the tunnels during the course of the simulation and spending an average time of ca. 
152 ns inside the tunnels. Ca. $30 \%$ of these water molecules spent less than $10 \mathrm{~ns}$ inside the

2 tunnels, but a considerable amount of them (ca. 20\%) remained inside the tunnels for more than

3 half of the simulation time (Fig. 13-SI). The visual inspection of these 370 water molecules

4 revealed that the majority of them explore only a small portion of the tunnels. On the other hand,

546 water molecules were able to cover almost one half of the tunnels inside almost one of the

6 monomers composing the $H p$ UreDFG complex (Fig. 14-SI). Among these water molecules, only

7 two passed in the proximity of the Arg95-Asp140 bottleneck on the right side, possibly due to

8 the persistent closure of that gateway during the simulation. On the other hand, in the remaining

944 cases, 13 water molecules were able to pass from $H p \mathrm{UreF}$ to $H p \mathrm{UreD}$ or vice versa. Fig. 5B-E

10 reports selected examples of such water molecules, able to traverse a large part of tunnel 1.

11 These water molecules started their journey from the inside of the protein complex (Fig. 5B,C),

12 or come from the bulk of the solvent and enter the tunnels at the $H p$ UreG- $H p$ UreF interface (Fig.

$135 \mathrm{D}$ ) or from the mouth of tunnel 1 (Fig. 5E). Among the selected solvent molecules, there are

14 cases of water molecules entering/exiting the tunnel from the mouth of tunnel 2 (6 cases) and

15 tunnel 3 (3 cases), demonstrating the feasibility of these routes for the trafficking of water

16 molecules within the $H p U r e D F G$ protein supercomplex.

18 CONCLUSIONS

19 The $H p$ UreDFG complex and the tunnels observed in the crystal structure appear to be stable in

20 solution in the hundreds of nanoseconds time scale. The traffic of water molecules inside the

21 tunnels that start from the proposed $\mathrm{Ni}(\mathrm{II})$ binding site located at the $H p \mathrm{UreG}-H p \mathrm{UreF}$ interface

22 and pass through $H p \mathrm{UreF}$ and $H p \mathrm{UreD}$ can be regulated by the opening of two main bottlenecks, 
1 the first located at the $H p \mathrm{UreF}-H p \mathrm{UreD}$ interface (bottleneck 1), which remains always open,

2 and the second in the core of $H p \mathrm{UreD}$ (bottleneck 2). The latter appears to be of particular

3 importance because it is able to control the flow of water molecules as well as $\mathrm{Ni}(\mathrm{II})$ ions.

4 Indeed, $\mathrm{Ni}(\mathrm{II})$ ions can travel through the tunnels either in their hydrated form, or directly

5 establishing bonds with the atoms found on the tunnels' walls, as reported for other ions, ${ }^{51-53}$

$6 \mathrm{Ni}(\mathrm{II})$ ions have a smaller radius $(0.83 \AA)^{54}$ with respect to water molecules, but their movement

7 can be stopped by the closure of bottleneck 2 . The latter can further regulate the access to three

8 different tunnel openings on the $H p$ UreD surface. In particular, the exit of tunnel 2 is in the

9 vicinity of $H p$ UreD Asp61 and Glu83, two crucial residues for urease activation, ${ }^{32}$ suggesting

10 that this route is favorable for $\mathrm{Ni}(\mathrm{II})$ ions trafficking from $H p \mathrm{UreG}$ to the apo-urease reaction site

11 (see Scheme 1). On the other hand, tunnel 1 is the most stable along the simulation and its

12 opening mouth is also located in a highly conserved region on the $H p U r e D$ surface. Considering

13 that i) $\mathrm{Ni}$ (II) insertion in the urease reaction site should be subsequent to the carbamylation of a

14 conserved lysine residue, ii) a carbonate/bicarbonate ion cannot pass through the bottlenecks of

15 the tunnels inside the $H p$ UreDFG complex because of size constraints, and iii) the opening of

16 tunnel 1 shows the largest diameter with respect of the exits of tunnels 1 and 3 , we put forth the

17 hypothesis of the possible involvement of the terminal part of tunnel 1 in the

18 carbonate/bicarbonate transport inside the reaction site of apo-urease through the terminal part of

19 tunnel 2 (see Scheme 1).

20 The present study highlights the presence of potential distinct routes for the traffic of $\mathrm{Ni}(\mathrm{II})$ ions,

21 water molecules, and carbonate ions, all necessary for the activation of urease through

22 incorporation of the metal ions and the carbamylation of the conserved lysine residue that is

23 essential for $\mathrm{Ni}$ (II) binding and positioning in the active site. The identified bottlenecks can 
1 represent potential new targets for drugs aimed at eradicating infections by ureolytic human

2 pathogens as alternative to the currently used antibiotic treatments. The present results, together

3 with the development of a multi-site model of $\mathrm{Ni}(\mathrm{II})$ ions currently underway in our laboratories,

4 pave the way to the atomistic simulations of $\mathrm{Ni}(\mathrm{II})$ permeation through the $H p$ UreDFG tunnels. 

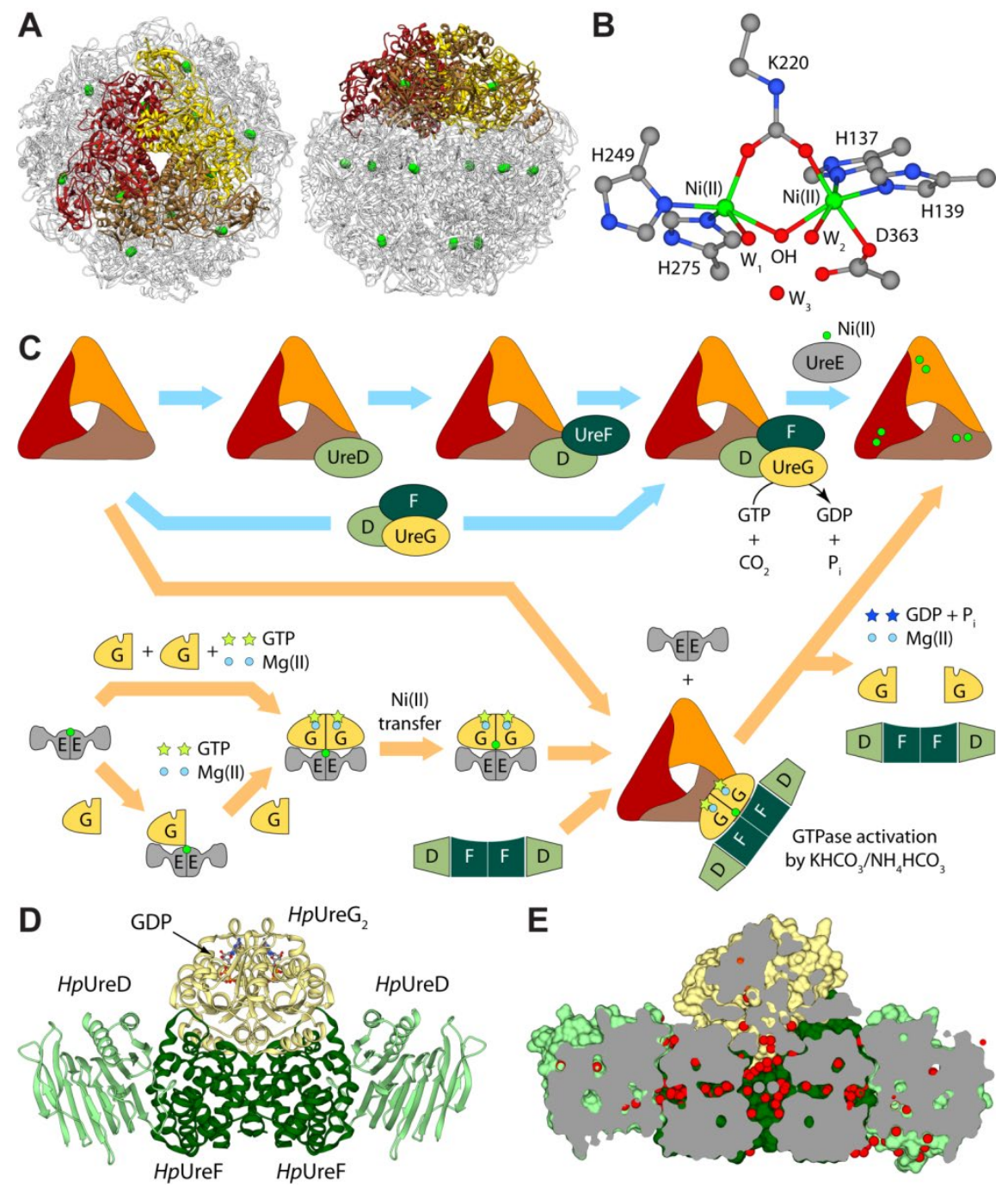

3 Figure 1. (A) Ribbon diagram of urease from H. pylori (PDB code: 1E9Z). Ribbon colors

4 highlight the chains composing the trimer of oligomers constituting the minimal quaternary

5 structure of urease. $\mathrm{Ni}(\mathrm{II})$ ions are reported as green spheres. The right panel is rotated by $90^{\circ}$

6 around the horizontal axis vs. the left panel. (B) Coordination geometry of the Ni(II) ions in

7 native urease active site (source Sporosarcina pasteurii, PDB code 4CEU). Color scheme:

8 nickel, green; carbon, gray; nitrogen, blue; oxygen, red. (C) Schematic representation of the

9 proposed mechanisms for urease activation. (D) Ribbon diagram and (E) longitudinal section of 
1 the solvent-excluded surface of the apo $H p \mathrm{UreDFG}$ crystal structure (PDB code $4 \mathrm{HI} 0$ ). $H p \mathrm{UreD}$,

$2 H p \mathrm{UreF}$, and $H p \mathrm{UreG}$ chains are colored as in panel (C). Water molecules are depicted as red

3 spheres, GDP is reported as balls-and-sticks and colored according to atom type.
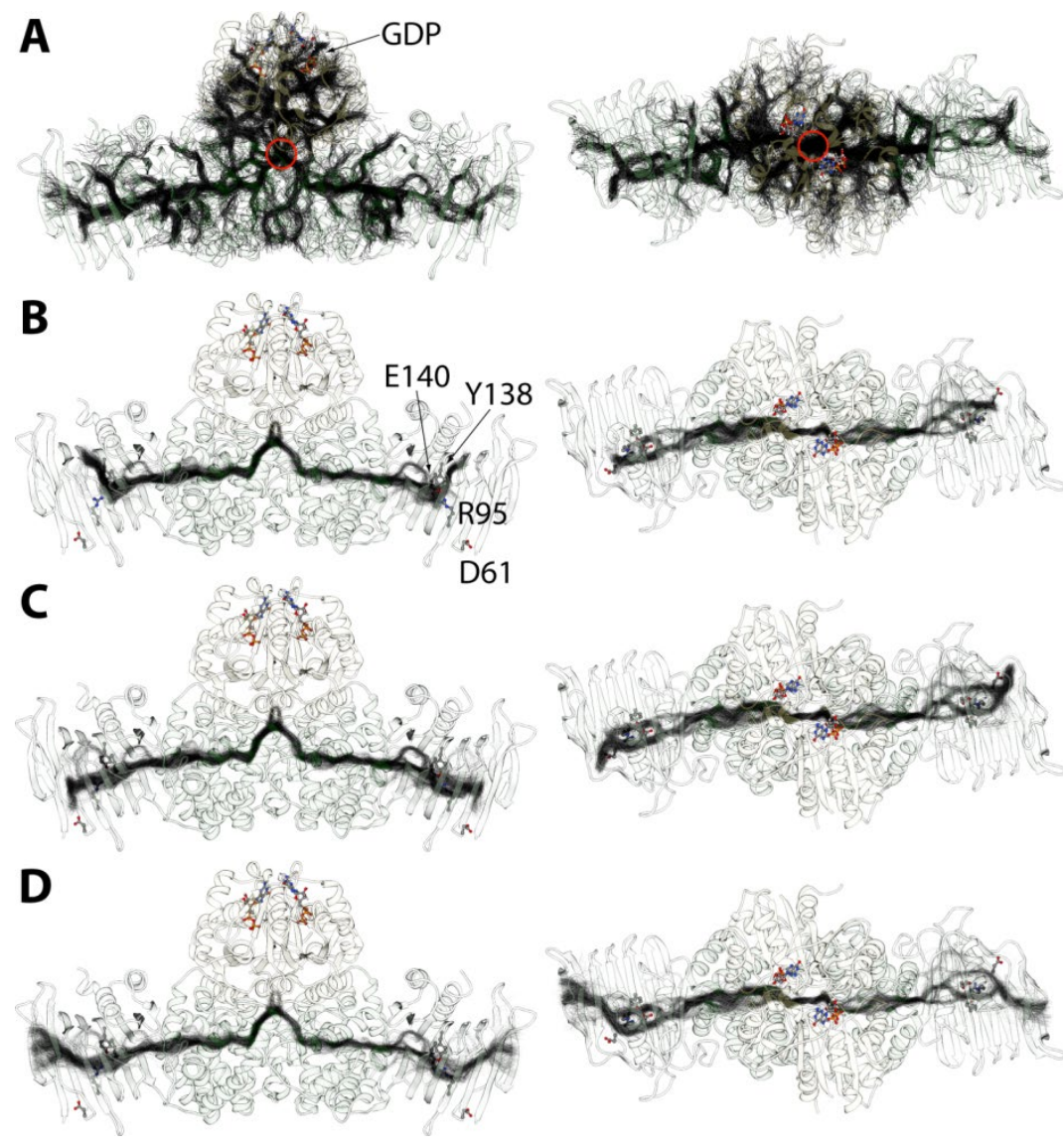

5 Figure 2. Ribbon diagram of the $H p U r e D F G$ complex and tunnels identified throughout the

6 MD simulation by CAVER 3.0, all depicted in one frame as the tunnel centerlines. In the right

7 panels, the $H p$ UreDFG complex is rotated by $90^{\circ}$ around the horizontal axis with respect to the

8 orientation in the left panels. In panel (A) all the tunnels identified in the protein complex are

9 reported (only one frame per ns was considered for clarity reasons). The red circles identify the

10 starting point position of the tunnels. Tunnels 1-3 are depicted in panels (B-D), respectively (see

11 Table 1 and 2). Residues cited in the text are reported as balls-and-sticks. 

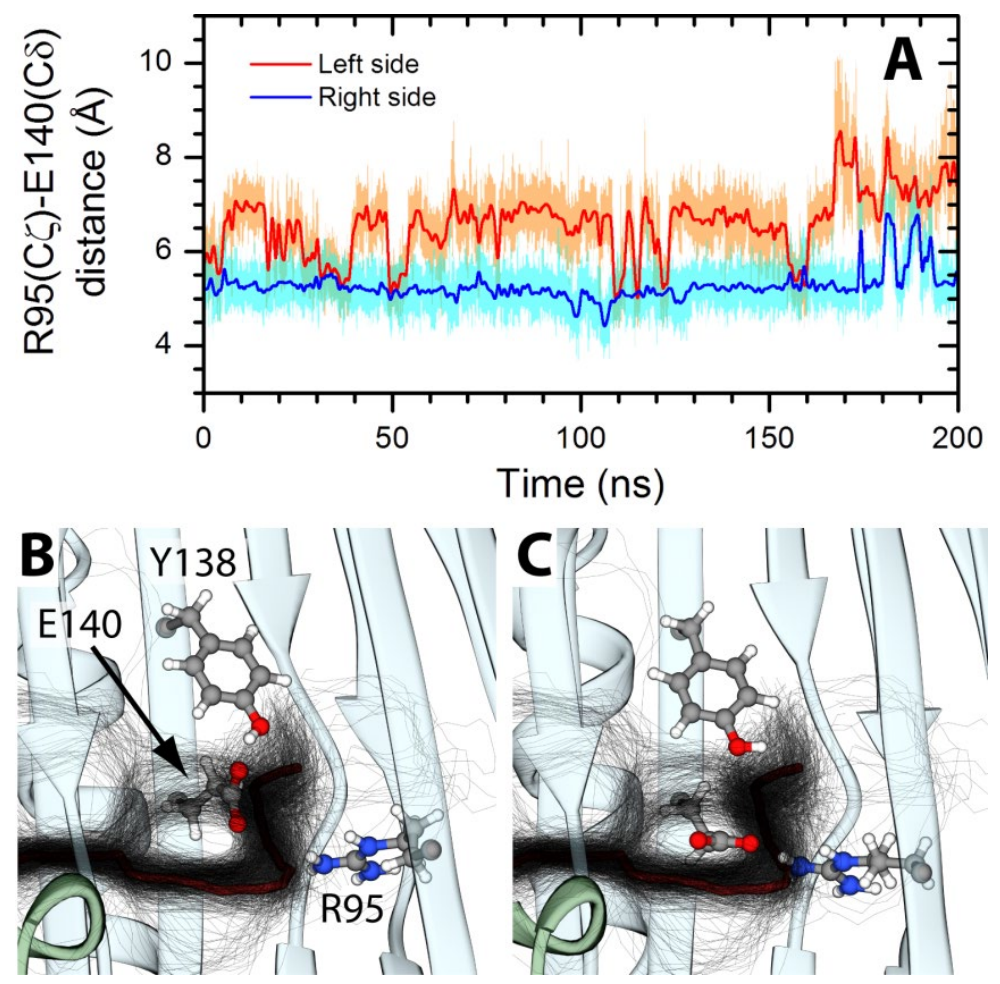

2 Figure 3. (A) $\underline{H p} \mathrm{UreD} \mathrm{Arg} 95 \mathrm{C} \zeta$ and Glu140 $\mathrm{C} \delta$ distance plotted as a function of time. The

3 orange and light blue lines represent the effective sampling during the simulation, while the red

4 and blue lines have been obtained by applying a Fast Fourier Transform filter in order to cut-off

5 noise. (B, C) Selected snapshot showing HpUreD Arg95, Tyr138 and Glu140 in different

6 arrangements during the simulation. In panel (B), tunnel 1 (black lines) is open, while in (C) it is

7 closed. 

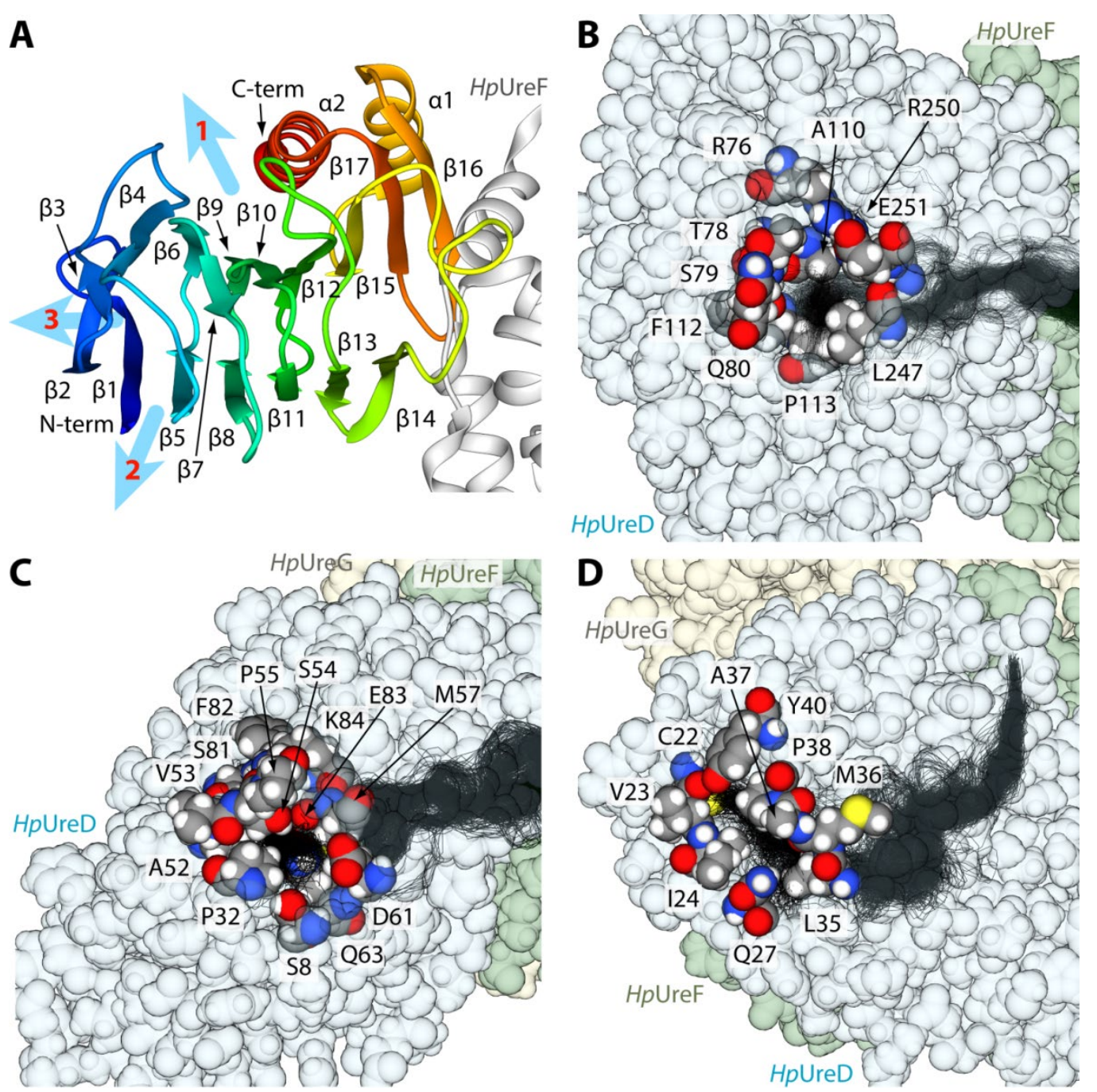

2 Figure 4. (A) Ribbon diagram of $H p U r e D$ as found in the $H p U r e D F G$ complex. The

3 ribbons are colored from blue in the proximity of the $\mathrm{N}$-terminal to red at the $\mathrm{C}$-terminus. Tunnel

4 openings are indicated by light blue arrows. Details of tunnel 1 (B), 2 (C) and 3 (D) exits. $H p \mathrm{UreD}, H p \mathrm{UreF}$ and $H p \mathrm{UreG}$ atoms are reported as spheres and are colored in light blue, light

6 green and light yellow, respectively. Residues located next to each tunnel exit are colored

7 according to atom type. The tunnels identified throughout the MD simulation by CAVER 3.0 are

8 depicted as the tunnel centerlines. 

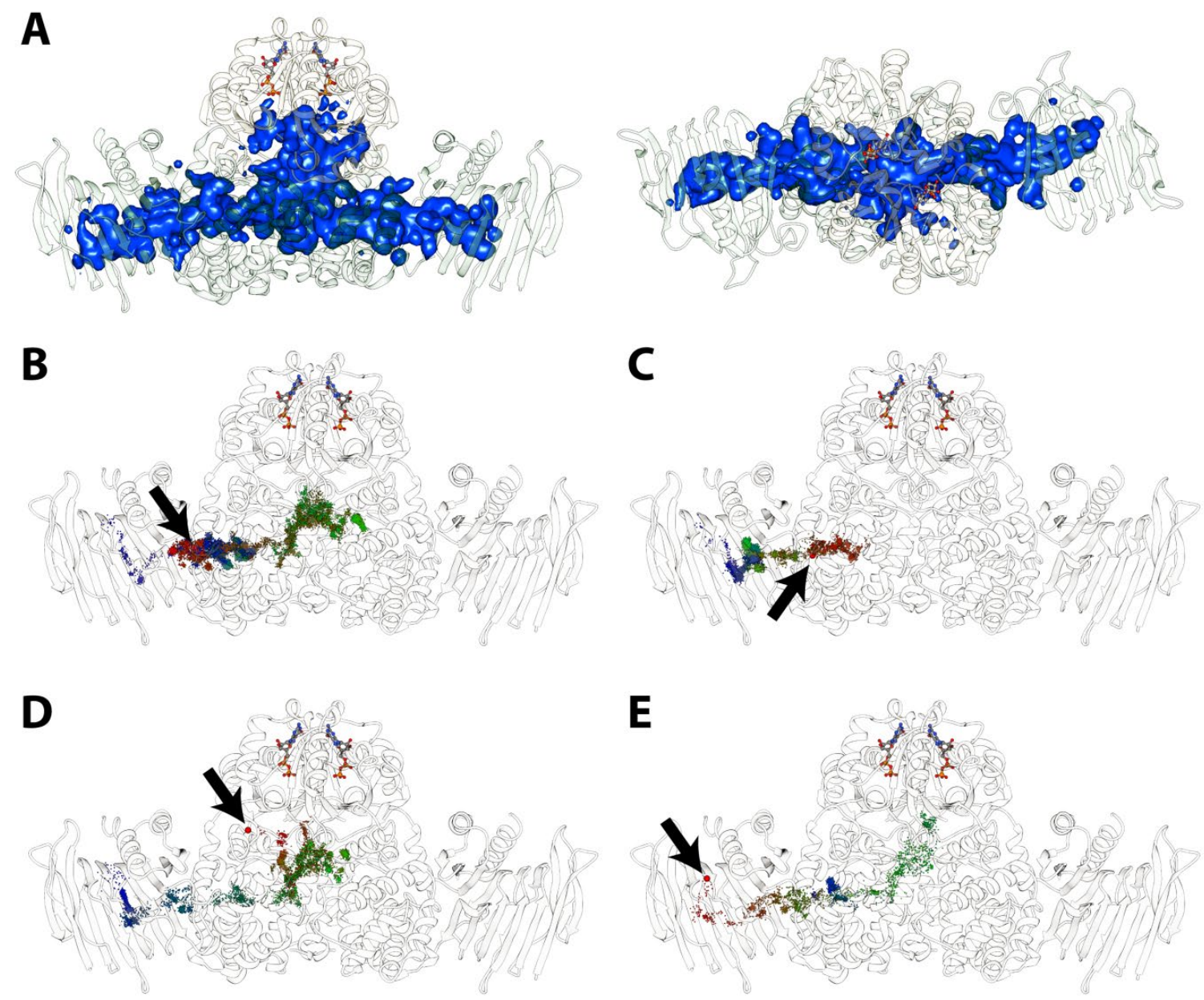

2 Figure 5. (A) Density isosurface of the water molecules found inside the $H p U r e D F G$

3 tunnels contoured at 0.025 oxygen atom $\AA^{-3}$ (blue). In the right panel, the $H p U$ reDFG complex is

4 rotated by $90^{\circ}$ around the horizontal axis with respect to the orientation in the left panel. (B-E)

5 Trajectory of four selected water molecules inside the $H p$ UreDFG tunnels. In each frame, the

6 water molecule is reported as a sphere colored from red to green and finally to blue, accordingly

7 to the simulation time. The starting frame is indicated by a red sphere of larger radius with

8 respect to the others, and by a black arrow. The $H p$ UreDFG complex is reported as white ribbons

9 and GDP is depicted as balls-and-sticks. 


\section{SCHEMES}

2

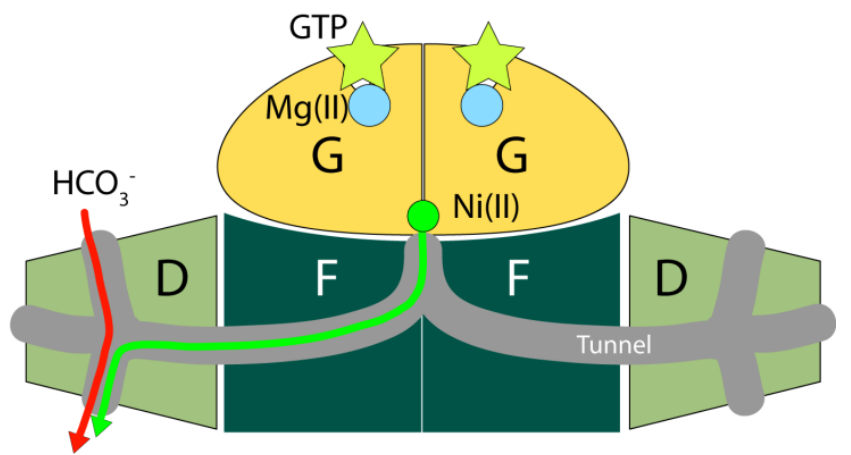

3 Apo Urease

4 Scheme 1. Schematic representation of the pathways followed by Ni(II) ions (green arrow)

5 and by the carbonate/bicarbonate ion (red arrow) inside the $H p U r e D F G$ tunnels. 


\section{TABLES}

Table 1. Analysis of the tunnels identified by CAVER 3.0 and passing through both $H p \mathrm{UreF}$ and $H p \mathrm{UreD}$ during the MD simulation (Fig. 2B-D and 5-SI).

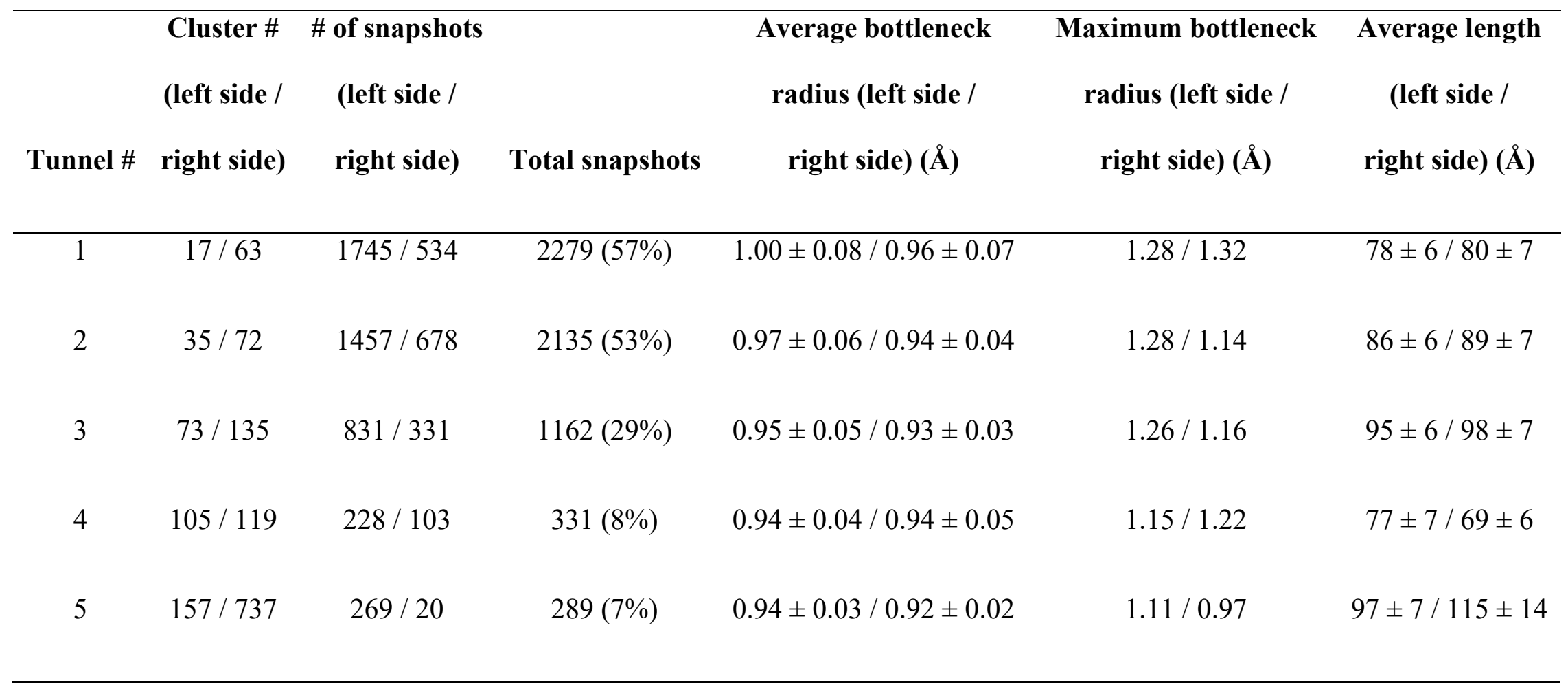


Table 2. Relevant regions in tunnels 1-3 identified by CAVER 3.0 and passing through both $H p U$ reF and $H p U r e D$ during the MD simulation (Fig. 2B-D).

\section{Tunnel \# HpUreD residues (and conservation ${ }^{a}$ ) at tunnel exit $\quad$ Most frequent bottleneck residues}

\begin{tabular}{ccc}
\hline Arg76 (8), Thr78 (9), Ser79 (9), Gln80 (9), Ala110 (6), & HpUreF: Ala233, Val235 \\
Phe112 (9), Pro113 (9), Leu247 (8), Arg250 (6), Glu251 & HpUreD: Arg95, Leu114, Glu140, Ile141, Ile142, Thr160, & Asp174, Thr176, Tyr197, Asn199, Lys237 \\
& & (3) \\
& Ser8 (8), Pro32 (9), Ala52 (9), Val53 (9), Ser54 (9), & HpUreD: Phe33, Ala52, Gln63, Glu83, Arg95, Pro111, \\
& Pro55 (9), Met57 (7), Asp61 (9), Gln63 (9), Ser81 (8), & Phe112, Leu114, Glu140 \\
& Phe82 (9), Glu83 (7), Lys84 (9) & HpUreD: Leu12, Ile24, Gln27, Leu35, Met36, Ile48, Ile77, \\
Cys22 (9), Val23 (6), Ile24 (6), Gln27 (5), Leu35 (7), & Arg95, Pro111, Glu140 \\
Met36 (9), Ala37 (9), Pro38 (8), Tyr40 (9) & \\
\hline${ }^{a}$ Conservation calculated by the ConSurf server. ${ }^{47}$ The score goes from 0 (variable) to 5 (average) to 9 (highly conserved).
\end{tabular}

\footnotetext{
${ }^{\mathrm{a}}$ Conservation calculated by the ConSurf server. ${ }^{47}$ The score goes from 0 (variable) to 5 (average) to 9 (highly conserved).
} 


\section{ASSOCIATED CONTENT}

Supporting information. RMSD and RMSF of the HpUreDFG complex along the simulation;

diagrams and relevant regions of tunnels 4 and 5; analysis of bottleneck residues found in tunnels 1-5; multiple sequence alignment of UreD sequences and ConSurf analysis; distribution of the time spent inside the tunnels by water molecules; and trajectory of selected water molecules inside the $H p \mathrm{UreDFG}$ tunnels.

\section{AUTHOR INFORMATION}

\section{Corresponding Author}

*Phone: +39-051-209-6204; Fax: +39-051-209-6203; E-mail: stefano.ciurli@unibo.it.

\section{Author Contributions}

The manuscript was written through contributions of all authors. All authors have given approval to the final version of the manuscript.

\section{Notes}

The authors declare no competing financial interest.

\section{ACKNOWLEDGMENT}

FM was supported by CIRMMP (Consorzio Inter-universitario di Risonanze Magnetiche di Metallo-Proteine) and the University of Bologna. This project was granted 48,000 core hours on the Eurora and PLX supercomputer at CINECA (Italy, ISCRA project HP10CV9TCE). 


\section{REFERENCES}

1. Finney, L. A.; O'Halloran, T. V., Transition metal speciation in the cell: insights from the chemistry of metal ion receptors. Science 2003, 300 (5621), 931-936.

2. Martinez-Finley, E. J.; Chakraborty, S.; Fretham, S. J. B.; Aschner, M., Cellular transport and homeostasis of essential and nonessential metals. Metallomics : integrated biometal science 2012, 4 (7), 593-605.

3. Sigel, A.; Sigel, H.; Sigel, R. K. O., Interrelations between Essential Metal Ions and Human Diseases. Springer: Netherlands, 2013; Vol. 13.

4. Ma, Z.; Jacobsen, F. E.; Giedroc, D. P., Coordination Chemistry of Bacterial Metal Transport and Sensing. Chem. Rev. 2009, 109 (10), 4644-4681.

5. Ba, L. A.; Doering, M.; Burkholz, T.; Jacob, C., Metal trafficking: from maintaining the metal homeostasis to future drug design. Metallomics : integrated biometal science 2009, 1 (4), 292-311.

6. Higgins, K. A.; Carr, C. E.; Maroney, M. J., Specific metal recognition in nickel trafficking. Biochemistry 2012, 51 (40), 7816-7832.

7. Musiani, F.; Zambelli, B.; Bazzani, M.; Mazzei, L.; Ciurli, S., Nickel-responsive transcriptional regulators. Metallomics : integrated biometal science 2015, 7 (9), 1305-1318.

8. Zambelli, B.; Musiani, F.; Benini, S.; Ciurli, S., Chemistry of $\mathrm{Ni}^{2+}$ in Urease: Sensing, Trafficking, and Catalysis. Acc. Chem. Res. 2011, 44 (7), 520-530.

9. Maroney, M. J.; Ciurli, S., Nonredox nickel enzymes. Chem. Rev. 2014, 114 (8), 42064228.

10. Roesler, B. M.; Rabelo-Goncalves, E. M.; Zeitune, J. M., Virulence factors of Helicobacter pylori: a review. Clin. Med. Insights Gastroenterol. 2014, 7, 9-17. 
11. Kusters, J. G.; van Vliet, A. H.; Kuipers, E. J., Pathogenesis of Helicobacter pylori infection. Clin. Microbiol. Rev. 2006, 19 (3), 449-490.

12. Zhang, M., High antibiotic resistance rate: a difficult issue for Helicobacter pylori eradication treatment. World J. Gastroenterol. 2015, 21 (48), 13432-13437.

13. Hu, Y.; Zhang, M.; Lu, B.; Dai, J. F., Helicobacter pylori and antibiotic resistance, a continuing and intractable problem. Helicobacter 2016, 21 (5), 349-363.

14. Balasubramanian, A.; Ponnuraj, K., Crystal structure of the first plant urease from jack bean: 83 years of journey from its first crystal to molecular structure. J. Mol. Biol. 2010, 400 (3), 274-283.

15. Balasubramanian, A.; Durairajpandian, V.; Elumalai, S.; Mathivanan, N.; Munirajan, A. K.; Ponnuraj, K., Structural and functional studies on urease from pigeon pea (Cajanus cajan). Int. J. Biol. Macromol. 2013, 58, 301-309.

16. Ha, N. C.; Oh, S. T.; Sung, J. Y.; Cha, K. A.; Lee, M. H.; Oh, B. H., Supramolecular assembly and acid resistance of Helicobacter pylori urease. Nat. Struct. Biol. 2001, 8 (6), 505509.

17. Steyert, S. R.; Rasko, D. A.; Kaper, J. B., Functional and phylogenetic analysis of ureD in Shiga toxin-producing Escherichia coli. J. Bacteriol. 2011, 193 (4), 875-886.

18. Chang, Z.; Kuchar, J.; Hausinger, R. P., Chemical cross-linking and mass spectrometric identification of sites of interaction for UreD, UreF, and urease. J. Biol. Chem. 2004, 279 (15), 15305-15313.

19. Soriano, A.; Hausinger, R. P., GTP-dependent activation of urease apoprotein in complex with the UreD, UreF, and UreG accessory proteins. Proc. Natl. Acad. Sci. USA 1999, 96 (20), $11140-11144$. 
20. Zambelli, B.; Stola, M.; Musiani, F.; De Vriendt, K.; Samyn, B.; Devreese, B.; Van Beeumen, J.; Turano, P.; Dikiy, A.; Bryant, D. A.; Ciurli, S., UreG, a chaperone in the urease assembly process, is an intrinsically unstructured GTPase that specifically binds Zn2+. J. Biol. Chem. 2005, 280 (6), 4684-4695.

21. Musiani, F.; Ippoliti, E.; Micheletti, C.; Carloni, P.; Ciurli, S., Conformational fluctuations of UreG, an intrinsically disordered enzyme. Biochemistry 2013, 52 (17), 29492954.

22. Salomone-Stagni, M.; Zambelli, B.; Musiani, F.; Ciurli, S., A model-based proposal for the role of UreF as a GTPase-activating protein in the urease active site biosynthesis. Proteins 2007, 68 (3), 749-61.

23. Carter, E. L.; Flugga, N.; Boer, J. L.; Mulrooney, S. B.; Hausinger, R. P., Interplay of metal ions and urease. Metallomics : integrated biometal science 2009, 1 (3), 207-221.

24. Soriano, A.; Colpas, G. J.; Hausinger, R. P., UreE stimulation of GTP-dependent urease activation in the UreD-UreF-UreG-urease apoprotein complex. Biochemistry 2000, 39 (40), 12435-12440.

25. Yang, X.; Li, H.; Lai, T. P.; Sun, H., UreE-UreG complex facilitates nickel transfer and preactivates GTPase of UreG in Helicobacter pylori. J. Biol. Chem. 2015, 290 (20), 1247412485.

26. Fong, Y. H.; Wong, H. C.; Yuen, M. H.; Lau, P. H.; Chen, Y. W.; Wong, K. B., Structure of UreG/UreF/UreH complex reveals how urease accessory proteins facilitate maturation of Helicobacter pylori urease. PLoS Biol. 2013, 11 (10), e1001678. 
27. Lam, R.; Romanov, V.; Johns, K.; Battaile, K. P.; Wu-Brown, J.; Guthrie, J. L.;

Hausinger, R. P.; Pai, E. F.; Chirgadze, N. Y., Crystal structure of a truncated urease accessory protein UreF from Helicobacter pylori. Proteins 2010, 78 (13), 2839-2848.

28. Fong, Y. H.; Wong, H. C.; Chuck, C. P.; Chen, Y. W.; Sun, H.; Wong, K. B., Assembly of preactivation complex for urease maturation in Helicobacter pylori: crystal structure of UreFUreH protein complex. J. Biol. Chem. 2011, 286 (50), 43241-43249.

29. Zambelli, B.; Berardi, A.; Martin-Diaconescu, V.; Mazzei, L.; Musiani, F.; Maroney, M. J.; Ciurli, S., Nickel binding properties of Helicobacter pylori UreF, an accessory protein in the nickel-based activation of urease. J. Biol. Inorg. Chem. 2014, 19 (3), 319-334.

30. Bellucci, M.; Zambelli, B.; Musiani, F.; Turano, P.; Ciurli, S., Helicobacter pylori UreE, a urease accessory protein: specific $\mathrm{Ni}(2+)$ - and $\mathrm{Zn}(2+)$-binding properties and interaction with its cognate UreG. Biochem. J. 2009, 422 (1), 91-100.

31. Merloni, A.; Dobrovolska, O.; Zambelli, B.; Agostini, F.; Bazzani, M.; Musiani, F.; Ciurli, S., Molecular landscape of the interaction between the urease accessory proteins UreE and UreG. Biochim. Biophys. Acta 2014, 1844 (9), 1662-1674.

32. Farrugia, M. A.; Wang, B.; Feig, M.; Hausinger, R. P., Mutational and computational evidence that a nickel-transfer tunnel in UreD is used for activation of Klebsiella aerogenes urease. Biochemistry 2015, 54 (41), 6392-6401.

33. Sastry, G. M.; Adzhigirey, M.; Day, T.; Annabhimoju, R.; Sherman, W., Protein and ligand preparation: parameters, protocols, and influence on virtual screening enrichments. $J$. Comput. Aid. Mol. Des. 2013, 27 (3), 221-234. 
34. Hornak, V.; Abel, R.; Okur, A.; Strockbine, B.; Roitberg, A.; Simmerling, C., Comparison of multiple Amber force fields and development of improved protein backbone parameters. Proteins 2006, 65 (3), 712-725.

35. Jorgensen, W. L.; Chandrasekhar, L.; Madura, J. D.; Impey, R. W.; Klein, M. L., Comparison of simple potential functions for simulating liquid water. J. Chem. Phys. 1983, 79 (2), 926-935.

36. Meagher, K. L.; Redman, L. T.; Carlson, H. A., Development of polyphosphate parameters for use with the AMBER force field. J. Comput. Chem. 2003, 24 (9), 1016-1025.

37. Berendsen, H. J. C.; van der Spoel, D.; van Drunen, R., GROMACS: A message-passing parallel molecular dynamics implementation. Comput. Phys. Commun. 1995, 91 (1-3), 43-56.

38. Lindahl, E.; Hess, B.; van der Spoel, D., GROMACS 3.0: a package for molecular simulation and trajectory analysis. Journal Mol. Model. 2001, 7 (8), 306-317.

39. Van Der Spoel, D.; Lindahl, E.; Hess, B.; Groenhof, G.; Mark, A. E.; Berendsen, H. J. C., GROMACS: Fast, flexible, and free. J. Comput. Chem. 2005, 26 (16), 1701-1718.

40. Berendsen, H. J. C.; Postma, J. P. M.; van Gunsteren, W. F.; DiNola, A.; Haak, J. R., Molecular dynamics with coupling to an external bath. J. Chem. Phys. 1984, 81 (8), 3684-3690.

41. Essmann, U.; Perera, L.; Berkowitz, M. L.; Darden, T.; Lee, H.; Pedersen, L. G., A smooth particle mesh Ewald method. J. Chem. Phys. 1995, 103 (19), 8577-8593.

42. Hoover, W. G., Canonical dynamics: Equilibrium phase-space distributions. Phys. Rev. A 1985, $31(3), 1695-1697$.

43. Nosé, S., A molecular dynamics method for simulations in the canonical ensemble. Mol. Phys. 2002, 100 (1), 191-198. 
44. Nosé, S.; Klein, M. L., Constant pressure molecular dynamics for molecular systems. Mol. Phys. 1983, 50 (5), 1055-1076.

45. Parrinello, M.; Rahman, A., Polymorphic transitions in single crystals: A new molecular dynamics method. J. Appl. Phys. 1981, 52 (12), 7182-7190.

46. Chovancova, E.; Pavelka, A.; Benes, P.; Strnad, O.; Brezovsky, J.; Kozlikova, B.; Gora, A.; Sustr, V.; Klvana, M.; Medek, P.; Biedermannova, L.; Sochor, J.; Damborsky, J., CAVER 3.0: a tool for the analysis of transport pathways in dynamic protein structures. PLoS Comput. Biol. 2012, 8 (10), e1002708.

47. Celniker, G.; Nimrod, G.; Ashkenazy, H.; Glaser, F.; Martz, E.; Mayrose, I.; Pupko, T.; Ben-Tal, N., ConSurf: Using Evolutionary Data to Raise Testable Hypotheses about Protein Function. Isr. J. Chem. 2013, 53 (3-4), 199-206.

48. Altschul, S. F.; Madden, T. L.; Schaffer, A. A.; Zhang, J.; Zhang, Z.; Miller, W.; Lipman, D. J., Gapped BLAST and PSI-BLAST: a new generation of protein database search programs. Nucleic Acids Res. 1997, 25 (17), 3389-3402.

49. Pettersen, E. F.; Goddard, T. D.; Huang, C. C.; Couch, G. S.; Greenblatt, D. M.; Meng, E. C.; Ferrin, T. E., UCSF Chimera--a visualization system for exploratory research and analysis. $J$. Comput. Chem. 2004, 25 (13), 1605-1612.

50. Humphrey, W.; Dalke, A.; Schulten, K., VMD: Visual molecular dynamics. J. Mol. Graphics 1996, 14 (1), 33-38.

51. Ceccarini, L.; Masetti, M.; Cavalli, A.; Recanatini, M., Ion Conduction through the hERG Potassium Channel. PloS one 2012, 7 (11).

52. Corry, B.; Thomas, M., Mechanism of ion permeation and selectivity in a voltage gated sodium channel. J. Am. Chem. Soc. 2012, 134 (3), 1840-1846. 
53. Sauguet, L.; Poitevin, F.; Murail, S.; Van Renterghem, C.; Moraga-Cid, G.; Malherbe, L.; Thompson, A. W.; Koehl, P.; Corringer, P. J.; Baaden, M.; Delarue, M., Structural basis for ion permeation mechanism in pentameric ligand-gated ion channels. Embo J. 2013, 32 (5), 728-741.

54. Shannon, R., Revised effective ionic radii and systematic studies of interatomic distances in halides and chalcogenides. Acta Crystallogr. A 1976, 32 (5), 751-767. 


\section{Protein tunnels: the case of urease accessory proteins}

Francesco Musiani, ${ }^{\dagger}$ Dario Gioia, ${ }^{\ddagger}$ Matteo Masetti, ${ }^{\ddagger}$ Federico Falchi, ${ }^{\S}$ Andrea Cavalli, ${ }^{\ddagger}$, Maurizio Recanatini, ${ }^{\ddagger}$ and Stefano Ciurli ${ }^{\dagger}, *$

\section{SUPPLEMENTARY INFORMATION}

${ }^{\dagger}$ Laboratory of Bioinorganic Chemistry, Department of Pharmacy and Biotechnology, University of Bologna, Viale G. Fanin 40, I-40127, Bologna, Italy.

Laboratory of Computational Medicinal Chemistry, Department of Pharmacy and Biotechnology, University of Bologna, Via Belmeloro 6, I-40126, Bologna, Italy.

${ }^{\S}$ Compunet, Istituto Italiano di Tecnologia, Via Morego 30, I-16163, Genova, Italy.

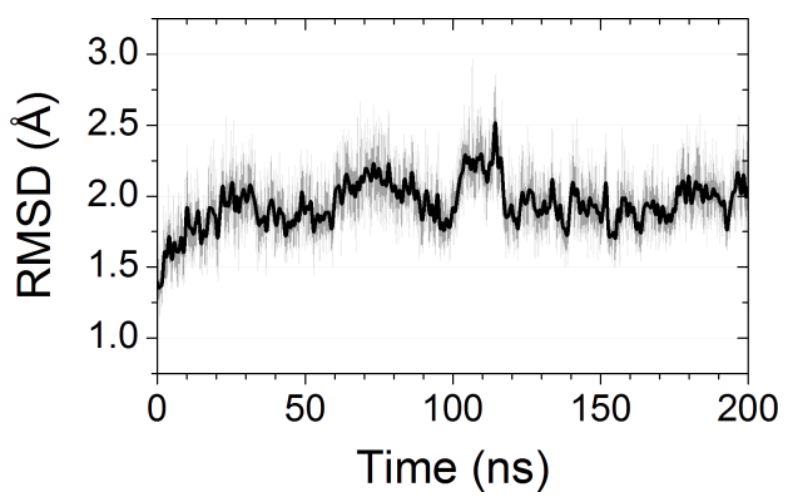

Figure 1-SI. Calculated root mean square deviations (RMSD) of the $H p$ UreDFG $C \alpha$ from the initial X-ray structure plotted as a function of time. The grey line represent the effective sampling of RMSD during the simulation, the black line has been obtained by applying a Fast Fourier Transform filter in order to cut-off noise. 


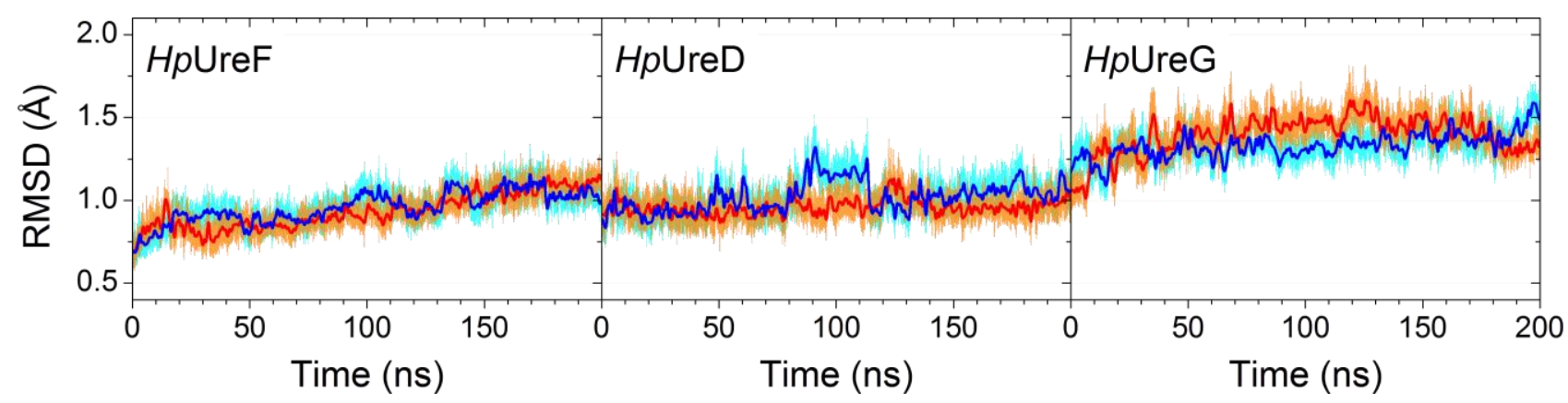

Figure 2-SI. Calculated RMSD of the monomeric $H p U r e F$ (left panel), $H p U r e D$ (central panel) and $\mathrm{HpUreG}$ (right panel) $\mathrm{C} \alpha$ from the initial X-ray structure plotted as a function of time. The RMSD plots of the different monomers of the same protein are in light blue and orange. The blue and red lines have been obtained by applying a Fast Fourier Transform filter in order to cut-off noise.

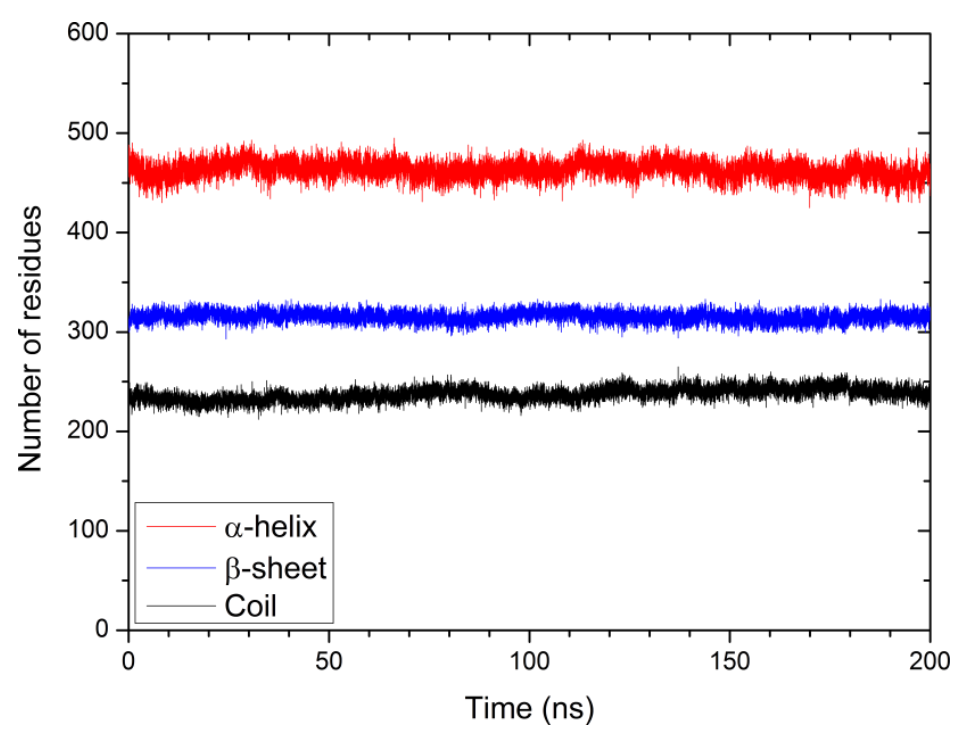

Figure 3-SI. Secondary structure content of the HpUreDFG complex plotted as a function of time. 


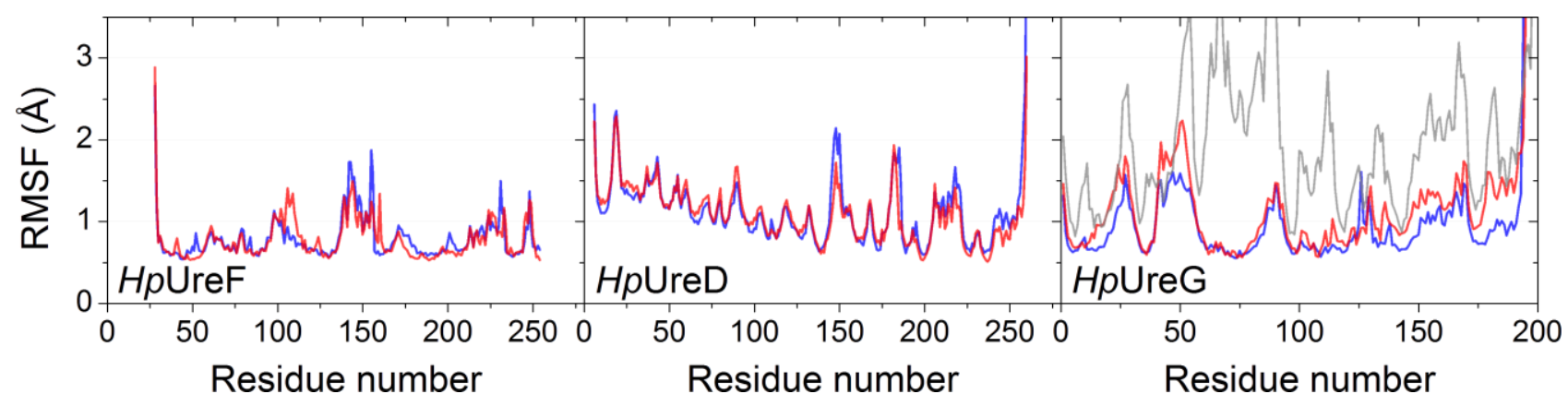

Figure 4-SI. Calculated root mean square fluctuations (RMSF) of the monomeric HpUreF (left panel), $H p \mathrm{UreD}$ (central panel) and $H p \mathrm{UreG}$ (right panel) $\mathrm{C} \alpha$ during the simulation. The RMSF plots of the different monomers of the same protein are blue and red. In the right panel, the gray line represent the average RMSF obtained from replica exchange MD simulations performed on the HpUreG model structure (1).

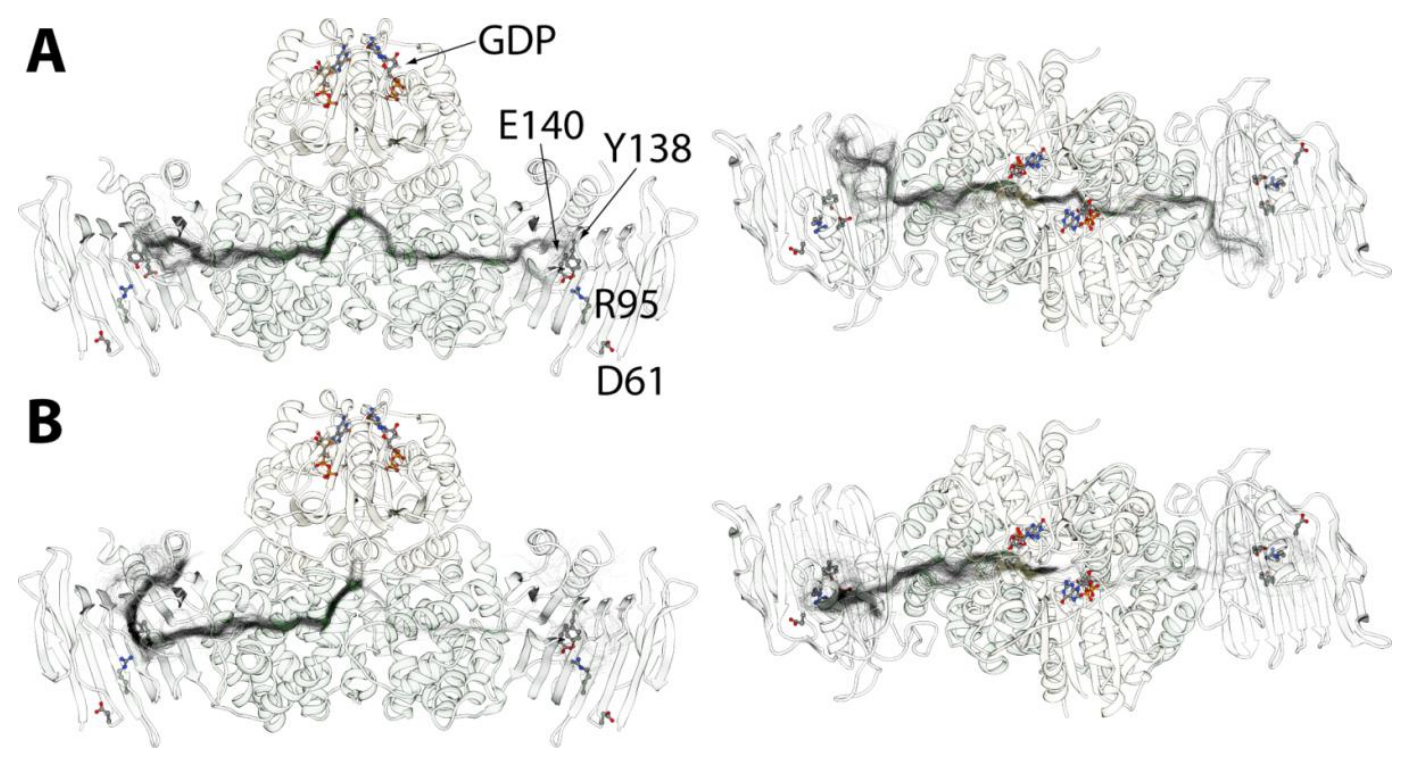

Figure 5-SI. Ribbon diagram of $H p U r e D F G$ complex and tunnels 4 (A) and 5 (B) identified throughout the MD simulation by CAVER 3.0 all depicted in one frame as the tunnel centerlines (see Table 1 and 1-SI). In the right panels, the $H p$ UreDFG complex is rotated by $90^{\circ}$ around the horizontal axis with respect to the orientation in the left panels. 
Table 1-SI. Relevant regions in tunnels 4 and 5 (Table 1) identified by CAVER 3.0 and passing through both $H p \mathrm{UreF}$ and $H p \mathrm{UreD}$ during the MD simulation (Fig. 5-SI).

\section{$H p U$ reD residues (and}

Tunnel \# $\quad$ conservation $^{\text {a }}$ ) at tunnel exit

Most frequent bottleneck residues

$4 \quad$ Ser132 (2), Ser133 (3), Ser134 (8),

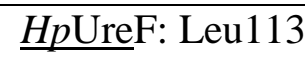

Gln135 (4), Gln166 (7), Asn204 (4), $\quad \underline{H p U r e D: ~ L e u 130, ~ L e u 136, ~ I l e 164, ~ G l n 166, ~}$

His233 (7)

Ile171, Tyr172, Tyr173, Val201, Val203,

His 233

5

Ile216 (7), Glu217 (1), Ser219 (1), $\quad$ HpUreD: Ser139, Ile141, Leu198, Leu200,

Val222 (1), Asp223 (1)

Val236, Leu246, Leu249, Arg250, Ile253,

${ }^{a}$ Conservation calculated by the ConSurf server (2). The score goes from 0 (variable) to 5 (average) to 9 (highly conserved).

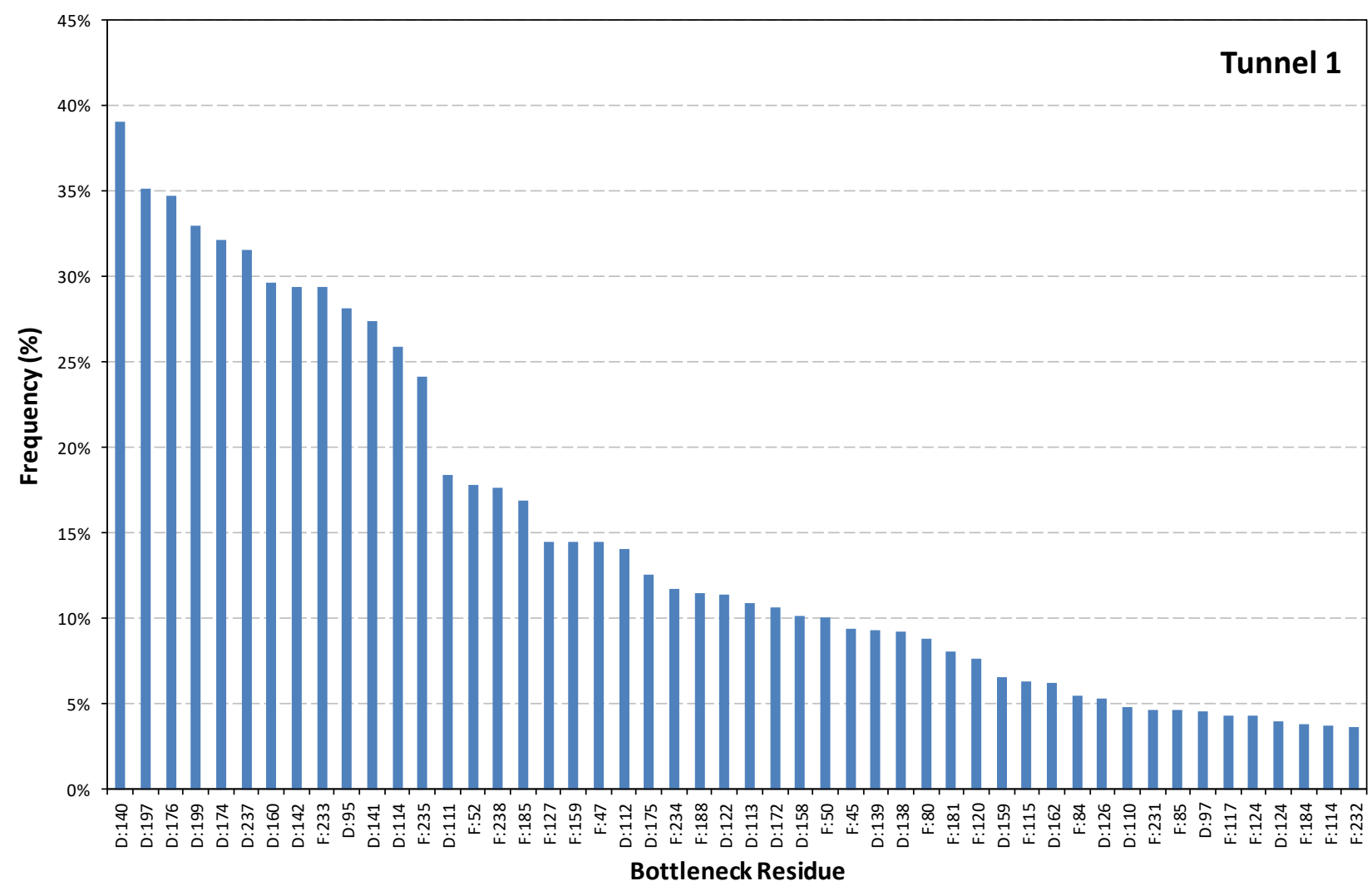

Figure 6-SI. Analysis of bottleneck residues found in tunnel 1 (Table 1). 


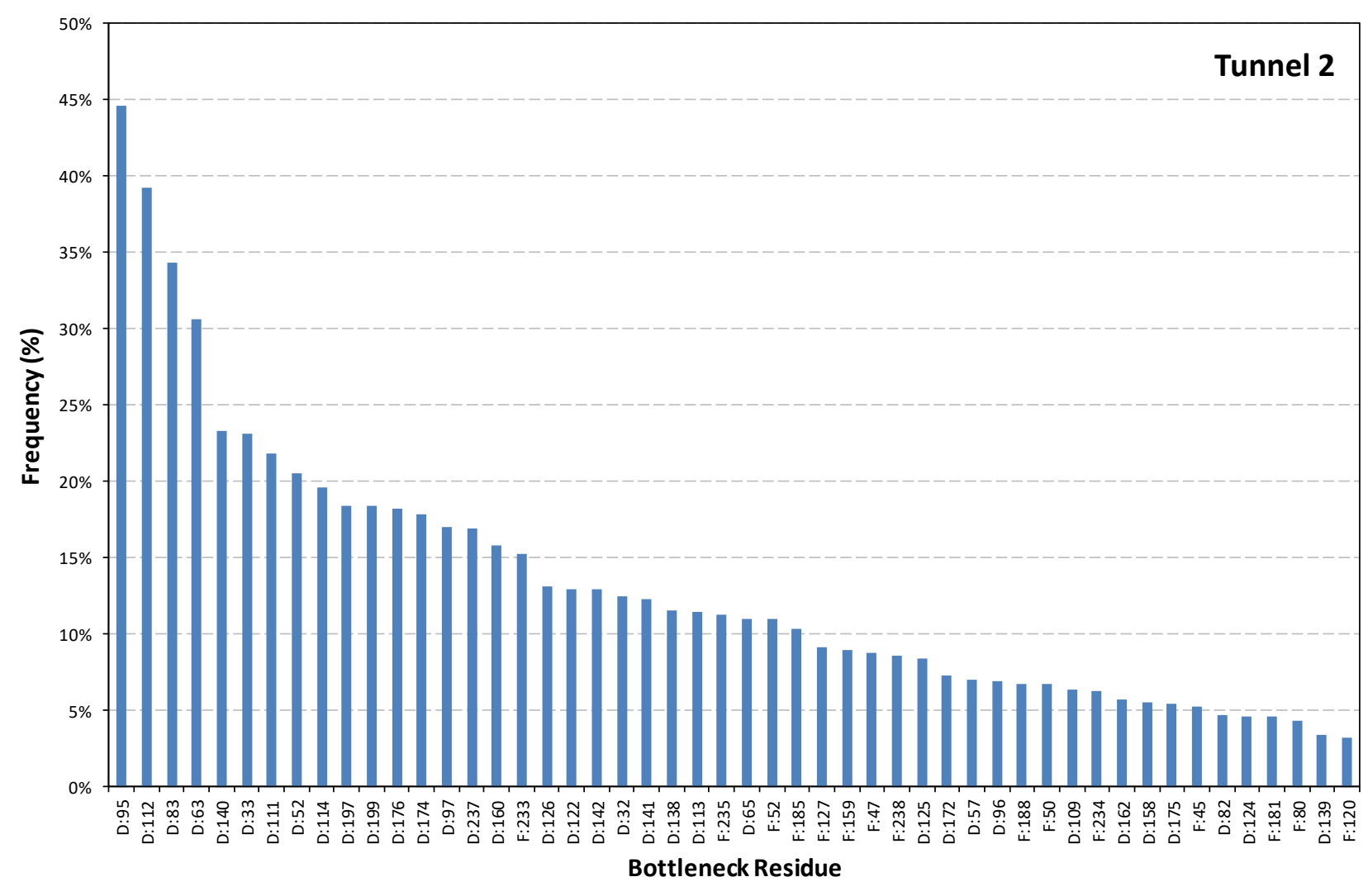

Figure 7-SI. Analysis of bottleneck residues found in tunnel 2 (Table 1).

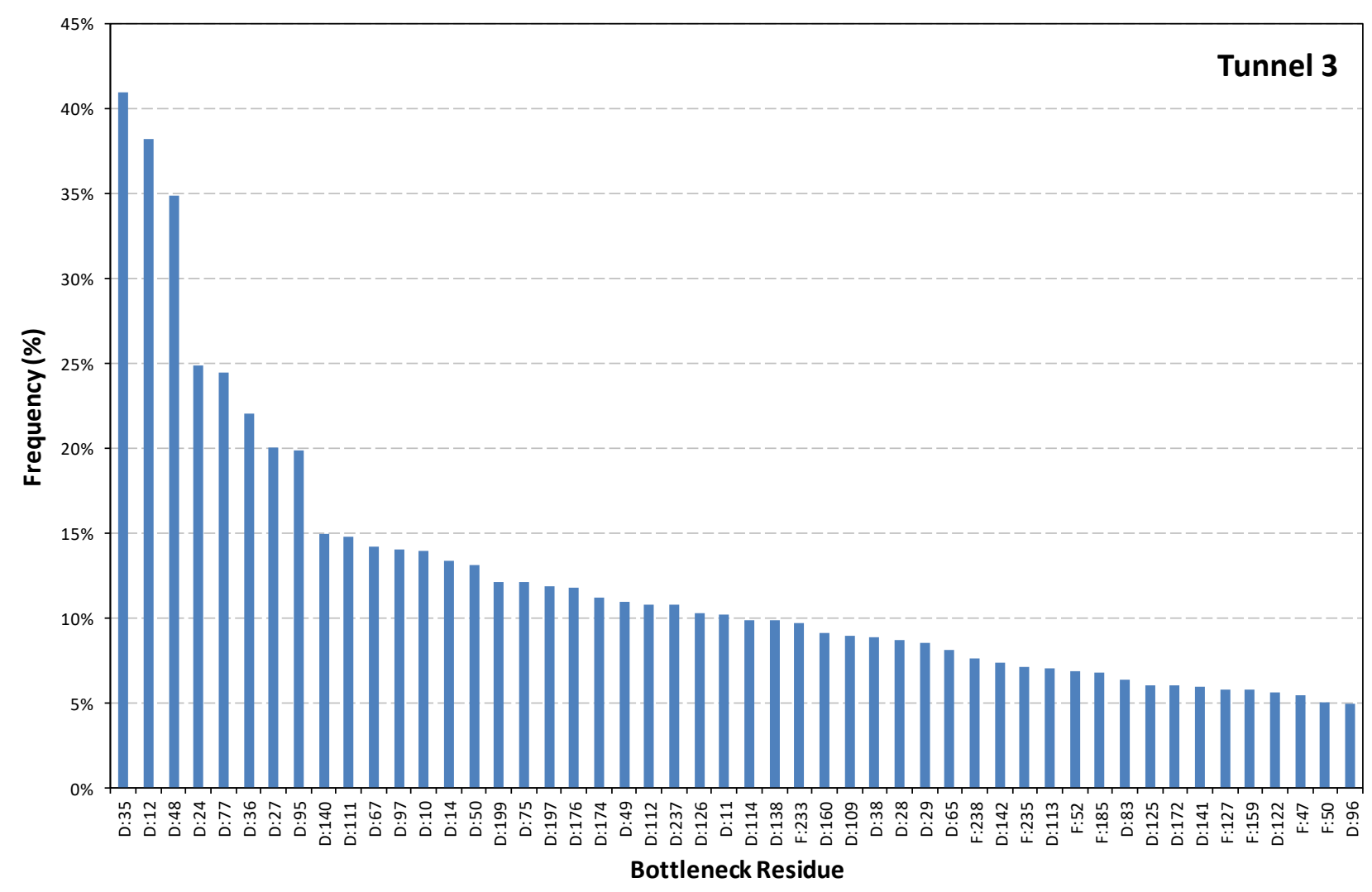

Figure 8-SI. Analysis of bottleneck residues found in tunnel 3 (Table 1). 


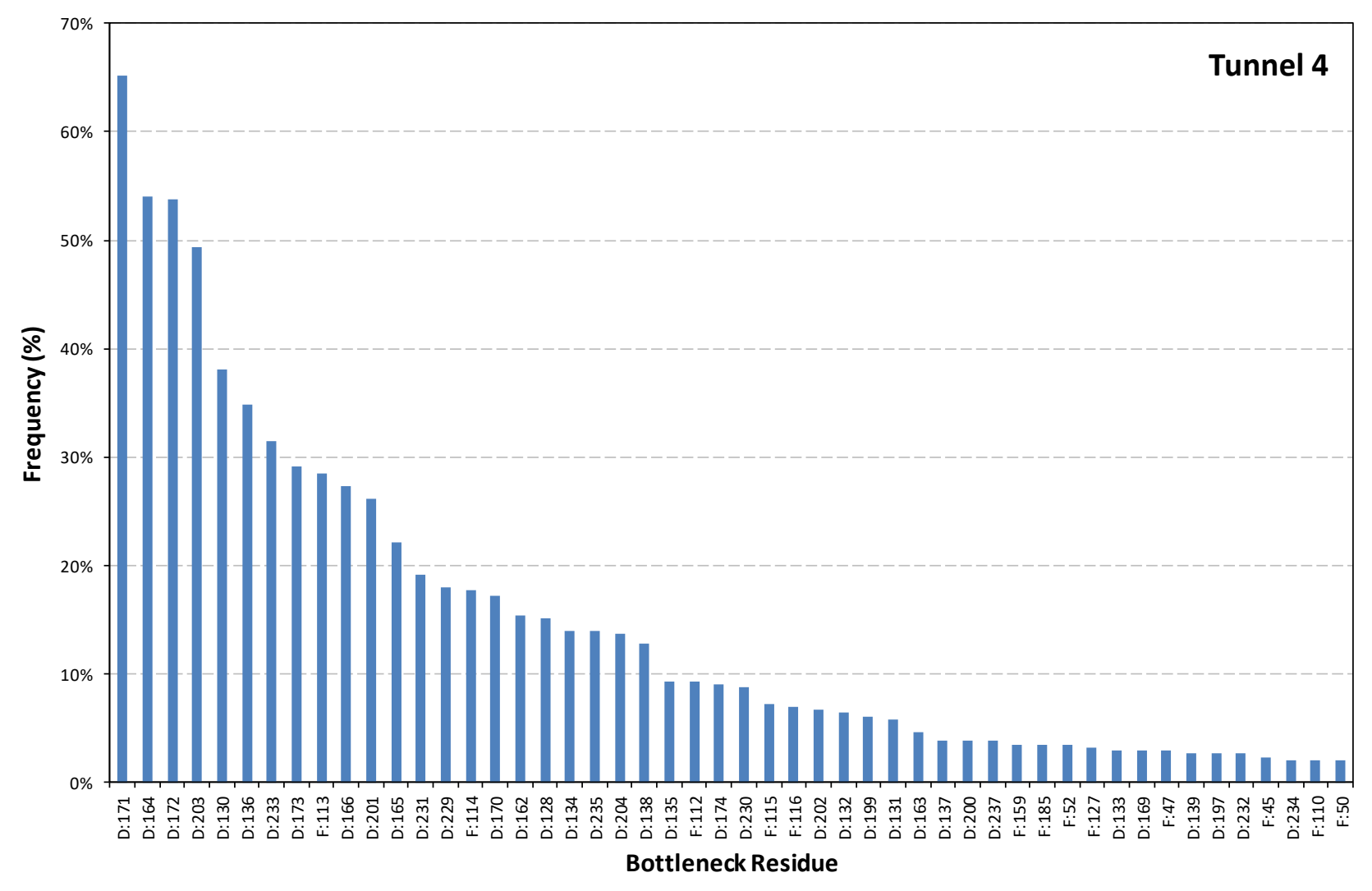

Figure 9SI. Analysis of bottleneck residues found in tunnel 4 (Table 1).

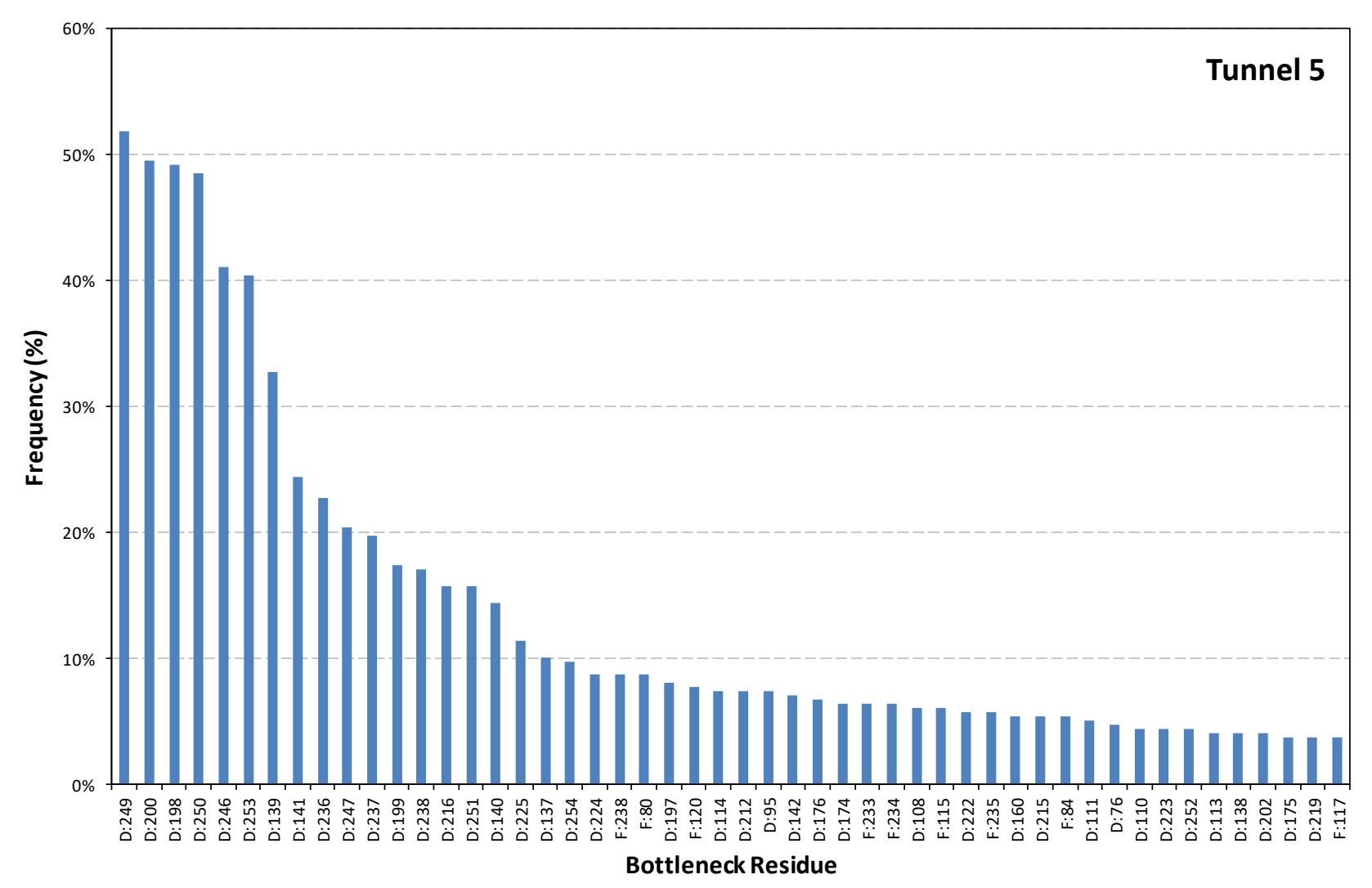

Figure 10-SI. Analysis of bottleneck residues found in tunnel 5 (Table 1). 
Figure 11-SI. Multiple sequence alignment obtained by using PSI-BLAST and considering the 150 UreD best sequences with more than $15 \%$ and less than $90 \%$ sequence identity with respect to HpUreD.

HpUreD

UniRef90 A0A0K9H6B6 4266

UniRef90_A0A0K9GXZ4_4_265

UniRef90_A0A0A3IXZ5 ${ }^{-}{ }^{-}$-264

UniRef90 K9ZPZ7 $7 \quad 2 \overline{7} 3$

UniRef90_A0A0C1X̄DA 3 13_272

UniRef90-UPI000379D $\overline{7}$ E3 4266

UniRef90 UPI0002DF3930 $1 \overline{3} 277$

UniRef90_A0A0MOWOK1_1 266

UniRef90-UPI000422C $\overline{8} 8 \overline{5} \quad 4 \quad 265$

UniRef90 B4W160 8270

UniRef90_Q8YQZ4_10_269

UniRef90 A0A0P1B̄UZ $\overline{9} 3269$

UniRef90_A0AOM1JRC4 $1 \overline{7} 282$

UniRef90 UPI0007108B $5 \mathrm{C}^{-} 4266$

UniRef90 UPI0006A76A92 4 265

UniRef90_W4ETC9_4_265

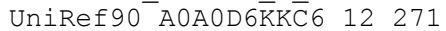

UniRef90 A0A0D8ZYE2 $11^{-} 271$

UniRef90_B2IT63_10_ 269

UniRef90 UPI000 $308 \overline{7} 66 \mathrm{C} \quad 11271$

UniRef90 K9R6Q0 $10 \quad 280^{-}$

UniRef90 A0A127D3L $\overline{2} 4264$

UniRef90-UPI0002893īD $\overline{6} 4266$

UniRef90-AOAOMOENP $6 \quad 4 \quad \overline{2} 6 \overline{6}$

UniRef90 AOAOS3PHU 6 - $1 \overline{6} 275$

UniRef90 A0A081NYG6 3 364

UniRef90_A0A0K9GPB1 4-266

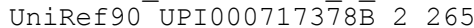

UniRef90 K9W1V1 $14 \quad 278$

UniRef90 K9U4Q1 $17^{-} 272$

UniRef90 A0A0M2 $\overline{\text { SWM }} 64265$

UniRef90_UPI0003652 $\overline{\mathrm{A}} 4 \overline{8}+11$ - 275

UniRef90 UPI00047A812C $1 \mathrm{C}^{-} 286$

UniRef90 K9TKA4 $12 \quad 277$

UniRef90 M7NKH7 ${ }^{-} \overline{2} 69$

UniRef90 K6DR39 ${ }^{-} 265$

UniRef90_A0A0B4R $\bar{R} \bar{S} 1$ 1_265

UniRef90 A0A168N9T6 4-266

UniRef90 A0A139X4D9 ${ }^{-} 274$

UniRef90_UPI00030AB $\overline{1} 9 \overline{2}$ _16_277

UniRef90 K7W9HO 9269

UniRef90 UPI000 $34 \overline{\mathrm{A}} 5 \mathrm{E} 0 \mathrm{C} \quad 10 \quad 263$

UniRef90 AOAOAOE $403 \quad 4 \quad \overline{2} 65^{-}$

UniRef90 UPI0007172 $\overline{6} 3 \overline{\mathrm{C}} 4266$

UniRef90_K9QPZ4_10_269

UniRef90-UPI0002D28249 $14 \quad 276$

UniRef90-F9DU20 4266

UniRef90_UPI000 $\overline{4} 7 \overline{9} 33 \mathrm{CA} 33266$

UniRef90 W7REE8 4266

UniRef90_UPI00074 $4 \overline{4} 1 \mathrm{C} 40 \_4 \_265$

UniRef90 A0A0T7BRT9 $7 \overline{2} 6 \overline{8}$

UniRef90 UPI0006A78 $\overline{3} 5 \overline{7} 4266$

UniRef90_UPI0007C7BB46_4_266

UniRef90_UPI000472611B_4_265

UniRef90 UPI0002ACBAOD $1 \overline{1} 270$

UniRef90_A0A0C2KR59_11_269

UniRef90 K9WE93 $4 \quad 2 \overline{7} 7$

UniRef90 A0AOMOSB $\overline{3} 0 \quad 16277$

UniRef90 K9Q9K1 $10 \quad \overline{2} 68$

UniRef90 A0A0S3TTX4 17278

UniRef90 K9VQF3 $56 \quad \overline{3} 23^{-}$

UniRef90 W1SM28 4 - 265

UniRef90 AOAOC1 $\bar{N} 9 \overline{3} 5 \quad 15285$

UniRef90_A0A139SK67_11_275

UniRef90 UPI00041C7 $\overline{C D C}^{-} 4265$

UniRef90_K9XHH8_15_275

UniRef90-UPI0002E7D901 4265

UniRef90-A0ZB05 $10 \quad 269$ $\begin{array}{rrrrrr}1 & 10 & 20 & 30 & 40 & 50 \\ 1 & 1 & 1 & 1 & \mid\end{array}$

---MNTYAQESKLRLKTKIGADGRCVIEDNFFTPPFKLMAPFY------PKD-DLAEIMI

-------WTGTLRLDVE-ERQGKTVAKNVYFQGALKVMRPVY------HDDSGQACYYI

--------WTGILSLDLE-NRNGKTVAKRAYFQGALKVMRPIY------HDDSGQVCYYI VNSPI DKNWHGRLNLVYA-KRQDSTQLIYNHHQAPFNIORPFY------PEGQEVCHSVI

-------GWHGKLNLVYA-DRLGTTALISNSHQAPLKVQRPFY------PEGQQICHSVI -------WTGSLSLELE-DRNGKTVAKRVYFQGAFKVMRPIY------TDDSGQVCYYI -------SWHGKLDLLYA-NROGITQLIHAHHQAPLKVQRPFY------PEGKAVCHSVI -----MNDWTGSLSLDLE-DRNGKTVAKRVYFQGAFKVMRPIY------ADDSGQVCYYI -------WTGTLRLDVE-VRQGKTVAKNVYFQGALKVMRPIY------HDNSGQACYYI -------WQGSLELVYA-NDQGKTRLVRDRITS PLKVQRPFY------PEGQGVCHTVV -------GWHGKLNLVYA-DRSNSTQL I YNHQQAPLKVQRPFY------PEGEKVCHSVI VNSPIDKTWHGKLNLVYA-HRLNSTOLIHSHHOAPLKIOKPFY------PEGEKICHSVI ---VRQAGWQGI LNLVYA-NHQGKTQVTDSYMKAPLKIQRPFY------PEGET ICHSVV -------WTGVLRLGAE-ERNGKTVAKNVYFQGAYKVMRPIY------HDESGQVCYYI -------WTGDLSLDLE-NRNGKTVARNVYFQGAFKVMRPIY------HDNSGQVCYYI --------WTGVLSLDLE-ERRGKTVAKNVYFQGALKVMRPIY------HDNSGQVCYYI -------TWHGKLNLVYA-DRKNATQLI YNHQQAPLKVQRPFY------PEGEKVCHSVI --------WHGS LNLVYA-QHQGKTQVIHAQVKAPLKVQRPFY------PE-DGVCHSVV -------GWHGKLNLVYA-DRQGATQL I YNQQQAPLKVQRPFY------PEAEKVCHSVI ------TGWYGKLSLVYA-HRQNTTTLI IHNQNQAPLKVQRPFY------PEGQQVCHSVI ----SSQSWHGKLNLVYN-HSQNKTALIQSRNQAPLKVQRPFY------PEGQSVCHSVI -------WTGVLCLDVE-DRNGKTVAKNVYFQGALKVMRPVY------HDDSGQACYYI -------WTGVLRLDAE-DRNGKTVAKNVYFQGAFKVMRPIY------HDDSGQACYYI --------WTGTLSLDLE-ERKGKTVAKRVYFQGALKVMRPIY------EDDSGQVCYYL -------GWHGKLDLVYA-DRSNSTGLIYNHQQAPLKVQRPFY------PEGDKICHSVI -------WTGYLRLAVA-PKHGKTIATDLYYENAFKLTRPLY------PDESGQPHYYI -------WTGELRLDLE-ERLGKTVAKNVYFQGALKVMRPVY------HDDSGQVCYYI -----TAWTGELSLSLE-DRGGKTVAKRVYFOGALKVMRPVY------HDDSGKVCYYI -----KSSWHGSLDLKFA-CRDGGSQVIKSQGKAPLKVQRPFY------PEGREVCHSVI ------TWHGNLDIVYA-LRNGKTQPISDRVQAPLKVQRPFY------PEG-DICHTAI -------WTGELSLDLE-NRNGKTVAGNVFFQGAFKVMRPIY------HDDSGQVCYYI ---LNPTDWHGI LQLGFE-YRQGKTQLIRNQGQAPLKVQRPFY------PEGDEVCHSVI ------GWHGKLNLVYA-HSQSGTQLIFNRNQAPLKVQRPFY------PEGQEVCHSVI -----QGWHGSLELVYA-QSGNATQMVSAKATAPLKIQRPFY------PEGEGVCHSVI ---MTVTQWTGELNLSLE-DRAGKTVARNVYFQGAFKVMRPIY------HDDSGKVCYYI -------WTGVLHLDAE-DRKGKTVAKKVYYQGAFKVMRPIY------HDNSGQACYYI -----MGQWTGELSLDIE-ERKGKTVAKNVYFQGAFKVMRPVY------LEDSGKVCYYL -------WTGSLSLDLE-DRLGKTVAKRVYFQGAFKVMRPIY------ADDSGQVCYYI -------GWHGKLDLVYA-QCQGKTTLI HNQNIAPLKVQRPFY------PEGQE ICHSVI --------WHGNLHLVYA-DRQNQTQL I FNQNQAPLKVQRPFY------PEGQKVCHSVI ------QGWHGLLNLVYA-NRQDSTQL I YNHHQAPLKVQRPFY------PEGQE ICHSVI ------GWHGQLNLVYA-DRHNSTQL I YNHHQAPLKVQRPFY------PEGEKVCHS I I -------WTGVLHLNAE-DRKGKTVAKNVYYQGAFKVMRPIY------HDDSGRACYYI -------WTGSLSLDLE-DRKGKTVAKRVYFQGALKVMRPIY------LDDSGQVCYYI -------GWHGKLNLVYA-DRLGATELIYNHQQAPLKIQRPFY------PEGERVCHSVI ----NQGWYGNLNLVYA-RTQGETQLIHSQSQAPLKVQRPFY------PEGKNVCHSVI -------WTGVLDLAME-NRQGRSVAKSVYFQGAFKVMRPVY------LNNYSYPCYYI -------AWTGLLHLNAE-DRRGKT I SKNVYFQGAFKVMRPIY------HDESGQPCYYI -------WTGVLRLDAE-EKNGKTIAKNVYFQGAYKVMRPIY------HDESGQACYYI -------WTGDLSLDLE-CRNGRTVARNVYFQGAFKVMRPIY------HDNSGQVCYYI ------SWHGKLHLTYG-SHGGKTQLVSSQNQAPLKVQRPFY------PEGEAVCHS I I -------WTGVLHLGAE-ARNGKTVANKVYFQGAFKVMRPIY------HDDSGQVCYYI --------WTGVLRLSME-KKRDKTVTKQVYFQGAFKMLRPHY------LDNSGQACYFI --------WTGVLSLDAE-VRNGKTVGKDVYFQGAYKVMRPVY------HDDSGQACYYI -------WHGNLNLVYA-QHQGKTQVIHSQMKAPLKVQRPFY------PEG-GVCHSVV ------TGWHGKLNLVYA-HRQNTTA L I HNQNQAPLKVQRPFY------PEGQEVCHSVI ----SSSGWHGSLQLVYA-HDHNGTOLTHAQVQAPLKVQRSFY------PEGSAVCHSVV -------WYGNLDLVYA-YRQNQTQLIFNQNQAPLKVQRPFY------PEGQEVCHSVI ------AWHGKLNLIYA-DRQNSTQLIYNHHQAPLKVQRPFY------PEGEKVCHSVI -------WHGNLHLVYA-HHQNQTQLI I NNQNQAPLKVQRPFY------PEGKEVCHSVI -----QTAWHGRLNLAYA-NRS GATQI I HNQMQAPLKVQRPFY------PEGKDVCHSVI -------WTGALNLEVE-DRKGKTVAKKVYFOGAFKVMRPIY------HDDSGHACYYI ------ GWHGKLDLVYA-QRQGTTALIYNQNQAPLKVQRPFY------PEGQE ICHSVV ----DSSGWHARLALDFA-RQGPRTVLVGNRHTGPLRVQKPLH------PEGEAVCHAIV -------WTGVLRLDLE-ERLGKTVAKNVYFOGALKVMRPVY------HDDSGOVCYYI ------SWHGSLNMVYT-CVDGATTVTHQQMQAPLKVQRPFY------PEGAEVCHSVI -------WTGVLELDVE-NRGGRTVADNIY FQGAFKVMRPVY------LNGYSHPCYYI -------TWHGKLNLVYA-DRLNSTQLIYSHNQAPLKVQRPFY------PEGAEICHSVI 
UniRef90 D4ZSS4 5270 UniRef90_A0A0F5ȲFȲ1_6_271 UniRef90-K9T9Y9 $59 \overline{3} 2 \overline{2}$ UniRef90 K9VAD2 10273 UniRef90_W7Z4J7_4 $\overline{2} 65$ UniRef90 Q47G52 $1 \overline{3} 278$

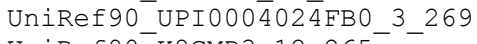
UniRef90_K8GMD3_12_265 UniRef90 A0A0S3ÜB1 $\overline{2} \quad 16269$ UniRef90_A0A0F7D4R9_4 $\overline{2} 65$ UniRef90 AOYQS4 $52 \overline{7} 1$ UniRef90 A0A0Q8RCLL2 $14 \quad 276$ UniRef90_UPI0005625009-5 271 UniRef90-UPI000305E365 $1 \overline{6} 284$ UniRef90-UPI0002E38242 $11^{-} 269$ UniRef90_G8Q511_12_270

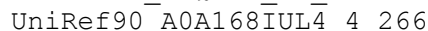

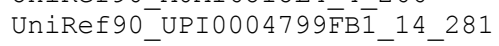
UniRef90 Q3KIS7 $11 \quad 269$ UniRef90 K9XZ09-12-271 UniRef90 A0A090 RU $8 \overline{6} \quad 25 \quad 288$ UniRef90_A0A0M5LWB1_11_269 UniRef90_A0A0C2I8A1_11_269 UniRef90_H3SNI3_3_265 UniRef90 A0A000 X̄PT $8 \quad 11269$ UniRef90 K4ZJ70 4 265 UniRef90 A0A085V 95111269 UniRef90 A0A098SV87 11-271 UniRef90_A0A0A1GEL6_9_ 267 UniRef90 I 4CP19 $92 \overline{6} 7$ UniRef90_AOAOWOP $2 \overline{\mathrm{S}} 5$ _11_269 UniRef90_C3K5A6_11 269 UniRef90 A0A078EV3 $\overline{6} 9267$ UniRef90_J3GGT8_11_ $\overline{2} 6 \overline{9}$ UniRef90 A5L5M9 32 - 304 UniRef90_A0A0J6 GPDD 8 11_270 UniRef90_Q4KJ05_11_ 269 UniRef90 A0A0V7Z̄eT $\overline{1} 2281$ UniRef90_A0A075PF54 $1 \overline{1} 269$ UniRef90 A0A0D5Y774 11 269 UniRef90 A0A0Q5EC30 11271 UniRef90_I 4N4V9_11_269 UniRef90 D4TUH $6^{-} \overline{2} 66$ UniRef90_UPI0004 $8 \overline{\mathrm{A}} \mathrm{E} 6 \mathrm{EC} 1266$ UniRef90_UPI0007398261_11'_285 UniRef90-B0C790 $12 \quad 273$ UniRef90_A0A066ŪMR $\overline{7}$ 26_298 UniRef90_A0A0Q9XWI2_4 265 UniRef90 A0A0S7ZTJ9 $14 \quad 276$ UniRef90_A6SZ04_26_286 UniRef90 U3H3U5 9 267 UniRef90 A0A073 $\overline{\mathrm{C} Y} \overline{5} 2 \quad 6272$ UniRef90_U6ZYXI_11_ $27 \overline{0}$ UniRef90-UPI000 67 C $\bar{F} 5$ D $4 \quad 26284$ UniRef90_A0A0K2BGW7_26-28 8 UniRef 90_A0A0110EK6 40-302 UniRef90 G4T117 $15 \quad 272$ UniRef90_Q87VP5_11-271 UniRef90 A0A089ȲS3̄ 11269 UniRef90 UPI0004174C $9 A-9267$ UniRef90_UPI000379F3E4_1̄ 286 UniRef90 A4VQU8 9267 UniRef90_A0A0M3V̄ $4 \bar{J} 1$ _ 7297 UniRef90-A0A098ESZ3- 4266 UniRef90 UPI000345DD̄ $\overline{1} 13277$ UniRef90-UPI00047D06E7 $9 \overline{2} 70$ UniRef90 I3BUX5 1262

UniRef90 UPI000780B9AB 11271 UniRef90_UPI000255752C_11_273 UniRef90 UPI000484E5E1 $11^{-} 269$ UniRef90 A0A0D6AS13 1 2 64 UniRef90_UPI00034A4 5 5D 18281 UniRef90-UPI00046A7B93 $11^{-} 269$ UniRef90_I3YAM1 6262 UniRef90 A0A0D9ĀT7 9267 UniRef90_UPI0003FDB $\overline{5} \overline{5}$ _4_265 UniRef90 K9SBL5 6267 UniRef90_UPI000 $\overline{4}$ OĀC544_17_274
----NPSEWHGILNLTYS-ONHGITOVVDKYTTAPYKIORPFY------PPGEEICHSVA -----STGWQGILRLKYA-KDNNSTKLIEAYSQAPLKIQRSFY------PEGKDICHNVI ------GWHGSLDLVYS-CERDTTYLTHALVKAPLKVQRPFY------PEGKSVCHSVI ----NSH IWHGKLNLIYA-KRQNKTQL I HAHHQAPLNIQRPFY------PEGEE ICHSVA -------WTGVLRLEAE-ERNGKTVAKRVYFQGAFKVMRPIY------HDDSGQACYYI -----SPSWHAELHLGFA-RAGERTVLRENRHRGPLRVQKALY------PEGEAVCQTIV INSPIDKSWHGKLNLVYA-NCQNSTQLVYNHHQAPFKVQRPFY------PEGEEICHTVI -----SSSWQGKLTLSYG-FVDKETRILKSQVQAPLKVQRPFY------PEGSEICHSVI -------WHGI LRLDFE-NRRGITOLSRNOGQAPLKVORPFY------PEGGGVCHCVV --------WTGI LELDVE-NRQGRTVADNIYFQGAFKVMRPVY------FGKNSYPCYYI ----NLTGWQGILRLKYA-KDNNSTKLIETYSQTPLKIQRSFY------PEGKEICHNVI ----SHARWQAQLTLGFV-SDRDTTRLMERTHRGPLRVQKPLY------PEGGQVCHAIV ---VNAQGWQALLKLQFA-KRAERTRIVSRERRGPLAVQRPFY------PEG-GVCHTYI -------WHGNLHLIYA-DRQNQTQLI FNQNQAPLKVQRPFY------PEGQKVCHSVI -----TPSWHAELELGYA-RFGATTRPVQRRHKGPLRVQKHLY------AEGPEVCQH I I -----TPSWHAELDLGYA-RFGDCTRPVQRRHKGPLRVQKHLY------AEGPEVCQHI I -------WTGYLRLAVQ-RKKETT I PSEVFHQGALKVTPAIY------LDDPQQPCFYI ---VAAPTWHAELHLGFA-HRAGRTVLRENRHRGPLRVQKALY------PEGDGVCQALI -----TPSWHAELELAYA-RFGDCTRPTRRRHLGPLRVQKHLY------AEGPEVCQHI I -------GWYGS LELVYA-HYEGKTKILHSFHQAPLKLQSPFY------PEGQQICHSVI ------FGWKARLSLGFV-NRGDKTVLKHRSQQGPLAIQRPLY------PEG-NPCHTYI -----TPSWHAELELGYG-RFGDSTRPTLRRHFGPLRVQKHLY------AEGPEVCQHII -----TPSWHAELELGYA-RFGDCTRPVTRRHLGPLRVQKHLY------AEGPEVCQHI I ------SWTGQLELKIE-HRGDRSAASRQYHQGAYKIARPIY------PDRSGQVHYYV -----TPSWHAELALGYG-RFGDSTRPTLRRHLGPLRVQKHLY------AEGPEVCOHI I -------WTGVLRLNAE-ERNGKTVARDVYFHGAFKVMRPIY------HDDSGQACYYI -----TPSWHAELELGYG-RFGDSTRPTQRRHKGPLRVQKHLY------AEGPEVCQHI I -----TPSWHAELELAYG-RFGDSTRPTORRHKGPLRVQKHLY------AEGPOVCOHI I -----TPHWNAELELGYA-RFEGGTRPVLRRHSGPLRVQKHLY------PEGPEVCQHI I -----TPHWHAELELGYA-LCAGATRPVLRRHNGPLRVOKHLY------PEGPDVCOHI I -----TPSWHAELELAYA-HAGGATRPVLRRHQGPLRVQKHLY------AEGPDVCQH I I -----TPSWHAELELGYA-RFGDTTRPVMRRHLGPLRVQKHLY------AEGPEVCQHI I -----TPEWHAELELGYA-RFGDCTRPVQRRHSGPLRVQKHLY------AEGPEVCQH I I -----TPSWHAELELGYA-RFGESTRPVQRRHKGPLRVQKHLY------AEGPEVCQHI I ------GWQAS LNLTFV-DRGDKTVLKNRQQSGPLAVQRPLY------PDG-ETCHTYI -----TPSWDAELELGYG-RFGESTRPTLRRHAGPLRVQKHLY------AEGPQVCQH I I -----TPSWHAELELAYA-RCGATTRPVLRRHLGPLRVQKHLY------AEGPEVCQHI I ----------LNLTYA-SRQGKTVIVEQQNQAPLKVQRPLYPEEQTDPEGQKICHS I I -----TPSWHAALELGYA-RFGATTRPVLRRHLGPLRVQKHLY------AEGPEVCQHI I -----TPSWHAELELGYA-RYGDSTRPVLRRHQGPLRVQKHLY------AEGPEVCQHI I -----TPSWHAELELGYA-RFGDSTRPVQRRHLGPLRVQKHLY------AEGPEVCQH I I -----APSWHAELELGYG-RFGDTTRPTLRRHLGPLRVQKHLY------AEGPEVCQHI I ------SWHGKLELVYA-QRQNSTQLMFSHNQAPLKVQRPFY------PEGEKICHSVI -----MNTWTGNLQLKIE-NKKGKS I PKDIYFQGAFKLMRPKY------FDDSGQPCYFI -------WQGRLALTFC-DRQGETYLSRCFVQAPLKVQRPFY------PEGRGVCHGVM ------SWHGRLSLTYE-KKAHOTOVOOSYHOAPLNLORPFY------PEG-PVCHSVM -------GWQANLNLTFA-DRGDKTVLKHRYQLGPLAVQRPLY------PDG-KTCHSYL -------WTGILQLDVE-NRQGKSVTKNLHFQGAFKIMRPVY------HQQSKHPCYYI ---MQANGWHAQLDLDFA-QRESRTVLARRQHFGPLVVQKPFY------PEG-AVCHVYI --------QARLSLAFT-DDAGTTRMTERSHFGPLRVQKTLY------PEHPAVCHAII -----TPSWHAELELGYA-RRDERT I PVLRRHLGPLRVQKHLH------AEGPEVCQH I I ---INPSQWQGI LELDYQ-KINNSTQLVKAYSQAPLKIQRSFY------PEGQEICHS I I -----TPSWHAELELAYA-CTGNATRPVLRRHQGPLRVQKHLY------AEGPQVCQHI I --------VARLRLGFS-DDAGVTRMTERSHFGPLRVQKPLY------PEHPS ICHAI I -------KARLTLGFA-DDAGTTRMIERS HFGPLRVQKPLY------PEHPAVCHAVI -----RPGWQARLALAFE-RRGETSALVRREHFGPLRVQKALY------PEGPDVCHAII ----SRQGWQAELRLGFA-KNESRTVLRHRAHRGPLTVQRPFY------PEG-DVCHLYL -----TPSWHAELELGYG-RFYDCTRPTQRRHKGPLRVQKHLY------AEGPEVCQHI I -----TPSWHARLELGYA-RFGDSTRPTLRRHLGPLRVQKHLY------AEGPEVCQHI I -----TPHWQAELELGYA-RIGGATRPVLRRHSGPLRVQKHLY------AEGPEVCOHIV -------GWQGSLNLIYA-NRTGTSQLVGERVGAPLKVQRPFY------PEGAAVCHSVI -----TPHWQAELELGYT-RIGDATRPVLRRHSGPLRVQKHLY------PEGSEVCQH I I ----TATAWQGKLNLVYE-NCQNSTQLIYNHHQAPLKVQRPFY------PEGEQVCHSVI -------WTGI LRLDAE-DRYGKTVARNVYFQGALKVMRPIY------HDNSGQACYYI ----NDSAWHARLTLGFA-DDAGTTRLVERSHAGPLRVQKPLY------PEGGAVCHAIV -----SSGWKAKLELAYV-ARPERTVLARSSRRGPLAVQRAFY------PED-GVCHSYV ---MAASGWOAELSLGFA-CRGGKTVLAERRORGPLAVQRPFY------PEG-DVCHAYV -----TPSWHAELELGYG-RFGDSTRPIQRRHKGPLRVQKHLY------AEGPEVCQH I I -----TPSWHAELELGYA-RDTDTTRPVMRRHKGPLRVQKHLY------AEGPQVCQHI I -----TPSWHAELQLGYA-RFGDSTRP I LRRHSGPLRVQKHLY------AEGPQVCQHI I ---MSGQNWQGKINLVYE-YQEGKTKIKSAYHQAPLKIQRSFY------PEGDSICHSVI ------WHGKLELDFA-NRDGATHVKHSYSQAPWKLQRPFY------PEGDRICHSVI -----TPSWHAELELAYA-RFGATTRPVLRRHLGPLRVQKHLY------AEGPQVCQH I -----PGWNARLALGFA-ERAGRTRLVERHQRGPLAVQRPFH------PEG-APCHCYL -----TPHWNAELELGYA-RFDHVTRPVLRRHSGPLRVQKHLY------PEGPEVCQH I I -------WTGVLDLVME-NRLGRSVAKSVYFQGAFKVMRPVY------ENKNSYPCYYI ----TTQPWCGTLDLVYA-QRQGITQP I HNLALAPLKIQRPFH------PEG-AVCHSVI ----SAQGWEAKLALGFA-RQHGKTVLAHRRHYGPLTVQRPFY------PEG-GVCHVYI 
UniRef90 A6D6Q9 31296 UniRef90_B8HW54_12-274

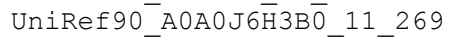

HpUreD

UniRef90_A0A0K9H6B6_4_266

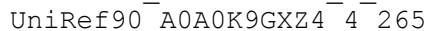
UniRef90_A0A0A3IXZ5_4_264 UniRef90_K9ZPZ7 7273 UniRef90 A0A0C1X̄DA $3 \quad 13 \quad 272$ UniRef90_UPI000379D7E3_4_266

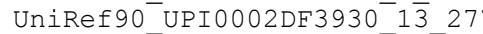
UniRef90_A0A0MOWOK1_1_266

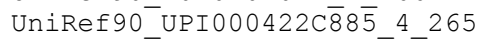
UniRef90 B4W160 8270 UniRef90_Q8YQZ4_1̄ 269 UniRef90 AOAOPIBUZ $\overline{9} \quad 3269$ UniRef90 A0A0M1JRC4 ${ }^{-} \overline{7} 282$ UniRef90_UPI0007108B5C_4_266 UniRef90-UPI0006A76A92 ${ }^{-}{ }^{-}{ }^{-} 265$ UniRef90_W4ETC9 4265 UniRef90_A0A0D6 KK KC $6 \_12 \_271$ UniRef90 A0A0D8ZYE2 $11-271$ UniRef90 B2IT63 $10 \quad \overline{2} 69^{-}$

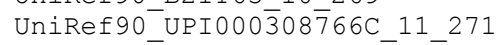
UniRef90 K9R6Q0 $10 \quad 280$ UniRef90_A0A127D̄ $35 \overline{2} \_4264$ UniRef90-UPI00028931̄D $\overline{6} 4266$ UniRef90-AOAOMOENP 6 4 $\overline{2} 6 \overline{6}$ UniRef90_A0A0S3PHU6_1 $1 \overline{6} 275$ UniRef90-A0A081NYG6 ${ }^{-}{ }^{-} \overline{2}$ ' 64 UniRef90_A0A0K9GPB1-4-266 UniRef90-UPI00071737 $8 \bar{B} 2265$ UniRef90 K9W1V1 $14 \quad 278$ UniRef90_K9U4Q1_17_272 UniRef90-AOA0M2 $\overline{\mathrm{S} W M} \overline{6} \quad 4265$

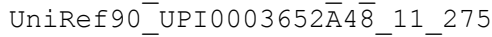
UniRef90_UPI00047A812C_16_286 UniRef90 K9TKA4 12277 UniRef90_M7NKH7_-1_ 269 UniRef90 K6DR39- ${ }^{-} 265$ UniRef90 A0A0B4 $\bar{R} \overline{\mathrm{S}} \mathrm{S} 1265$ UniRef90-A0A168N9T6 4-266 UniRef90 A0A139X4D9 $7{ }^{-} 274$ UniRef90-UPI00030AB̄̄ $9 \overline{2} 16277$ UniRef90-K7W9HO 9269

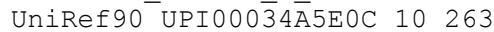
UniRef90_AOAOAOE4Q3_4_ 265 UniRef90-UPI0007172 $\overline{6} 3 \overline{\mathrm{C}} 44266$ UniRef90 K9QPZ4 $10 \quad 269$ UniRef90_UPI0002D28̄249_14_276 UniRef90- F9DU20 4266

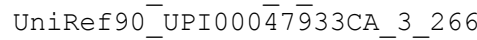
UniRef90-W7RFE8 4266 UniRef90 UPI00074 $\overline{4} 1 \mathrm{C} 40 \quad 4265$ UniRef90_AOAOT7BRT9 $7 \overline{2} 6 \overline{8}$ UniRef90 UPI0006A78 $\overline{3} 5 \overline{7} 4266$ UniRef90-UPI0007C7BB46 4-266 UniRef90_UPI000472611B-4265 UniRef90-UPI0002ACBA0D $1 \overline{1} 27$ UniRef90_A0A0C2KR59_11_26 UniRef90 K9WE93 $4 \quad 2 \overline{7} 7$ UniRef90 A0A0M0SP 3016277 UniRef90 K9Q9K1 $10 \quad \overline{2} 68$ UniRef90-A0A0S3T̄TX $\overline{4} \quad 17 \quad 278$ UniRef90 K9VQF3 $56 \overline{3} 23^{-}$ UniRef90 W1SM28 $4 \overline{2} 65$

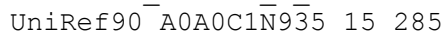
UniRef90-A0A139SK67 ${ }^{-} 11^{-} 275$ UniRef90 UPI00041C7CDC 4265 UniRef90 K9XHH8 $15 \quad 275$

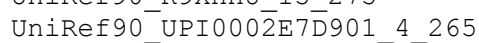
UniRef90-A0ZB05 $10 \quad 269$ UniRef90 D4ZSS4 ${ }^{-} 5 \overline{2} 70$ UniRef90 AOAOF5ȲFȲ1 6271 UniRef90 K9T9Y9 $59 \overline{3} 2 \overline{2}$
----TQFGWKASLDLTFI-DRGDKTVLKHRSQQGPLAIQRPLY------PEG-NPCHTYL ------SWQGNLDLKFA-RKQDTTQLI HCLGKAPLKLQRPFY------PEGPQICHGVI -----TPHWLAELELGYG-RFGDSTRPTLRRHCGPLRVQKHLY------AEGPQVCQHI I

51

60

70

80

90

100

LAVSPGMMRGDAQDVQLNIGPNCKLRITSQSFEKIHNTEDGF--------ASRDMHIVVG LNPGGGYLDGDRYRMQIALDKQAKMTLTTQSATKVYKTPNNY--------VYQETEISLK LNPGGGYLDGDRYNLQFSLKEKTKLTLTTOSATKVYKTPNOH--------AYQETEFILK LNPGGGYLDGDRYRMEISVDAGAEVILTTQSATKVYKTPKSL--------AYQETEITLK LHTAGGIVGGDRLSSDIHLEKDSQALITTAAAGKVYRSNGLP--------AKQTVNIQIG LHTAGGVVGGDRLSLNFHLQPNTQALITTAAASKIYRSNGTQ--------AKQSVNIQVD LNPGGGYLDGDRYKMDISADEGSKVTLTTQSATKVYKTPKNY--------AYQETVIRLK LHTAGGVVGGDKLSCNFQLQPESQVLITTAAAGKIYRSNGRQ--------ATQNINIEVS LNPGGGYLDGDRYKMQISADEGSKVTLTTQSATKIYKTPKSH--------AYQETEINLK LNPGGGYLDGDRYKLQFSLKEQAKLTLTTQSATKVYKTPNQH--------AYQETEFFLK LHTAGGIVGGDRLSOTIHLOEDSOALITTAAASK IYRSNGOR-------ANORI H I HVE LHTAGGVVGGDRLSYNLHLQPNAQALITTAAAGKVYRSDGLQ--------ARQTIEIKID LHTAGGVVGGDRLSYNLHLQPHTQALITTAAASK IYRTNGLQ--------ARQNINIQID LHTAGGIVGGDRLAQNFHLRENAKALITTAAASKIYRSNGNN--------AQQTINIKVD LNPGGGYLDGDRYQMKISLEKQAKLTLTTQSATKIYKTPNSH--------AYQEAEFNLK LNPGGGYLDGDRYRMKISAAENSKVTLTTQSATKVYKTPTDH--------VYQETEISLK LNPGGGYLDGDRYKMEISANEGAKVTLTTQSATKVYKTPKSF--------AYQETTISLK LHTAGGVVGGDRLSLNFHLQPHAQALITTAAASKIYRSNGLQ--------AKQI I D IKVD LHTAGGIVGGDRNTLSFHLQPQSQALITTAAASKIYRSNGSS--------ASQNVQIQVD LHTAGGMVGGDRLS SN I HLQPQAQALITTAAASK IYRSNGLQ--------ARQT IQMQVD LHTAGGIVGGDRLSCNFHLQPNAQALITTAAASKIYRSNGTQ--------AQQNIEIRVD LHTAGGIVGGDRLSSDFHLQPDSKALITTAAANKIYRSNGLQ-------ARQNIDIKID LNPGGGYLDGDRYKIQITLEKQARLTLTTQSATKVYKTPNTH--------AYQETEIILQ LNPGGGYLDGDRYQLKISLEKQAKLTLTTQSATKIYKTPKKH--------AYQETEINLK LNPGGGYLDGDRYKMEISADEGSKVTLTTQSATKVYKTPKGY--------AYQETQIHLQ LHTAGGVVGGDRLSYNFHLQPNAQALITSAAAGKIYRSNGLL--------AKQTINIKID LNPGGGYVDGDRYKLDIELAEDAKLLLTTOSSTKVYKTRNTA--------PVODMEIRMK LNPGGGYLDGDRYHLHIALEEQARVTLTTQSATKVYKTPQSY--------AYQETEIFLK LNPGGGYLDGDRYRMEIAVEEGAKVTLTTQGATKVYKTPNDH--------VYQETEISLK LHTGGGVVGGDRLSLNFHLQPNTHALITSAAAGKVYRSNGLE--------ARQTVEMRVE LHTAGGIVGGDCLS INLQLQPRSQALVTTTAASKIYRSNGLQ--------ARQIVEIQID LNPGGGYLDGDRYRMKISAGEDSKVTLTTOSATKVYKTPKDH--------VYOESEILLK MHTAGGIVGGDRLTFDFHLASGSQALITTPAASKIYRTNGRE--------AHQVIRVDVA LHTAGGVVGGDRLSYHLHLQPNAQALITTAAAGKIYRSNGTT--------ARQTIEIKVD LHTAGGIVGGDSLGQS I HVQENAHALITTAAAAKIYRSTGEV--------ARQS IKINVD LNPGGGYLDGDRYRMDITAEPDARVTLTTQGATKVYKTPKDH--------AYQETTMTLK LNPGGGYLDGDSYQMKISLAENARMTLTTQGATKVYKTPNKY--------AYQESDISLK LNPGGGYLDGDRYRMKVSASTGSKVTLTTQSATKVYKTPKGY-------AYQETEIYLE LNPGGGYLDGDRYKMEISADEGSKVTLTTQSATKVYKTPTSY--------AYQEAEINLK LHTAGGVVGGDRLSYKVHLOPKAOALITTAAASKIYRSNGAO--------ARONIDIOVD LHTAGGVVGGDRLSYDFHLQPHAQALITTATAGKIYRTNGMT--------AKQMIEIKVD LHTAGGIVGGDRLS SHI HLQPDTNALITTAAAGKIYRSNGLP--------ARQTVNIQVD LHTAGGIVGGDRLSSKI HLQPDAQAVITTAAASKIYRSNGLP--------ATQTINLKID LNPGGGYLDGDRYQMKIGLGENAKLTLTTQGATKVYKTPNRF--------AYQESEISLQ LNPGGGYLDGDRYKLEFTADEGSKVTLTTQSATKVYKTPKSH--------AYQETTIHLK LHTAGGVVGGDRLSTKIHLQPHTQAVITTAAAGKIYRSNGLQ-------ARQTIDIQID LHTAGGIVGGDRLSCNFHLEPHAQALITTAAASKIYRTNGLR--------ARQTINIQID LNPGGGYLDGDRYRMEITLDEOAOLTLTTOSATKVYKTPTRO--------VYOESVFHMK LNPGGGYLDGDRYKMKISLEKNARVTMTTQSATKVYKTPKNH--------AYQEAEFLLE LNPGGGYLDGDRYQMKISLKKQARLTLTTQSATKIYKTPHTH--------AYQETEFNLR LNPGGGYLDGDRYRMKISAAENSKVTLTTOSATKVYKTPKDH--------VYOESEIFLK LHTAGGVVGGDRLSTNI HLQPQSQVLLTTAAASKIYKSNGLQ--------ARQDVTIHID LNPGGGYLDGDRYQMKISLEKQARLTLTTQGATKIYKTPNKH--------AYQETEITLK INPGGGYVDGDRYRMEITLEEQAELILTTQSATKVYRTPHTP--------VLQENEIILK LNPGGGYLDGDRYQMQVTVQEEARLTLTTQSATKIYKSPRSF--------SYSEMEFTLK LHTAGGIVGGDRNNLSFHLQPHSQSLITTATASKIYRSNGLL--------AKQNIQMQVD LHTAGGVVGGDRLSCNFHLQRNAQALITTAAASKIYRSNGTQ--------ARQS IEITVD LHTAGGIVGGDRLSQTIHLSPHAHALITTAAASKIYGSKGKSRACPQGQPAKQTIQIQID LHTAGGVVGGDRLSYDFHLQPDAQALITTATAGKIYRSNGMI-------AKQVIEIKVE LHTAGGVVGSDRLSSHFHLQPNTQALITTAAASKIYRSNGLQ--------ARQTIDIQID LHTAGGVVGGDRLSYNFHLQPHAQALITTATAGKIYRSNGTI--------AKQKIEIKVD LHTAGGVVGGDRLSGHFHLQPNAKALITTAAAGKIYRSSGLE--------SQQNIDIQLD LNPGGGYLDGDRYQMKLSLLEKAKLTLTTQSATKVYKTPNNF--------AYQEAEISLQ LHTAGGVVGGDRLSCKVHLQPKAQALITTAAASKIYRSNGAQ-------ARQNIEIQID LHPPAGIVGGDSLAIAVDLAAGAHALLTTPGAGKWYRSGGPS--------ASLTQTITVG LNPGGGYLDGDRYHLQISLEKQARLTLTTQSATKVYKTPYSY--------AYQETEIFLK LHTAGGVVGGDKLSLNFHLQQNAHTLITTAAASKIYRSNGWE--------ARQNIQVQVD LNPGGGYLDGDTYRMKVTLAEDSRLTLTTQSSTKVYKTPVSY--------AYQETEFHLE LHTAGGVVGGDRLSSNIHLQTNAQALITTSAASKIYGTNGLQ--------ARQNIDIQVD LHTAGGMVGGDRLSQNLHLQADTKVLLTTAAASRVYRSTGKT--------ASQNVKIKLE LHTAGGIVGGDRLLQEIHLQPKTQAVITTASASKIYRSSGKQ--------AKQTVKIKVD LHTAGGIVEGDSLSQTIRLRENANTLITTAAAGKVYRSNGKL--------AKQIVRIKIE 
UniRef90 K9VAD2 $10 \quad 273$

UniRef90 W7Z4J7 ${ }^{-} \overline{2} 65$

UniRef90-Q47G52 $1 \overline{3} 278$

UniRef90 UPI000 $402 \overline{4} \mathrm{FBO} 3269$

UniRef90_K8GMD3_12_265

UniRef90_A0A0S3ŪB1 $\overline{2} \_16269$

UniRef90 AOA0F7D4R9 4 465

UniRef90_AOYQS4_5_271

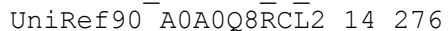

UniRef90_UPI0005625009_5_271

UniRef90-UPI000305E365-16 284

UniRef90 UPI0002E38242 $11^{-} 269$

UniRef90_G8Q511_12_270

UniRef90_A0A168İUL $\overline{4} 4266$

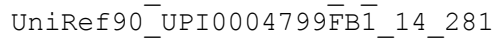

UniRef90_Q3KIS7_11_269

UniRef90 K9XZ09 $^{-} 12^{-} 271$

UniRef90_A0A090 RU $8 \overline{6} \_25$ _288

UniRef90-A0A0M5LWB1 $11^{-} 269$

UniRef90 A0A0C2I8A1 $11^{-} 269$

UniRef90 H3SNI3 $32 \overline{6} 5$

UniRef90_A0A0Q0X̄PT'8_11_269

UniRef90- K4ZJ70 $4 \quad 2 \overline{6} 5$

UniRef90_A0A085V̄951_11_269

UniRef90 A0A098SV87 $11^{-} 271$

UniRef90-A0A0A1GEL $6^{-} 9 \overline{2} 67$

UniRef90 I4CP19 $92 \overline{6} 7$

UniRef90'A0A0W0 $\overline{\mathrm{P}} 2 \overline{\mathrm{S}} 5 \quad 11269$

UniRef90_C3K5A6_11_ 269

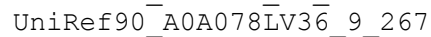

UniRef90- J3GGT8 $11 \overline{2} 6 \overline{9}$

UniRef90 A5L5M9-32-304

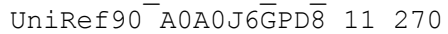

UniRef90_Q4KJ05_11_ 269

UniRef90 AOAOVTZ̄QT' 2281

UniRef90 A0A075PF54 $1 \overline{1} 269$

UniRef90_A0A0D5Y774_11-269

UniRef90 A0A0Q5EC30- $11^{-} 271$

UniRef90- I4N4V9 $11 \overline{2} 69$

UniRef90-D4TUH6 ${ }^{-}{ }_{7}^{-} \overline{2} 66$

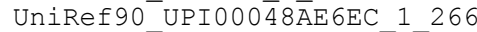

UniRef90_UPI0007398261_11_285

UniRef90 B0C790 $12 \quad 273$

UniRef90 A0A066ÜMR $\overline{7} 26298$

UniRef90_A0A0Q9XWI2_4_ 265

UniRef90 A0A0S7ZTJ9 $1 \overline{4} 276$

UniRef90_A6SZ04 $26 \quad \overline{2} 86$

UniRef90_U3H3U5_9 267

UniRef90 A0A073C̄ $\overline{5} 26272$

UniRef90_U6ZYX1_11_ $27 \overline{0}$

UniRef90 UPI00067CF5D4 26284

UniRef90-A0A0K2BGW7 26- $28 \overline{8}$

UniRef90_A0A011QEK6_40_302

UniRef90-G4T117 $15 \quad \overline{2} 72$

UniRef90-Q87VP5 $11^{-} 271$

UniRef90_A0A089ȲS3̄̄_11_269

UniRef90 UPI0004174C $9 \mathrm{~A}^{-} 9267$

UniRef90-UPI000379F3E4_1̄_286

UniRef90_A4VQU8_9_267

UniRef90-A0A0M3V̄ $4 \bar{J} 1 \quad 7297$

UniRef90_A0A098ESZ3-4-266

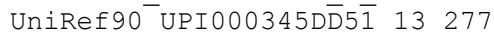

UniRef90_UPI00047D06E7_-9_-̄70

UniRef90-I3BUX5 1262

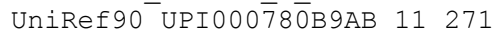

UniRef90_UPI000255752C-11-273

UniRef90-UPI000484E5E1 $11^{-} 269$

UniRef90-A0A0D6AS13 $1 \overline{2} 64$

UniRef90_UPI00034A $4 \overline{2} 5 \overline{\mathrm{D}}$ _18_281

UniRef90 UPI00046A7B93 ${ }^{-} 11^{-} 269$

UniRef90_I3YAM1_6_262

UniRef90 AOA0D9ÄIT̄7 9267

UniRef90-UPI0003FDB $\overline{5} F \overline{5} \quad 4 \quad 265$

UniRef90 K9SBL5 6267

UniRef90_UPI000 $40 \bar{A} C 54417274$

UniRef90-A6D6Q9 $31 \quad 296$

UniRef90-B8HW54 $12-274$

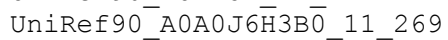

LHTAGGVVGGDKLSYDVHLQDNSQALITTAAASKIYRSNGYQ--------AKQDIKIKLD LNPGGGYLDGDRYQMKISLNERARLTLTTQSATKIYKTPNQL--------AYHETEINLK LHPPSGIAGGDHLAISAEVGEGSHAQLTTPGAGKWYRSGGAE--------ASQRVAFTVG LHTAGGILGGDRLTSDI HLQPQTNALITTAAASKIYRSQGLP--------ARQIVNIQVN LHTAGGVVGGDRLFLNLELQPQAHALITTAAAGKIYRSNGLE--------AQQIVTVKVA MHTAGGIVGGDRLSFEFRLAADSRSLITTPAASKIYRTNGRE--------AHQTIQIDIE LNPGGGYLDGDTYRMRVSLGEDSRLTLTTQSSTKVYKTPKSY--------AYQETEFHLK LHTGGGIVGGDRLLQEI HLQPQTQALITTASASKIYRSSGKQ--------AKQTINIQVD VHPPGGVVGGDELRIDASVGQNAGALLTTPGAAKWYKANGHI--------SRQDVHLQAG LHPPGGVVGGDSLDIQVHVESGAQALITTPGATKFYRSGGRL--------ATQIQTLSVA LHTAGGVVGGDRLSYNFHLQPHAQALITTATAGKIYRSNGMT--------AKQIIEIKVD VHPPGGIAGGDRLDIRASVERDAWAQLTSPGAAKWYRATGS---------ASQTLSLKVA VHPPGGIAGGDRLDISAHVGPDAWAQLTSPGAAKWYRAAGP---------AYQQLSLSVA MSFGGGYVGGDRYKLEIHLGEQAQMLLTTQSATKIYKTINRP-------AMQEMNIVLE LHPPSGIAGGDHLAIDIAVDDNSHAQITTPGAGKWYRSGGAA--------ASQTVTLNVA VHPPGGIAGGDRLDISARVAQGAWAQITSPGAAKWYRAAGP---------AYQSLNLHVA LHTAGGIVGGDRLSOKIOVOPNAHSLITTAAASKIYRSNGRE--------AKOILTIEIE LHPPGGVVGGDTLQIKAKAERGASVLITTPGATKFYRSENKY--------AKQSQILSVE VHPPGGIAGGDRLNICASVGPDAWAQLTSPGAAKWYRAAGP---------AYQSLTLNVA VHPPGGIAGGDRLAISARVEPAAWAQLTSPGAAKWYRATGP---------AYQTLDLKVA MNPGGGYVGGDRYRMELELGEGASSLMTTQSSTKIYRTPKEP--------VFQLTRIALE VHPPGGIAGGDRLHINAHVGPDAWAQLTSPGAAKWYRAAGP--------AYQTVELSVA LNPGGGYLDGDRYLMQVSLEEGARLTLTTQAATKIYKTPKKP--------AYQEVEIRLK VHPPGGIAGGDRLDISASVGPNAWAQLTSPGAAKWYRAAGP---------AYQQLDLQVA VHPPGGIAGGDRLDIDVSVGANAWAQLTSPGAAKWYRAAGP---------AYQQLELSVA VHPPGGIAGGDRLDISVAVGSGAWAQLTSPGAAKWYRAGGP---------AFQNVHLRVE VHPPGGIAGGDRLDISASVAAGAWAQLTSPGAAKWYRAVGP---------AFQDLRLRVE VHPPGGIAGGDRLAIHARVDTGAWAQLTSPGAAKWYRANGP---------ASQRLELQVA VHPPGGIAGGDRLDISAHVGAGAWAQLTSPGAAKWYRAGGP---------AYQQLDLCVE VHPPGGIAGGDRLDISAHAGRNAWVQLTSPGAAKWYRSSGP--------ASQTLNLHVE VHPPGGIAGGDRLDISASVGTNAWAQITSPGAAKWYRAAGP--------AYQKLDLRVA LHPPGGVVGGDTLNINVNLEHGAHALITTPGATKFYRSNNKY--------AKQKQTLRVE VHPPGGIAGGDRLNIRASVGPGAWAOLTSPGAAKWYRAAGP---------AYOTVELKVA VHPPGGIAGGDRLAISARVDSGAWAQLTSPGAAKWYRATGP---------ASQTLNLQVA LHTAGGVVGGDRLSCNFDLQPNSQALITTAAASKIYRSNGSQ--------ARQKIEINVD VHPPGGIAGGDRLDITAHLAQGAWAQLTSPGAAKWYRASGP---------AYQQLALTVE VHPPGGIAGGDRLQIRASVDRDAWAQLTSPGAAKWYRATGP---------AYQTLELTIA VHPPGGIAGGDRLAISAOVGPOAWAOLTSPGAAKWYRAAGP--.------AFOHLDLHVE VHPPGGIAGGDRLDINVNVGADAWAQLTSPGAAKWYRAAGP---------AYQTLNLSVA LHTAGGVVAGDRLSSNIHLQSETDVLITTAAASKIYRSNGLY--------AKQTVSIKID LNPGGGYLDGDRYRMDLNLEEKAELLLTTOAATKVYKTPNQS--------VIQETNISMG LHTAGGIVGGDRLSTTLQLEANAHALLTTATAGKVYRSNGQE--------AQQEVQISLA MHTAGGMVGGDRLSINVTLQPQTHALLTTTSAGKVYRSNGHG--------AQQTVQCQLD LHPPGGVVGGDTLNIDISAESGAHTLITTPGATKFYRSNAKY-------AKQKQMLHVA LNPGGGYLNGDTYRMEVSVQEEAKATLTTQSATKIYKTPSKH--------AYQETEIHLK IHPPGGVVGGDTLS INVTSCERSOTLITTPAANKFYRSSGPV--------ARLEOILTLK VHPPGGIVGGDQLTITARVGDRAHALLTTPGAGKWYRANGQL--------SQQQVSLEVG VHPPGGIAGGDRLDLSARVGDGAWAQLTSPGAAKWYRARGP---------AFQTLALRVE LHTAGGMVGGDRLSQT INLQPETQVLLTTPAASKIYRSSGET--------AQNTINIEIQ VHPPGGIAGGDRLAIRARVDSGAWAQLTSPGASKWYRAASP---------ASQLLELAVE VHPPGGIVGGDELHIDATLGDQAHALLTTPGAGKWYRANGNL--------SHQYVTLQAA VHPPGGILGGDVLNISARVGDNAHALLTTPGAGKWYRANGFV--------SQQQVSLTAT LHPPGGIAGGDSLEISLHVGAGAHALLTTPGAGKWYRSGGRP--------ARQSLSVRVG LHPPGGVVAGDRLTIEVKAEHGSHALITTPAAGKFYRSEGDC--------ASQSVTMTIE VHPPGGIAGGDRLDISVNVGAHAWAQLTSPGAAKWYRAASP---------AFQQLELHVQ VHPPGGIAGGDRLDISAQVQANAWAQLTTPGAAKWYRALSP---------AYQSTELHVA VHPPGGIAGGDRLAIRAAVGDGAWTQLTSPGAAKWYRAAGP---------AFQTLELRVG LHTAGGVVGGDRLCFDITLHPDTRALITTAAAGKIYRTNGLE--------AKQTALIKIA VHPPGGIAGGDRLDISVTLGPGAWAQLTSPGAAKWYRAASP---------AFQDLQLRVE LHTAGGVVGGDHLSSHFHLKPNTQALITTAAASKIYRSNGLQ-------ARQTIDIQID LNPGGGYLDGDRYRMQFLLEENAKLTLTTQSATKVYRTPRLH--------AYQETEIVMK VHPPGGVVGGDQLS ISARVGPAAHALLTSPGAAKWYKANGKV--------SRQQVYLQAQ LHPPGGVVGGDELI IDVTVEAEAHALLTTPGATKFYRSAGPF--------AEQIQQFKVE LHPPGGVVGGDALHLHFNVDAAAHALLTTPGATKFYRSAGMQ--------AAQHQQFHIS VHPPGGIAGGDRLDISASVGPQAWAQLTS PGAAKWYRAASP---------AYQKLELKVA VHPPGGIAGGDRLDIDIHLGENAWAQLTSPGAAKWYRAAGP---------AYQQLNIRVE VHPPGGIAGGDRLDISASVERDAWAQLTSPGAAKWYRANSP---------AYQQLEVTVA LHTAGGIVGGDILSQT IHLSSNSQVFITTPAATKIYRTQEKK--------AFQEII INLE LHTAGGMVGGDRLSAE INLAENTHALITTAAAAKIYRSNGLI--------AQQSTRIQIA VHPPGGIAGGDQLAISARVDNGAWAQLTSPGAAKWYRANGP--------AGQTLALQVA LHPPGGLVGGDRLEIAVSVDSGAHALLTTPGATKLYRSNGAE--------AHQTQHLRVA VHPPGGIAGGDRLDISATVGPGAWAQLTSPGAAKWYRAAGP---------AFQNLQLRVE LNPGGGYLDGDRYQMKVTLGERAMLTLTTQSSTKVYRTPTKP--------VYQETIFHMK LHTAGGIVGGDRLTIRARLEPESHALLTTAAASKLYRSNGFE--------AQQRVHLDVG LHPPGGIVAGDHLSLEIDAEAGSHALITTPAAGKFYRSAGGL--------ARQDVSITVA LHPPGGVVGGDTLQISVHAIQGAKSLITTPGATKFYRSESKY--------AKQKQTLHVA LHTAGGVVGGDRLSLDIHLDTDTQVLLTQAAASKIYRSEGLE--------AHQQVRITLE VHPPGGIAGGDQLDIRASVGPNAWAQLTSPGAAKWYRAAGP---------AYQRIELTVA 

110
120
130
140
150
160

HpUred

UniRef90 A0A0K9H6B6 4266 UniRef90_A0A0K9GXZ4 4 ${ }^{-}$-265 UniRef90 A0A0A3IXZ5 4-264 UniRef90 K9ZPZ7 $7 \quad 2 \overline{7} 3$ UniRef90_A0AOC1X̄DĀ3_13_272 UniRef90 UPI000379D7E3 4266 UniRef90 UPI0002DF3930' $1 \overline{3} 27$ UniRef90 AOAOMOWOK1 1 266 UniRef90 UPI000422C $\overline{8} 8 \overline{5} 4265$ UniRef90-B4W160_8_270 UniRef90_Q8YQZ4 ${ }^{-} 1 \overline{0} 269$

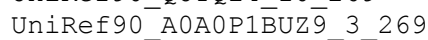
UniRef90_A0A0M1 JRC4_17 282 UniRef90 UPI0007108B5C 4266 UniRef90_UPI0006A76A92 - ${ }^{-}{ }^{-} 265$ UniRef90 W4ETC9 4265

UniRef90 A0A0D6 KKC̄ $6 \quad 12271$ UniRef90-A0A0D8ZYE2 $11^{-} 271$ UniRef90 B2IT63 $10 \quad \overline{2} 69$

UniRef90 UPI000308766C 11271 UniRef90_K9R6Q0 $10 \quad 280$

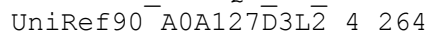
UniRef90_UPI00028931D $\overline{6}$ _4_266 UniRef90-AOAOMOENP $6 \quad 4 \quad \overline{2} 6 \overline{6}$ UniRef90 A0A0S3PHU6 $1 \overline{6} 275$ UniRef90_A0A081NYG6_3_- 264 UniRef90 A0A0K9GPB1 ${ }^{-}{ }^{-} 266$

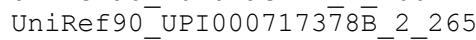
UniRef90_K9W1V1_14_278 UniRef90 $\mathrm{K}^{-} \mathrm{KU} 4 \mathrm{Q1}{ }^{-} 17^{-} 272$ UniRef90_AOA0M2 SWM $\overline{6}$ 4_265

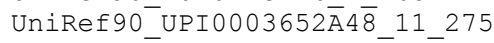
UniRef90 UPI00047A812C-16 286 UniRef90_K9TKA4_12_277 UniRef90 ${ }^{-} \mathrm{M}_{\mathrm{NKH}}{ }^{-}{ }^{-1} \overline{2} 69$ UniRef90- K6DR39-4 265 UniRef90_AOA0B4 RES 1 1 265 UniRef90 A0A168N9T6 ${ }^{-}{ }^{-} 266$ UniRef90_A0A139X4D9-7-274 UniRef90_UPI00030AB̄̄ $9 \overline{2}$ 16_277 UniRef90 K7W9H0 9269

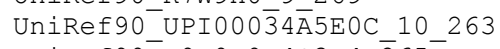
UniRef90 AOAOAOE4Q3 $4 \overline{2} 65$ UniRef90-UPI0007172 $\overline{6} 3 \overline{\mathrm{C}} 4266$ UniRef90_K9QPZ4_10_269 UniRef90-UPI000 $\overline{2}$ D2 $\overline{8} 24914276$ UniRef90_F9DU20_4_266

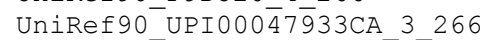
UniRef90 W7REE8 4266 UniRef90_UPI00074 $\overline{4} 1 \mathrm{C} 40 \_4265$ UniRef90'AOAOT7BRT9 $7 \overline{2} 6 \overline{8}$ UniRef90 UPI0006A78 $\overline{3} 5 \overline{7} 4266$ UniRef90 UPI0007C7BB46-4-266 UniRef90-UPI000472611B-4 265 UniRef90-UPI0002ACBA0D_1̄ 270 UniRef90-A0A0C2KR59 $11^{-} 26 \overline{9}$ UniRef90 K9WE93 $42 \overline{7} 7$

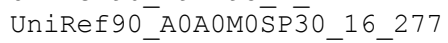
UniRef90 K9Q9K1 $10 \quad \overline{2} 68$ UniRef90_A0A0S3TTX $\overline{4}$ 17_278 UniRef90 K9VQF3 $56 \quad \overline{3} 23$ UniRef90-W1SM28 $4 \overline{2} 65$ UniRef90-AOAOC $1 \bar{N} 9 \overline{3} 5 \quad 15 \quad 285$ UniRef90 A0A139SK67 ${ }^{-} 1^{-} 275$ UniRef90_UPI00041C7C̄DC_4_265 UniRef90_K9XHH8_15_275 UniRef90-UPI000万̄E7D̄ 9014265 UniRef90 A0ZB05 $10 \quad 269^{-}$ UniRef90 D4ZSS4 ${ }^{-} 5 \overline{2} 70$ UniRef90 A0A0F5Y Y FY 16271 UniRef90 K9T9Y9 59 3 $3 \overline{2}$ UniRef90 K9VAD2 ${ }^{-} 10^{-} 273$ UniRef90 ${ }^{-}$W7Z4J7 $^{-} 4 \overline{2} 65$ UniRef90_Q47G52 $1 \overline{3} \quad 278$ UniRef90_UPI000 $402 \overline{4} \mathrm{FBO} 3$ _269
ENAFLDFAPFPLIPFENAHFKGNTTISLRSSSQLLYSEI IVAGRVARNELFKFNRLHTKI EGSYLEYIPDPLIAYRHARYKQKNI IRMEKGATFLYSDILTPGWSPEGDKFSYDTLQLIN KGSYLEYIPDPLIMYRNARYKQKNVIRMEQGATLIYSDI ITPGWSPDGEQFSYDQLQLMN KGSLLEYLPDPLIAYQNAHYKQKNVI HMETGATF IYTDILTPGWSPNGEKFSYNTVQLVT ANACLEYLPQETILFNGAVYRQDLKVKLDTNSSFIGWEITRLGRSARGEKFLEGEMRSHT AGACLEWFPQETIVFNGAIYRQDLRVELATKASYLGWEITRFGRSARGEKFVQGEWRNHT KGSYLEYLPDPLIAYQNAHYKQKTVVHIERGATFLYTDILTPGWSPNGEKFTYDTVQLMT TGATLEWLPQETIVFDGAIYRQDTRINLAENANF I GWEITRFGRSARGEKFLHGNWKSNT KGSYLEYLPDPLIAYQHAHYKQKTVVHMEPGATFLYTDILTPGWSPSGERFSYDTIQLVT KGSYLEYIPDPLIMYRDAQYVQKNVIRMEKGATLIYSDILTPGWSPDGDQFSYDRLRLLN AGACLEWLPQETIVFNGADYQQQMTVELAPGASWLAWEITRFGRTARKERFLQGDWRSHT AGACLEWLPQETI LFNGA IYRQDLRVELATGANFLGWEITRFGRSARGEKFYQGEWRSHT AGACLEWLPQET I LFNGA I YRQDLRVELAPGASWLGWEITRFGRTARGEKFVQGEWRSHT NDACLEFI PQET IVFNQALYRQDLTVELAPGASFFGWEITRFGRSARGEKFLAGAWRSNT EGSYLEYIPDPLIGYQDARYKQKNMI HMEKGCTLLYSDI ITPGWSPGGEKFSYDKLQLIN KGSYLEYLPDPLIAYENAHYKQKNVVYLESGSTFLYTDILTPGWSPSGEKFSYDTIQLKN RGSYLEYLPDPLIAYENARYKQKNVIHMESGATFLYTDILTPGWSPSGTRFSYDTVQLVT AGACLEWLPQETILFNSAIYRQDLRVELATEASWIGWEITRLGRSARGEKFLQGEWRSHT ANACLEWLPQETIVFNGAIYRQDLRVELAPGASWLGWEITRFGRTARGERFLEGEWKSHT PGACLEWLPQETILFNDA IYRQDLRVELATGASWLGWEITRFGRSARGEKFLQGEWRSHT SGACLELLPQETIVFNGAIYRQDLRVELATKASWIGWEITRFGRSARGEKFLQGEWRSHT KNACLEWLPQETIVFSGASFRQDIKIELADDANF I GWEITRFGRTARQEKFLTGEWRSNT SGCYLEYIPDPLIMYQDARYKQKNVIRMEKGATFLYSDILTPGWSPDGDRFSYNRLQFIN EGSYLEYIPDPLIGYKDARYKQKNVI HMEKGTTLLYSDI ITPGWSPDGERFSYDILQLIN KGSYLEYLPDPLIAYENAHYKQKNVVHMESGATFIYTDILTPGWSPEGKKFSYNTIQLVT AGACLEWLPQET I LFNGA IYRQDLRVKLATGANFLGWEITRFGRSARGEKFYQGEWRSHT KGSFLEYVPDPLIAYRHAQYKQKTTIRMERGSTLIFSDIVTPGWSPDGELFSYDKLRLKT AGSYLEYIPDPLIAYQHARYKQKNVI HMEKGATFLYSDI ITPGWSPNGERFSYDKVQLIN KGSYLEYLPDPLIAYENAHYKQKNVIHIEEGATFLYTDIITPGWSPSGDKFSYKTIQLIN AGACLEWLPQEN I I FNDANYRQDLRVELATDATWMGWEITRLGRTARGEQFLQGNWRSHT EGACLEWLPQET IVFNGANYRQDLRVELAPGASWLGWEITRFGRSARGERFLQGEWRSYT KGSYLEYLPDPLIAYENAHYKQKNVVRMESGSTFLYTDILTPGWSPSGEKFSYDTIQLKT EGACLEWLPLDS IVFNQA IYRQTMQINLAQGANWLGWEITRFGRSARGEKFVEGNWRSRT AGACLEWIPQETIVFNSALYRQDLRVELTTGASYLSWEITRFGRSARGEKFLQGEWRSNT SGA ICEWLPQES I I FNGA IYRQDLRIELAPDARFLLWE INRFGRSARGETFVQGEWRSQT AGSYLEYLPDPLIAYKDAAYROKNIVRMESGATFLYTDILTPGWSPDGGOFAFDSVRLIN AGSYLEYIPDPLIAYQNARYKQKNVIRMDQTATFLYSDILTPGWSPEGERFSYTTVQLLN KGSYLEFLPDPLIAYENANYRQYNTVRLETGATFLYTDILTPGWSPSGKKFTYHSVQLVN KGSYLEYLPDPLIAYENAHYKQRNIVHMERGATFLYTDILTPGWSPSGEKFSYDTIQLVT AGASLEWLPQETIVFNGAIYRQDLRVELATGANWI GWEITRFGRSARGEKFCLGEWRSHT DGACLEWLPQETIVFDGALYRQDINVKLATTASYIGWEITRFGRSARGEKFLQGEWRSHT SHACLEYLPQETILFNGGIYRQDLRVELATDASYLAWEITRFGRSARGEKFVQGEMRSHT TGACLEWLPQETILFNDGIYRQDLRVELATGASFLGWEITRFGRTARGEKFYSGEWRSHT AGSYLEYFPDPLIAYONAHYKOKNVIKMHPSATLLYSDIITPGWSPEGERFSYKSVOLLN KDSYLEYLPDPLIAYENAHYKQKNVVHMDRGATFLSTDILTPGWSPSGGKFSYDTIQLVS AGACLEWLPQETILFNGAIYRQDLRVELATGANFIGWEITRFGRSARGEKFYQGEWRSHT ANACLEWLPQETIVFNSALYRQDLRVELATGASYLGWEITRFGRTARGEKFVQGEWRSHT KDSYLEYLPDALIAYKDAKYYQKNIVHMEKGATLLYSDILTPGWSPEGEKFSYDMLRLKT AGSYLEYIPDPLIAYQHAKYKQKNVIRMDKTATLLYSDI ITPGWSPEGEQFSYETIQLLN EGSYLEYIPDPLIGYQDARYKQKNVVYIEKGCTLLYSDIVTPGWSPSGEKFTYNMLQFIN KGSYLEYLPDPLIAYENAHYKQKNIVHMESGSTFLYTDILTPGWSPSGENFSYDTIQLKT SHACLEYLPQETIVFNSANYRQDVRI HLAVDASFLGWE ITRFGRTARNEQF IQGEWRNYT EGSFLEYLPDPLIGYRDARYKQKNVI HMEKGSTLVYSDI ITPGWSPEGXPFSYDMLQLIS KGSVLEYIPDPLIAYRDAKYKQNTI IRMERGATLFYSDILTPGWS PDGEWFRYDLLQLKN NGSYLEYI PDPLIGYRDARYKQKTVVHMEKGATLLYSDI ITPGWSPDGEKFSYHTLQLKT TDACLEWLPQETIVFDGAIYRQDLQVELAPGAKWLGWEITRFGRTAKGERFLHGDWKSHT AGACLEWLPQETIVFNGA I YRQDLRVELATEGSFLGWE INRFGRSARGEIFATGEWRSHT QAACLEWLPQETIVFNGAIYQQDLRVELAPGASWLGWEITRFGRSARGERFLQGEWRSHT DGACLEWLPQETIVFDGALYQQDLRVNLATKASY IGWEITRFGRSARGEKFLQGEWRSHT AGACLEFLPQETILFNGADYRQDLRVELATGACFLGWEITRCGRSARGEKFLEGKWRSHT DHAYLEWLPQETIVFDGALYRQENIVKLATNSHYLGWEITRFGRSARGEKFLQGEWRSHT TGANLEWLPQETIVFDGAIYRQNLRVELAPTARILLWEITRFGRSARGENFLSGEWRSHT PGSYLEYLPDPLIAYQNAKYKQKNI IRMDKTATFLYADIVTPGWSPDGERFSYQTVQILN AGACLEWLPQETI IFNGA I YRQDVRVELSAAANWMGWEITRFGRSARGEKFYTGEWRSHT DGAVCEWLPQETLVFDGARGGQTTEIELAADARFVGVELLCFGRTASGERFAHGDFAMRT AGSYLEYFPDPLIAYQDARYKQKNI IRMEKGATLLYSDI ITPGWSPNGKRFSYDKVQLIN SNACLEWFPQETIVFNGAIYRQDLRVELAPGATWTGWEITRFGRSARGEKFLQGNWRSHT KGSYLEYLPDPLIAYKDAKYVQKNVVHMERGSTLLYSDIVTPGWSPEGKEFSYDTLRLKN AGACLEWLPQETIVFNGAIYRQDLRVELAPGGSWLGWEITRFGRTARGEKFLQGEWRSHT KGAYLEYLPRETI IFNGA IYRQDLRVELAPEATWLGWEITRFGRSARGENFGQGEWRSHT ENACCEYLPRETI I FNGA IYRQDLQVELGQNATWLGWEITRFGRTARGEKYTQGEWRSCT SGACLEWVPQETI I FNGA IYQQDLRVELAPGASWLGWEITRLGRSARGEKFLEGNWRSHT SNSYLEWLPQETI I FNDAEYSQKLRVEVGENATFMGWEITRFGRSARGEKFTAGEFRSYT KGSYLEYITDPLIGYQDARYKQKTVINMEKGAAFLYSDI ITSGWSPNGKQFSYDLLQLIN EGATLEWLPQETIVFDGARARMETQVDLAADSRY I GWDILCLGRVAAGERFEKGRFDLFL DHSHLEYLPQETILFNGAIYRQDLRVELGKNANYLGWEIMRFGRSARGEKFLGGEMRSHT 
UniRef90 K8GMD3 12265 UniRef90_A0A0S3ŪB1 $\overline{2} \_16269$ UniRef90'A0A0F7D4R9 4 265 UniRef90 AOYQS4 $52 \overline{7} 1$

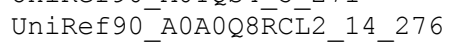
UniRef90 UPI00056250009 5271 UniRef90 UPI000305E365 $1 \overline{6} 284$ UniRef90_UPI0002E38242-11-269 UniRef90 G8Q511 $12 \quad 270$ UniRef90_A0A168İUL $\overline{4}$ 4_266

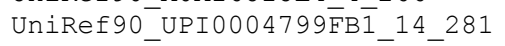
UniRef90 Q3KIS7 11269 UniRef90_K9xz09-12_271 UniRef90_A0A090RU8 $\overline{6} \_25 \_288$ UniRef90_A0A0M5LWB1_11_269 UniRef90_A0A0C2I8A1_11_269 UniRef90 ${ }^{-} \mathrm{H} 3 \mathrm{SNI} 3 \quad 3 \quad 2 \overline{6} 5$ UniRef90_A0A0Q0X̄PT8_11_269 UniRef90 K4ZJ70 $4 \quad 2 \overline{6} 5$ UniRef90 A0A085V̄ $9 \overline{5} 111269$ UniRef90_A0A098SV87_11-271 UniRef90 A0A0A1GEL $6^{-} 9 \overline{2} 67$ UniRef90-I4CP19 $92 \overline{6} 7$ UniRef90_AOAOWO $2 \overline{\mathrm{S}} 5$ _11_269 UniRef90 C3K5A6 $11 \quad \overline{2} 69$

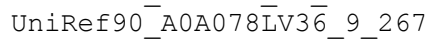
UniRef90- J3GGT8 $11 \quad \overline{2} 6 \overline{9}$ UniRef90- A5L5M9-32-304 UniRef90 A0A0J6 GPD 811270 UniRef90_Q4KJ05 $11 \quad \overline{2} 69$

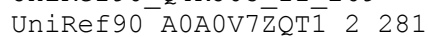
UniRef90_A0A075PF54_11_269 UniRef90 A0A0D5Y774-11-269 UniRef90_A0A0Q5EC30_11_271 UniRef90 I 4N4V9 $11 \overline{269}$ UniRef90-D4TUH6 ${ }^{-} \overline{2} 66$ UniRef90_UPI0004 $8 \overline{\mathrm{A}} \mathrm{E} 6 \mathrm{EC}$ _1_266 UniRef90-UPI0007398261'1̄ 285 UniRef90_B0C790_12 273 UniRef90_A0A066ÜMR $\overline{7} 26298$ UniRef90 A0A0Q9XWI2 $4 \overline{2} 65$ UniRef90_A0A0S7ZTJ9_14_276 UniRef90 A6SZ04 $26 \quad \overline{2} 86$ UniRef90-U3H3U5 $9 \overline{2} 67$

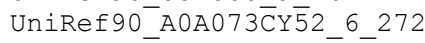
UniRef90 U6ZYX1 $11 \overline{2} 7 \overline{0}$ UniRef90_UPI000 $\overline{6} 7 \mathrm{CF} 5 \mathrm{D} 4 \quad 26284$

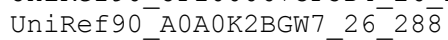
UniRef90 A0A011QEK6 40 302 UniRef90 G4T117 $15 \quad \overline{2} 72$ UniRef90-Q87VP5 $11^{-} 271$ UniRef90 A0A089ȲS3̄̄ 11269 UniRef90_UPI0004174 C9A_9_267 UniRef90_UPI000379F3E4 ${ }^{-} \overline{1} \quad 286$ UniRef90_A4VQU8_9_267 UniRef90-AOAOM3V̄ $4 \bar{J} 1 \quad 7297$ UniRef90-A0A098ESZ3-4-266

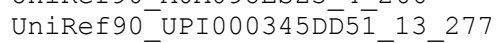
UniRef90_UPI00047D06E7_9_ 270 UniRef90- I3BUX5 1262 UniRef90_UPI0007̄ōBAAB_11_271 UniRef90 UPI000255752C-11-273 UniRef90_UPI000484E5E1_11_269 UniRef90 A0A0D6AS13 1 264 UniRef90-UPI00034A $4 \overline{2} 5 \bar{D} \quad 18 \quad 281$ UniRef90_UPI00046A7B93_11_269 UniRef90- I3YAM1 6262 UniRef90-A0A0D9ÄIT̄7 9267 UniRef90_UPI0003FDB $\overline{5} \overline{5} \quad 4265$ UniRef90 K9SBL5 6267 UniRef90-UPI000 $40 \bar{A} C 544 \quad 17 \quad 274$ UniRef90-A6D6Q9 $31 \quad 296$ UniRef90 B8HW54-12-274

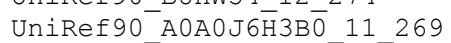

PNACLEWLPQET IVFAQAQYRQQMQ I DLAPGALWI GWEITRFGRTARGEKFFAGEWRSRT NGACLEWLPLDAIVFNQAS FRQEMMINLAPGAEWI GWEITRFGRSARGERFVEGNWRSQT KNSYLEYLPDALIAYKDAKYIQKNVVYMEKGATLLYSDIVTPGWSPEGDAFSYDTLRLKS SEACCEYLPRETIVFNGAIYRQDLYVELAQNATWLGWEITRFGRTARGEQFTAGEWRSCT DSATLEWLPQETIFFDAAHVRLDTA IELGTDATY I GTE I LCFGRTASGESFDSGMVEQKT KGGMLEWMPQENIFFPDANARIETHIALEPGAAF I GWDIQCLGRPVNDEPFDIGSMASAT EHACLEWLPQETI IFDGALYQQDLRVNLATEASY IGWEITRFGRTARGEKFLQGEWRSHT AGATLEWLPQETIVFSAAQAELATRIELEGDARLFYWDIVALGRPASGERFDRGHFQAHL PGATLEWLPQETIVFSAAQAELSTS I DLQGDGRLFYWDMVALGRPASGERFDLGHFOSRI KGSYLEYMPDP I IAYEHAKYLQNT IVHMNPGSAMIYGDI ITPGWSPDGKWFRYHTLQIKT AGATLEWLPQES IVFDGAIARMDTHVTLAADSRYLGWDILCLGRAAAGERFDHGRFDLHC DGATLEWLPQETIVYSAAQAELTTS IELEGDARLFYWDVVALGRPASGERFDLGHFQAHI PGATLEYLPQENIVFSGAIYRQDLRIQLAPGANWIGWE INRFGRSARGEQFIAGEWRSYT KGARLEWLPQENIFFPDAHVRMDTQVHLEKDAQFLGWEMHCFGRPALNEGFS SGHLVGKT AGATLEWLPQETIVFSGARAELTTRIELEGDARLFYWDMVALGRLASGERFEHGHFQSQL AGATLEWLPQETIVFSAAQAELRTT I DLEGDARLFYWDMVALGRPASGERFDRGHFHSQL AGSYLEWLPDSVIAYRDSRYRQQTDIRMHSSAALILGEIVTPGWSPDGEHFSYDEITLKT AGATLEWLPQETIVFSAAQAELSTQIELQGDARLFYWDMVALGRMASGERFECGHFQSRL KGSYLEYITDPI I GYEHARYKQKTVIWMEKGANLLYSEIVTSGWSPDGRQFSYDLLQFMN PGATLEWLPQETIVFSAAQAELTTRIELQGDAKLFYWDVVALGRPASGERFEGGHFQAQL SGGTLEWLPQETIVFSEAKAELTTRINLQGDARLFYWDVVALGRPASGERFDQGHFQAHI AGATLEWLPQETIVYCAAQAELSTS IELEGDARLFYWDI IALGRPASGERFDAGHFQAQL TGATLEWLPQETIVYSAAQAELSTVIELEGDARLFYWDMVALGRPAAGERFDAGHFQARI PGATLEWLPQETIVFSAAQAELTTC IELQGDARVCYWDI IALGRPASGERFAQGYLQAHL AGATLEWLPQETIVFSAAQAELTTRIELHGDARLFYWDVVALGRPASNERFDLGHFQSHL AGGTLEWLPQETIVYSAAQAELKTCI DLEADARLFYWDMVALGRPAATERFDDGYFQAQL AGATLEWLSQETI IFSDAQAELSTRIDLEGDARLFYWDVVALGRPASGERFDLGHFQAHI KGARLEWMPQENIFFPNAHVRLDTEIRLEKGAQFWGWEMHCFGRPAQNEGFEHGHLVGKT AGATLEWLPQETIVFSAARAELSTRIELEGDARLFYWDMVALGRQASDEHFDLGHFQSQL PGATLEWLPQETIVFSAAQAELTTRIELQGDARLFYWDI IALGRPASGERFEQGHFQAHL ERACLEWLPQET IVFNAADYRQDLRVDLANNASFLGWEINRFGRTARGEKFVQGNWRSHT AGATLEWLPQETIVFSAAQAELRTRIDLEGDARLFYWDVVALGRPASGERFDLGHFQSHL AGATLEWLPQETIVFSAAQAELSTRIELQGDARLFYWDVVALGRPASDERFEQGHFHSRL PGATLEWLPQETIVFSQAQAQLETCINLHGDARLCYWDVVALGRPASGERFAQGYFQSQL PGATLEWMPQETIVYSAAQAELQTHIELQGDARLVYWDMVALGRPAADERFARGYFQSHL RGSCLEYLPQETIVFNGGRYRQDVRIELGEGSSFIGWEISRLGRTARGEKFLEGEMLSHT KDSTLEYVPDP I IAYRSADY IQHNN I HMESGATLIYSDILTPGWSPDGS LFSYDNIQVKN SGACLEWLPQETIVFNGAEFRQQLRVDLEPGALWMGWEIARLGRSARGERFVCGNWRSHT TNAI LEWLPLGTIVFDQAQFRQTLQVELGPGAIFCGWDLTRFGRSARGERFMQGDWRSHT KDARLEWMPQENIFFPDAHVRLDTEIYLEKGAQFWGWEMHCFGRPAQNEGFEQGHLVGKT QGSYLEYLPDPLIAYKDACYVQKNIVRMEKGAEFLYTDILTPGWSPEGKHFSYESLRLIN QHASLEWLPQETILFNGCEVSATTCINLSDNSRF I GWE I SCLGRPAS GEAFDYGRVRQRF ADAALEWLPQETIFFNEADVRLEHNVTLAADARY I GGE I LCFGRTASGETFDSGRVAQRT AGATLEWLPQETIVFSGAQAELSTRIDLAADARLFYWDVVALGRPAAGEHFASGHFQAQL EQAYLEFIPREII IFNGAIFSQNLRVNLDPNACYLGWEITRFGRTARGE I FNQGQWKSCT PGATLEWLPQETIVFSAAQAELTTRIELHGDARLCYWDIVALGRPASGERFVQGHFOAHL AGARLEWLPQETIFFNEADVRLEHKVTLAVDASYIGGEILCFGRTASGESFTRGSVGQRT AGAALEWLPQETIFFNDADVRMEHSVDLAADACY I GGEILCFGRTASGESFNSGRVSQCT EGGVVEYLPQETIVFDGAEAQMQTQVELAAGALFCGWE ILCLGRTASGERFRHGRLQLAT ENAVLEWLPQETIVYEGARFTSETTIKIDTGSRFIAWEVIVLGRPASGEGFELGEALLNW PGATLEWLPOETIVFSNAOAELTTRIELHGDARLCYWDVVALGRPASGERFEHGHFQSHI AGATLEWLPQETIVYSAAQAELDTRIHLQGDARLFYWDIVAVGRPAAAERFDQGHFQSRI AGATLEWLPQETIVYAGAQPELDTRISLEDDARLFYWDMVALGRPASGERFDSGRLRARL GGACLEWLPQETIVYNNAIYRQDLRVELEPGAS I LIWEITRFGRSARGEQFLQGFWRSHT AGATLEWLPQETIVYSAAQAELNTRIELHGDARLFYWDIVALGRPAAGERFDAGHFQARL AGACLELLPQETILFNGADYRQDLRVELAPGACFLAWEITRFGRSARGEKFLQGKWRSHT KGSYLEYLPDPLIAYRNAKYLOKNI FRMEKGATLFYTDI ITPGWSPDGKLFSYSMLOLIN AGASVEWLPQES IFFDQARVALEQTVVLEADASY IGCE ILCLGRRASGETFNSGKIAQRT EGGALEWLPQETIFFPGACAGLKTQIQLHPKASYLGWEVHCLGRPTNQETFDSGELLFQT DG-CLEWLPQENIFFPSANALLSSEVHLHGTAQYLGWEI HCLGRPVIGETFAAGRALFKT AGGTLEWLPQETIVFSEAKAELTTRIDLECDARLLFWDVVALGRPASGERFEQGHFQAHL AGATLEWMPQETIVYSAAHAELVSNIELIGDGKLFYWDIVALGRPASDERFDLGHFQAEI AGATLEWLPQETIVFSAAQAELNTS IDLQGDARLFYWDVIALGRPASDERFEHGHFQSQI NDTYLEYLPQET IVFNKCQYQQKLRVNLRENATWLGWEI IRFGRSARGE I FTHGQWLNQT AGAYLEWLPQDS I I FDGA I YNQHLHVELAPQATWCGWEVCRYGRTARGESFLSGQVRSHT PGATLEWLPQETIVFSAAQAELSTQVDLQGDARLFYWDVVALGRPASGEHFAHGHFQSHL ADGILEWLPQENI LFAGTHARLATQVDLDPGARF I GWEVQALGRPANGERLTTGTADLSL PGATLEWLPQETIVYSAAQAELEMS IELQGDARLLYWDIVALGRPASGERFDAGHFQAQL KDSYLEYLPDALIAYKDASCYQKNS I YMEKGATLLYSDILTPGWSPEGEKFSYDMLRLKT AGACVEWLPQES IVFDGAVYRQDLRVELAPDAWWFGWELTRLGRSARGERFVQGNWRSHT EGAALEWLPQETI IYEGARLRSTVRVELASKARF I GWE ILSLGRPACGERFDEGLADLDV SGSRLEWLPQENIFFPDAHVRLDTE I HLERGAQFLGWEMHCFGRPALNEGYSAGHLLGKT PGAWLEWLPRETIVFNOAHYHODLRVELAPGAVWLGWEITRLGRTARGEOFLOGHWRSHT AGATLEWLPQETIVFSSAQAELSTRIELQGDARLFYWDMIALGRQASGERFERGHFQSHL 
HpUred

UniRef90 A0A0K9H6B6 4266 UniRef90_A0A0K9GXZ4_4_265 UniRef90 A0A0A3IXZ5 4264 UniRef90 K9ZPZ7 $7 \quad 2 \overline{7} 3$ UniRef90_A0A0C1X̄DĀ3_13_272 UniRef90 UPI000379D7E3 4266 UniRef90-UPI0002DF3930 $1 \overline{3} 27$ UniRef90 A0A0MOWOK1 1 266 UniRef90-UPI000422C $\overline{8} 8 \overline{5} \quad 4265$ UniRef90_B4W160_8 270 UniRef90_Q8YQZ4 ${ }^{-} 1 \overline{0} 269$ UniRef90 A0AOP1BUZ $\overline{9} 3269$ UniRef90_A0A0M1JRC4_17 282 UniRef90 UPI0007108B5C 4266 UniRef90_UPI0006A76A92_4_265 UniRef90 W4ETC9 4265

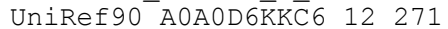
UniRef90_A0A0D8ZYE2_11_271 UniRef90 B2IT63 $10 \quad \overline{2} 69$

UniRef90 UPI000308766C 11271 UniRef90 K9R6Q0 $10 \quad 280^{-}$ UniRef90-A0A127D̄3L $\overline{2} \quad 4264$ UniRef90_UPI00028931D $\overline{6} 44266$ UniRef90 AOAOMOENP $6 \quad 4 \quad \overline{2} 6 \overline{6}$ UniRef90 A0A0S3PHU 6 $1 \overline{6} 275$ UniRef90_A0A081NYG6_3_ 264 UniRef90 A0A0K9GPB1 ${ }^{-} 266$ UniRef90_UPI000717378 $\overline{\mathrm{B}}$ _2_265 UniRef90_K9W1V1_14_278 UniRef90 K9U401 $17^{-} 272$ UniRef90_A0A0M2SWM $\overline{6}$ 4_265 UniRef90_UPI0003652Ā $4 \overline{8}$ _11_275 UniRef90 UPI00047A812C $16^{-} 286$ UniRef90_K9TKA4_12_277 UniRef $90^{-}$M7NKH7 $^{-}{ }_{1} \overline{2} 69$ UniRef90 K6DR39 ${ }^{-}{ }^{-} 265$ UniRef90 AOA0B4 $\bar{R} F \bar{S} 1 \quad 1265$ UniRef90 A0A168N9T6 $4-266$ UniRef90 A0A139X4D9 7 - 274 UniRef90_UPI00030AB̄̄ $9 \overline{2}$ 16_277 UniRef90 K7W9HO 9269 UniRef90_UPI000 $34 \bar{A} 5 \mathrm{E} 0 \mathrm{C} \_10 \_263$ UniRef90 A0AOA0E 4Q3 $4 \overline{2} 65$ UniRef90-UPI0007172 $\overline{6} 3 \overline{\mathrm{C}} 4$ 4 266 UniRef90_K9QPZ4 10_269 UniRef90 UPI0002D28249 $14 \quad 276$ UniRef90 F9DU20 4266 UniRef90_UPI000 $\overline{4} 7 \overline{9} 33 \mathrm{CA} 33$ 266 UniRef90 W7RFE8 4266 UniRef90_UPI00074 41 1C40_4_265 UniRef90 A0A0T7BRT9 $7 \overline{2} 6 \overline{8}$ UniRef90 UPI0006A78 $\overline{3} 5 \overline{7} 4266$ UniRef90-UPI0007C7BB46-4 266 UniRef90 UPI000472611B 4 265 UniRef90_UPI0002ACBA0D_1̄ 270 UniRef90 A0A0C2KR59 $11^{-} 26 \overline{9}$ UniRef90_K9WE93 $4 \quad 2 \overline{7} 7$ UniRef90 AOAOMOSP30 $16 \quad 277$ UniRef90 K9Q9K1 $10 \quad \overline{2} 68$ UniRef90 AOAOS3TTX 47278 UniRef90 K9VQF3 $56 \quad \overline{3} 23$ UniRef90 W1SM28 $4 \quad \overline{2} 65$ UniRef $90^{-}$AOAOC $1 \bar{N} 9 \overline{3} 5 \quad 15 \quad 285$ UniRef90 A0A139SK67 $11^{-} 275$ UniRef90_UPI00041C7CDC_4_265 UniRef90_K9XHH8_15_275 UniRef90-UPI0002E7D̄901 4265 UniRef90 A0ZB05 $10 \quad 269^{-}$ UniRef90-D4ZSS4 $5 \overline{2} 70$ UniRef90 A0A0F5 $\bar{Y} \overline{\mathrm{Y}} 1 \quad 6271$ UniRef90-K9T9Y9 $59 \overline{3} 2 \overline{2}$ UniRef90 K9VAD2 $10^{-} 273$ UniRef90 ${ }^{-}$W74 J7 ${ }^{-} \overline{2} 65$ UniRef90 Q47G52 $1 \overline{3} 278$ UniRef90_UPI0004024̄FBO_3_269
170
180
190
200
210

SILQDEKP IYYDNTILDPKTTDLNNMCMFDGYTHYLNLVLVNCPIEL----SGVRECIEE ELYVDDELAVYDH I KLNPRNQDMNTIGFMEGFSHLGSMIVVGEQTDS----DLLDRLHEA EVYMDDELVMYDH I KLNPAEQDMKA I GFMEGYTHLGSMIVIGEQTNA----DLLDRLYNS EIYLDGQLGVFDHIKLTPGKHS ISGIGFMEGYTHLGSMIVVSELTNN----SLLDELYEM EIWQNGI PQWIDRQ I LPGSEEVFHSPHGLAGYPVVGSLVWVGSSVSR----EI IEKARSI EIWQQGKPLWI DRQWLPGNEEVFHSPHGLAGQP ITGNLVWVGGVVSA----EIVDKARNL EIYWDGKLGVFDH I KLMPQQQT ISGLGFMEGYTHLGSMIAVSEQTEP----EYLDELYEA EVWQQGKPLWVDRQWLPGSEEIFYSPHALNGQPVVGTFIYIGSTVSP----EI IEKASSY EIYWNGRLGVFDHLKLVPQQQKISGLGFMEGYTHLGSMIA ISEQMDA----ALLDELYDA EIYMDDELVVYDH IKVNPAEQDMQS I GFMEGYTHLGSMFVIGEQTNA----ELLDKLHHL EIWQQGHPLW I DRQWLPGGEAVLDSPHGLAGEP IVGTL IWMGPPVSS----EI I DNARS I E IWQQGVPLW I DRQWLPGNDAVFHSPHGLAGQP IVGSLVWLGSP IST----EI IEKARNI EIWQQGVPLWI DRQWLPGKEEVFHSPHGLAGQP IAATLTWVGTSVTE----EILDKARNL EVWQAGEPLW I DRQCLFGSEEMFHS PNALKGYPLVGTLFWIGQPVSA----DAIASARNF E IYMENELVVYDH IKLSPATONINGLGLMEGYSHLGSMIVVDEKTDH----DLLDRLYEA EIYLDGKLGVYDHIKLVPGKSPMTGLGFMEGFTHLGSMIAVSEDTTN----ELLDELCEI EIHLDGKLGMFDH I KLTPHNQNLSGLGFMEGYTHLGSMVAVSENTDN----ALLDELYET EIWQQGVPLWI DRQYLPGSEEVFHSPHGLAGQP IVGSLVWVGNPVDS----EILAKARNL EVWQQGKPLW I DRQWLPATET I INSHHGLNGQP IVGSFAWIGQPVTK----EIVEQARNL EIWQQSVPLWIDRQCLRGSEDI FHSPHGLAGKP IVGSLVWVGGAVSA----EIVEKTRSI EIWQQGVPLWIDRQLLPGSEEVFHSPHGLAGQPLVGSLVYVGQEVSP----ELVEKVRSI EIWQNNKPLWI DRQYLPGSEEVFHSPHALAGKP IVGTLIYIGKPVSP----EIVQKIRTL EIYMDDELVAYDHIOLNPAAONIEKI GFMEGFSHLGSMLVVGEOTSP----DLLDRLYOA EIYMENELVVYDH IKLNPAMQNMEKLGLMEGYSHLGSLIVIDEKANH----ALLDRLYQA EVYLNGKLGVFDH I KLMPEKQTLSGLGFMEGFTHLGSMIAVSEYTNN----SLLDELYEV EVYQEGVPLWIDRQWLPGNEGVFHSSHGLNGQPIVGSFVWVGSAVTE----EFVQKARDI EIYVDGDLAVYDQVRLNPSEQDLTGIGLLEGYTHFGSLIVVGEQMTS----DFLDQLYEA EIYMDDELISFDH IKLNPATONIEALGFMEGFSHLGSMMVISEQMSP----DLLDRLYHA EIYLDGLLGVFDHIKLTPSQQSLTDIGFMEGYTHLGSMIVIGNQTNN----HLLDELYEM EIWRQGDPLWI DRQWLPGGENI INS PHDLAGYPVIASFAFVGKAVSK----DLIEKARNC EVWOOGOPLW I DROWLPGEEA I LNS PHGLAGHS IVASLTW I GCEVSP----ELVTKCRDV EIYLDGKLGVFDHIKLSPEDNSVEGLGFMEGFTHLGS LMAVSEETDN----QLLDELYDK EVWQAGKP IWIDRQWMPGSEENFASPHGLAGCPVVGSFAWVGQVVTP----ELVEKAREI EIWQQGKPLWIDRQWVPGSEE I FYSPHGLAGQPVVGSLVWVGSAVSV----EI IEKARN I EIWQQGRPLW I DRQHLQGSESAVSSNSALAGFP IVATLAW IGDPVTP----ELVQEARS I EIYVDGEPAVFDNIRLSPSDOKVGGLGFMEGYTHLGSMIAIGEOTTD----DLIDILHDL EIYMDDELVVFDHIKLQPSEQNIRGLGFMEGYSHLGSMIVVSEQSNS----SFLDQLYST KIYVDGDLAVFDHIKLSPGEQNISGVGMMEGYSHIGSMIVIGEQTTK----ELLDELYEA EIYWDGKLGVFDH IKLVPKQQNITGLGFMEGYTHLGSMIAVSDQMDN----VLLDALYEM EVWQMGVPLWIDRQWLPGSEDVFHSPHGLAGQPVTGSLVY IGQEVSQ----ELVHKARTL EIWQQDKPLWIDRQWLPGSEEVFHSPHGLAGQP IVGS LVYIGQKISP----ELVHQARNI EIWQNGI PLWIDRQIVPGSEEVFHS PHGLRDNPVVGSFVGVGFPISP----EI INQARSI EIWQHNIPLWIDRQWLPGNQDVFHSPHGLSGKP IVGTFVWVGDVVSA----EIVETARNL EIYMDGELVVYDHLHLKPALONIRGLGFMEGYTHLGSMFVVCKOMNP----SFLDOLYSL EIYVDGQIGVFDH IKLVPKQQSVSGLGFMEGYTHLGSMLVVSEYTNN----AFIDELYEA EIWQEGVPLWI DRQYLPGSEEVFHSPHGLSGQPIAGNF IYLGSPVSK----ETIEKARS I EIWQQGKPLWIDRQWLPGSDKIFHSPHGLNGQAIAGSLVWVQGAVSQ----DMIEKARDI EIYMEDELVVFDHIKLHPASQNMNGLGFMEGYTHLGS FIVVGEKMNE----DLLDRLHET EIYMDDELVVYDHIKLNPGQQNLRGIGFMEGFSHLGSMIVIGEQSNS----VLLDQLYSV EIYMENELAVYDHIKLCPAKQNIDSLGLMEGYSHLGSMIVINENVDH----DLLDRLYQA EIYLDGVLGVFDHIKLAPEKNS IAGLGFMEGYTHLGSMIAVSENTDN----GLLDMLYET E IWRDNQPLW I DRQY L PGDMAVFHS PHGLNSQA I AGS F I YLGKQISP----OLITQIRQM EIYMENELVVYDH I KLNPS IRNMEELGLMEGYSHLGSMIVIDEKSNQ----DLLDRLYQA EIYLDEKLIMFDHLKLQPDEAGVDGIGYMEGYTHLGSMIVMSEQVNE----DVLQRLYSV EIYMDEDLVVFDHIKLSPATQDIEGLGFMEGFSHMGSMIVIGEKSNA----ALLDLVYQE EVWQQGLPLWI DRQWLPAGEKI I DS PHGLAGLPIVGS LAWIGQPVEP----EIVEKARVL EIWQQGVPLWIDRQWLPGRVEVFHS PHGLAGQPLAGS LVYVGQEVSS----DLVEKARSI EVWQQGRPLWI DRQWLPGEEQVLDS PHGLAGKP IVAS LAWVGQAVSP----EMIEKARLI EIWQQNKP LWI DRQSLPASEEVFHS PHGLAGQP IVGSLVYIGQETSP----ELVNKARNL EIWQOGVPLWI DRQFLPGNTDIFHSPHGLFGQP IVGSLLWLGHPVST----EI IEQVRSI EIWQQGKPLW I DRQWLPGREEVFHSFHGLAGQP IVGSLVY I GRE ISP----EIVEKARNI EVWQENSPLWI DRQLLKGGEKMLES PHGLAGKPVVATLAWVGEPVTA----EFVEKVRDI EVYVDNELVVYDH IKLNPASQNMNGLGFMEGFSHLGSMLVVGKQTNS----SLLDQLYSA EVWQMGVPLW I DRQWLPGREDVFHSPHGLAGQPVTGSLVY I GQEVSH----ELVHKARS I RIRRDGQTLWLERGRVTGNS PLLAS P IGLAGQPVVATMWVVAPQVNE----GLRDACRAI EIYLDDELVSLDH IKLHPAKQHMEALGFMEGYSHLGSMMVVGEQMTP----ELLDRLYYA EVWQQQRPLW I DRQQLRPDVKVI DS PHGLAGKS I I GS FVW I GQPVSA----DVVEKVRML EIYMDDELVVFDH IKLOPARONMGGLGFMEGYTHLGS FMVIGEOTDD----DLLDSLYEI EIWQQGVPLWIDRQYLPGSEAVFHSPHGLAGQPIAGSLVWVGSDISA----EFLAKARSL EIWQNEKPLWI DRQWLPGGETILESPHGLGGWPVVATLTWVGEPVSK----ETLNHVRML EIWQNGKPLWIDRQWLPASEEILTSPHGLAGQA IVGTLAWVGHSVSE----EMLKEIRQI EIWQQGQPLLIDRQWLPAGEA I INSSLGLAGQP IVASL IW I GKPVSQ----NI IERAQTL EIWHLGKPLWIDROWVPGCEEVFHSHHGLGGNA I AGTL IWLKNPVSS----EI I TQVRNL EIYLDGELVVYDHIKLDPLHVNITSLGFMEGFTHLGSMIVVGEQVNH----DLLDQLYEA QVNRDQRPIWIERGGFDGSDPMLISPAGWAGATVCGTLLCAFPEWPMQAS-ALLEACRKI EIWQNDI PLWI DRQ I I PGNEEVFYSPHGLAGNPVVGTLVWVGNSVSG----EMI DKARSI 
UniRef90 K8GMD3 $12 \quad 265$ UniRef90 A0A0S3ÜB12 16269 UniRef90 A0A0F7D4R9 $4 \quad \overline{2} 65$ UniRef90 AOYQS 45271 UniRef90_A0A0Q8BतCL 2_14_276 UniRef90_UPI0005625009_5 271 UniRef90_UPI000305E365_16_284 UniRef90_UPI0002E38242_11_269 UniRef90 G8Q511 $12 \quad 270$ UniRef90_A0A168ĪUL $\overline{4} 44$ 266

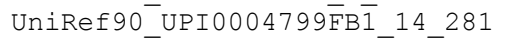
UniRef90 Q3KIS7 $11 \quad 269$ UniRef90_K9XZ09-12_271

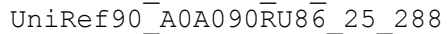
UniRef90_A0A0M5LWB1_11_269 UniRef90_A0A0C2I8A1_11_269 UniRef90 H3SNI3 $3 \quad 2 \overline{6} 5$ UniRef90_A0A0Q0X̄PTE_11_269 UniRef90 K4ZJ70 $4 \quad 2 \overline{6} 5$ UniRef90 A0A085V̄ $9 \overline{5} 111269$ UniRef90_A0A098SV87_11_271 UniRef90 A0A0A1GEL $69 \overline{2} 67$ UniRef90_I4CP19_9_267 UniRef90_AOAOWOP $2 \overline{\mathrm{S}} 5$ _11_269 UniRef90 C3K5A6 $11 \quad 269$

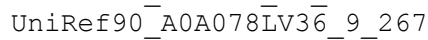
UniRef90 J3GGT8 $11 \quad \overline{2} 6 \overline{9}$ UniRef90 A5L5M9 $32-304$ UniRef90_A0A0J6GPD 8 _11_270 UniRef90_QKJ05 $11 \quad \overline{2} 69$

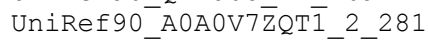
UniRef90_A0A075PF54_1̄ 269 UniRef90 A0A0D5Y774 $11^{-} 269$ UniRef90_A0A0Q5EC30 $11^{-} 271$ UniRef90 I 4N4V9 $11 \quad{ }^{-} 69^{-}$ UniRef90 D4TUH6 ${ }^{-} 7 \overline{2} 66$

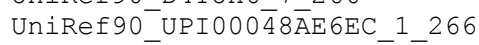
UniRef90 UPI0007398261 $1 \overline{1} 285$ UniRef90_B0C790_12_273 UniRef90 A0A066UMR $726 \quad 298$ UniRef90 A0A0Q9XWI2 $4 \quad \overline{2} 65$ UniRef90_AOAOS7ZTJ9_14_276 UniRef90-A6SZ04 $26 \quad 286$ UniRef90 U3H3U5 $9 \overline{2} 67$ UniRef90_A0A073C̄ $\overline{5} \overline{5} 2$ 6_272 UniRef90 U6ZYX1 $11 \overline{2} 7 \overline{0}$ UniRef90_UPI000 $67 \mathrm{C} \overline{\mathrm{F}} 5 \mathrm{D} 4 \quad 26284$ UniRef90_A0A0K2BGW7_26-28 UniRef90 A0A011QEK6 $40 \quad 302$ UniRef90_G4T117_15_272 UniRef90 Q87VP5 $11^{-} 271$ UniRef90 A0A089ȲS3̄ 11269 UniRef90_UPI0004174C CAA_9_267 UniRef90-UPI000379F3E4_1̄ 286 UniRef90_A4VQU8_9_267 UniRef 90-A0A0M3V $4 \overline{\mathrm{J}} 1 \quad 7 \quad 297$ UniRef90 A0A098ESZ3 4266 UniRef90_UPI000345DD̄5 13277 UniRef90_UPI00047D06E7_9 270 UniRef90-I3BUX5 1262 UniRef90_UPI0007 8 0̄B9AB_11_271 UniRef90-UPI000255752C ${ }^{-} 11^{-} 273$ UniRef90_UPI000484E5E1_11_269 UniRef90 A0A0D6AS13 1 2 64 UniRef90_UPI00034A425D_18_281
UniRef90-UPI00046A7B93_11_269 UniRef90_UPI00046A7B93
UniRef90_I3YAM1 6262 UniRef90 A0A0D9AIT7 9267 UniRef90_UPI0003FDB $\overline{5} \bar{F} \overline{5}+4265$ UniRef90 K9SBL5 6267 UniRef90_UPI000 $40 \bar{A} C 54417274$ UniRef90 A6D6Q9 $31 \quad 296$ UniRef90 B8HW54 $12^{-} 274$ UniRef90_AOA0J6B̈3BO 11269
EVWQQGRPLWIDRQWLPGNEETFSS PHGLANCPVVGSFAVIGQTVNP----DLIEKIRAT EVWQSGKP IWI DRQWLPGSEATFNS PHGLAGCPVVASFAWIGKTVDS----ECVEKARSI EI YMDGELVVFDHVKLQPEQQNMTGLGFMEGYTHLGSFIVIGEKTDD----ALIDRLYEV EIWQNGKPLWIDRQWLPANVEI LTSPHGLAGQA IVGTLAWVGHSVSE----EMLKEIRQL SIRRDGKLLWFEQGMLAAGSAAMTSPLGLAGNTVCATLIAVGKPLAA----SMMATLREA H IS I DGELVLI DQLRTEG-RALLDAAAGLRGYPMQAS LF IVPGEACRVSLTDLLEH IRES EIWQQDKPLWIDRQWLPGSEEIFHS LHGLAGQPIVGSLIYIGQEISP----EIVEKARS I DIRRDGQPLWHERQRIEGDDGLLDSPIGLDGQPVFATLLVTGE-IDS----ELLERCRNI DIRRDGQLLWHERQRIVGGDGLLDSPIGLGGDPVFATLLVTGE-IDS----ELLEQCRS I QVYLEDKLVVFDHLQLRPANDPMEGIGLLEGYTHLGSMIVIGERTDP----ELIERLSDS RIERAGKPLWIERGSVAGGDAMLHSPAGWAGATVCGTLLCSFPELPQQAA-ALLEALRTL DIRRDGRLLWHERQRIVGADGLLDSPIGLDGHPVFATLLVTGE-IDA----ELLERCRS I EVWQNNRLLWI DRQWLPGEAELINS INGLAGKPVIGTFSYLGKPVDK----EILEKINNL EIYLDGQRLLTEGLNVRGEDKLLKD-KGLLGYQMMGTLYISID--DE----DFYQLVQSI DIRRDGQLLWHERQRISGGDGLLDSPIGLDGNPVFATLLVTGE-ISA----QLLEICRNL DIRRDGQLFWHERQRIRGGDGLLDSP IGLDGQPVFATLLVTGE-IDS----ELLERCRSV MIEMDGVPVLFDHLRLRPGEOP I HGLGRMDGHTH I GS LYVVGPLATR----AFIEELAEK DIRRDGQLLWHERQRIVGDDGLLDSPIGLDGHPVFATLLVTGE-IST----ELLHTCRSL EIYLDGVLA IHDH IKLDPAAHRMTS LGFMEGYSHLGSMMMI SEQVDQ----DFLDRLYLE DIRRDGTLLWHERQRVIGGDGLLDSPIGLDGKTVFGTLLVTGE-IES----ELLEACRSI DIRRDGRLLWHERQRVVGNDGLLDSP IGLDGKPVFATLIVTGD-IDP----ELMERCGEL NISRDGELLWHERQRVTGNDGLLDSPIGLDGHPVFATMIVSGE-ISA----ELLERCRAL DIRRDGQLIWHERQRIAGGDGLLDSPIGLDGHSVFATLIVSGE-IDA----ELMERCREL DIRRDGRPLWHERQRIEGDDGLLESPVGLDGHPVFATLLITGQ-AED----DLLERCRAL DIRRDGQLLWHERORIVGADGLLDSPIGLDGOPVFATLLVTGD-IEP----ELLEHCRAI DIRRDGKLLWHERQRISGADGLLDS P IGLNGYPVFATLIATGE-IDA----DLLERCREI DIRRDGQLLWHERQRIVGNDGLLDS P IGLDGQPVFATLLVTGD-IDS----ELLEKCRLI EIYLDNQRLLTEGFDFHGGDKLMIN-MGLLDYAMMGTFYLTSN--EK----QDLELVQSL DIRRDGRLLWHERQRIVGGDGLLHSPIGLDGHPVFATLLVTGD-INP----ELLETCRSI DLYRDGRPLWHERORIGGGDGLLDSPIGLDGOPVFATLLVTGE-IDS----ELLERCRAL EIYQEGIPLWIDRQWLPGSEEIFYSPNGLAGQAVIGSLIFVGKTISK----DIVEQVRSL DIRRDGQLLWHERQRIVGDDGLLDSP IGLDGQPVFATLLVTGE-IDS----ELLEQCRAI DIRRDGQLLWHERQRLVGGDGLLDSPIGLDGQPVFATLLASGE-IDA----ELLERCRSI EIRRDGRLLWHERQRLEGGDGLLDSPIGLDGKTVFATLLMTGE-AGS----ELLETCRSL DIRRDGELLWHERQRVVGDDGLLDS PMGLDGHTVFATLLVTAD-ISP----ELLEQCRGF EIWQGEVPLWIDRQHI PGGVEAFYNPHSLKGNPVIGSFVCVGLPISE----ERIEKSRSG QIFMNGRRVVFDHLRLKPNSQDIGGIGLMEGFTHVGSMIVICDQVSK----EFMERIKEH QVWOAGRL IWVDPQWVAGGSEMMES LHGLAGY PVIASFALLGHPVSG----ELVERVRSL EIWQQGAPLWIDRQWLPGQPDIWES PHGLAGQPVVGSFLWVGQGVEP----NLVQTARDI EIYLDNKKLLTEGFNFHGGDKLMIN-MGLLNYPMMGTFYITAD--EP----QDLELVQSI EIYLNDE IVVFDHLHLS PRNKAMNGLGHMEGYTHLGSLIAISEKVND----AFIETLYNT ELYKHEKPLFIERALLEGGQPTLAAHWGLQSFTVTATMIAYP--ADK----AVLELARKS SIRRGGKLLWFEQGALQARSTSMHSPLSLAGYTVCATLIAVGKTMNG----AFLNELREE DIRRDGRALWHERQRISGDDGLLDSPIGLAGQPVFATLIATGQ-LDP----ELLERCREI EIWQNGCPVWI DRQGF IANEE I LNS PHGLGGKPVIATLTWVGQPVSE----DIVKNIRQI DIRRDGRPLWHERORISGGDGLLDS PVGLDGQPVFATLLVTGE-IDA----OLLERCRAI SIRRDGKLLWFEQGVLHAHAASMHSPLSLAGYTVCATLIAVGKTMTP----AFLQTLREE SIRRGGKLVWFEQGTLRAGTSSMTS PLALAGFTVSATLIAVGLPINA----AFLSELREQ RIERQGRPLWLERGRLLGASSWLDAAPGLAGFPVSASLLLAGRAVEP----EWLAACRAI RIVLGDQPIYLERLRLDA--QAFAARWGLSRHSSCGTLFAYP--ASA----EVLEIVRNV DIRRDGTLLWHERQRI I GADGLLDSP IGLDGKTVFATLLLTGD-VDS----DLLEVCRS L EIRRDGELLWHERQRIVGDDGLLDSAVGLGGKPVFATLLVTGE-IDP----ALLERCRGL DIRRDGRLLWHERQRVEGGDALLDSPIGLAGQPVFATLIASGE-IDA----DLLERCRQI E IWQOGRPLWI DRQQL I GGEETLNS P HGLAGKPVVGS LAWIGVRVTP----ELVEKARSI DIRRDDRLIWHERQRIAGADALLDSPIGLDGRSVFATLIASGE-LDA----DLLERCRGL EIWQQGVPLWI DRQFLPGNPE I FHS PHGLFGQPIVGSLIWLGHPVSS----EI IEKARSI EI YMEDELAAFDH I KLVPSVQN ISGLGFLENHTHLGSMIVIGEQANR----EFLDHLQNE QI HRDGKLVWWEQGALAGGGEMLRS PLGLDGHSVCATLLAVGKVLPA----AALASLREA DIQRDGEPLYKEHLQLDNPWD-LQGMAGLSGYPVMATMLALP--AGN----DALELARQA ALYRDGKPLLLDRLLIOGERD-LQLAAGLRGNPVFATLLATP--ATP----ELLEQARSL DIRRDGKLLWHERQRITGNDGLLDS PVGLGGKPVFATLIVTGE-VDA----ELMERCRAL NIRRDGELLWYERQRVVGDDGLLDSPIGLDGYPVFATLLLSAE-IAP----ELLEQCREL NIRRDGQLLWHERQRIVGNDGLLDSP I GLDGQPVFATLLVTGE-IDG----ELLERCRAL EVWYKDKPLWI DRQLLQGESNLFSA INGLANKPVIGNLTLISAKINQ----DI IREIREI EVWQQGRPLWI DRQRLSGGADT I HSPHALAGQPVVANLAFIGQVIPT----EIVEQARTL DIRRDGKPLWHERQRIVGGDGLLDSPIGLDGHPVFATLLATGE-ISA----ELLEHCRAL AIQRAGRPLLLDRLRIDAGTG-LDGPAGLRGFAVTGTLVATG--IDR----EDLAAVRGI NITRDGEWLWHERQRVTGDDGLLDSPIGLDGNPVFATLIVTGE-IDA----ELMERCREL EIYMENQLVAFDH I KLHPASQHMNELGFMEGYTHLGSLIVVGEKTSD----ALLDRLYET EVWROGOPLWIDROWLPGNPAWLDS PHGLHGRSLVGSFAVVGOPIAP----ELVAEARAL QVYCRDQPLLLERLKLDA--RAFAARWGLQGCSACGTLFAYP--AGA----ETLAAVQQL EVYLDKQLLLTEGLNVRGNDKLLKS-RGLLNYQMMGTVYVS ID--DE----DFYQLVQTL EVWQQGTPLWIDPQWLPGGEELLKSYHGLSGYPVVGTLVLIGQAAEA----ELIAQIRQI DIRRDGQLLWHERQRIVGGDGLLDSPIGLDGNPVFATLLVTGD-VSP----ELLDACRSL 
HpUreD

UniRef90 A0A0K9H6B6 4266 UniRef90_A0A0K9GXZ4_4_265 UniRef90_A0A0A3IXZ5 4-264 UniRef90 K9zPz7 $7 \quad 2 \overline{7} 3$ UniRef90_AOAOC1 $\bar{X} \mathrm{DA} 3 \quad 13$ UniRef90 UPI000379D7 E3 4266

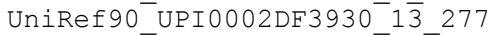
UniRef90 A0A0MOWOK1 1 266 UniRef90-UPI000422C $\overline{8} 8 \overline{5} \quad 4265$ UniRef90_B4W160_8 270 UniRef90_Q8YQZ4 $1 \overline{0} 269$ UniRef90 A0A0P1B̈UZ $\overline{9} 3269$ UniRef 90_A0A0M1 JRC4_17 282 UniRef90 UPI0007108B5C 4266 UniRef90_UPI0006A76A92_4_265 UniRef90 W4ETC9 4265

UniRef90 A0A0D6 KKK $6 \quad 12 \quad 271$ UniRef90_A0A0D8ZYE2_11_271 UniRef90-B2IT63 $10 \quad \overline{2} 69$

UniRef90 UPI000308766C 1127 UniRef90_K9R600_10_280 UniRef90-A0A127D̄3L $\overline{2} \quad 4 \quad 264$ UniRef90_UPI00028931D $\overline{6} 44 \_266$ UniRef90 AOAOMOENP $6 \quad 4 \quad \overline{2} 6 \overline{6}$ UniRef90 A0A0S3PHU 6 $1 \overline{6} 275$ UniRef90_A0A081NYG6_3_ 264 UniRef90 A0A0K9GPB1 ${ }^{-} 266$ UniRef90_UPI000717378 $\overline{\mathrm{B}}$ _2_265 UniRef90_K9W1V1_14_278 UniRef90 K9U401 $17^{-} 272$ UniRef90_A0A0M2 SWM 6 _4 265 UniRef90_UPI0 $003652 \overline{\mathrm{A}} 4 \overline{8} 11$ 11_27 UniRef90_UPI00047A812C_16_286 UniRef90_K9TKA4_12_277 UniRef90 M7NKH7 ${ }^{-}{ }^{-} \overline{2} 69$ UniRef90 K6DR39 ${ }^{-} 265$ UniRef90 AOAOB4 $\bar{R} F \bar{S} 11265$ UniRef90 A0A168N9T6 ${ }^{-}{ }^{-} 266$ UniRef90_A0A139X4D9 $7{ }^{-} 274$ UniRef90-UPI00030AB $\overline{1} 9 \overline{2} 1627$ UniRef90-K7W9HO 9269 UniRef90_UPI000 $34 \bar{A} 5 \mathrm{EOC} 10 \_263$ UniRef90 A0AOA0E 4Q3 $4 \quad \overline{2} 65$ UniRef90-UPI0007172 $\overline{6} 3 \overline{\mathrm{C}} 4$ 4 266 UniRef90_K9QPZ4_10_269 UniRef90 UPI0002D28249 $14 \quad 276$ UniRef90_F9DU20_4_266 UniRef90-UPI0004 $7 \overline{9} 33 \mathrm{CA} 3266$ UniRef90 W7RFE8 4266 UniRef90_UPI00074 4 1C40_4_265 UniRef90 A0A0T7BRT9 $7 \overline{2} 6 \overline{8}$ UniRef90 UPI0006A78 $\overline{3} 5 \overline{7} 4266$ UniRef90 UPI0007C7BB46 4 266 UniRef90 UPI000472611B 4 265 UniRef90_UPI0002ACBA0D_1̄ 270 UniRef90 A0A0C2KR59 11 269 UniRef90_K9WE93 $4 \quad 2 \overline{7} 7$ UniRef90 AOAOMOSP30 $16 \quad 277$ UniRef90 K909K1 $10 \quad \overline{2} 68$ UniRef90_A0A0S3TTX 4 _17_278 UniRef90 K9VQF3 $56 \quad \overline{3} 23$ UniRef90 W1SM28 $4 \quad \overline{2} 65$ UniRef90_AOAOCIN $9 \overline{3} 5$ 15_285 UniRef90 A0A139SK67 $11^{-} 275$ UniRef90_UPI0 0041 C7CDC_4_265 UniRef90_K9XHH8_15_275

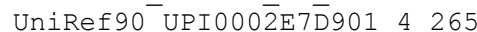
UniRef90-A0ZB05 $10 \quad 269$ UniRef90-D4ZSS4 $5 \overline{2} 70$ UniRef90 A0A0F5 $\bar{Y} \overline{\mathrm{Y}} 1 \quad 6271$ UniRef90_K9T9Y9_59 $\overline{3} 2 \overline{2}$ UniRef90 K9VAD2 $10^{-} 273$ UniRef90 W7Z4J7 $4 \overline{2} 65$ UniRef90-Q47G52 $1 \overline{3} 278$ UniRef90_UPI000 $\overline{4} 02 \overline{4} \mathrm{FBO} 33$ _269
SE

-GVDGAVSETASSHLCVKA SE MSH--DEN------------------------------EYRMGLSML PVKGFTIRV IQE--EST------------------------------DFKFGLSRLPVSGLSIRI

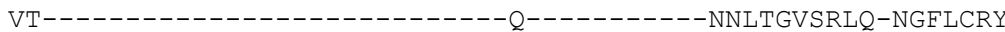
WC------------------------G---------KGEAGVTRLE-NGFLCRY

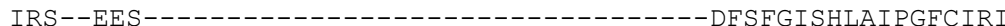
TQ-----------------------HSVLST-----------QYSFGVTRLE-HGF LCRY VMT--VEA-------------------------------DFTFGISEVS I PGFCLRI MDQ--NEQ------------------------------DYKFGLSMLSVKGFS IRV WT---------------------ADQR--------- QGEAGVTQTQAQGLLCRY

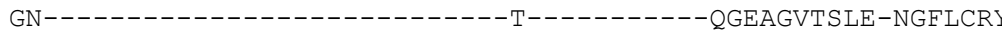

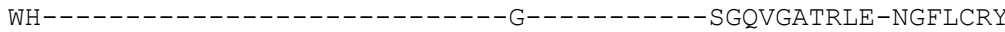
WY-----------------------NRKG----------EGEAGVTQI L-NGLVCRY

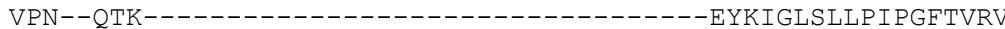
IHS--EEQ---------------------------NFKFGISRLAI PGLS IRI

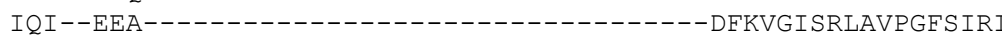

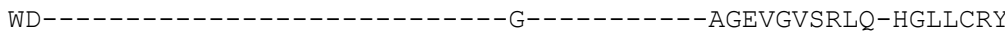
WQ---------------------PTNC---------HSLTGVTRLP-TGLLCRY

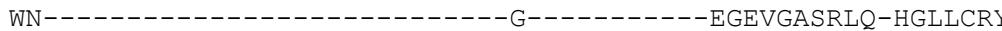

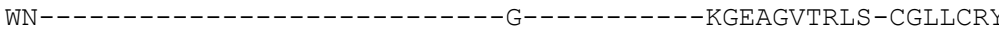
FI-----------------PPSPPLPI P---------PSSQGVTRIE-NGLLCRY ING--NTD---------------------------------RYKIGLSLLSVPGFTVRI IDA--NTK-------------------------------EYKVGLS FLS I PGETVRV IQI--EES----------------------------SFKFGISKLAVPGFS IRI

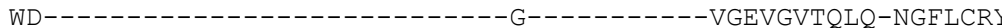
MDA--ETV-------------------------PCRMGLSMLPVSGFSVRV LNS--KTN-------------------------AYE I GLSLLPVKGFTLRV

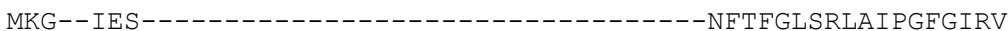
WQ--------------------AGEY---------QGESGVTTLL-EGMLCRY TC--------------------NVSTTIP----------ITNYGVTRL P-HGLLCRY IYS--EQA----------------------------NIKFGLSKLAIPGLS IRV

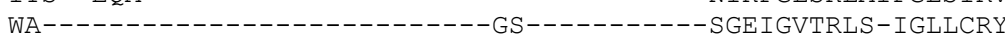

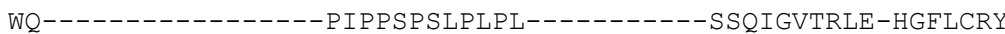
WE-------------------GRSSSS---------EGEAGVTRLT-HGLLCRY

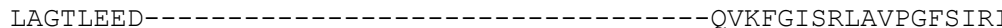
LSK--STY---------------------------ECKVGLSLLSVPGFTIRV ILS--QEA-------------------------DVKFGLSELVVSGLS IRI IQA--EEA------------------------------DFSFGISNLAI PGFS LRI FL------------------------S---PTPHSLLPTPSVGVTRLS - CGLLCRY

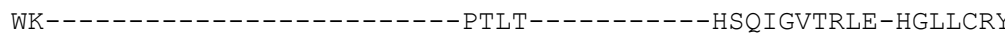

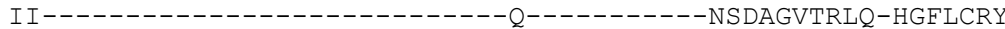
WN--------------------------G----------EGETGVTLLT-HGFLCRY

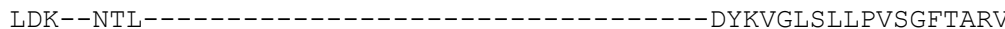
IQL--EQA-----------------------------DFKAGISKLAVSGFS IRI

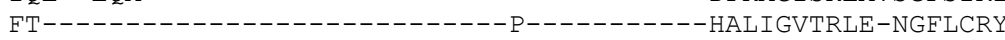
WH-------------------------G---------EGEVGVTRLE-HGFLCRY IQK--EAG----------------------------DFAFGLSKLAVPGFTIRI IEM--NTN-------------------------------DYKVGLSSLSVPGETIRV

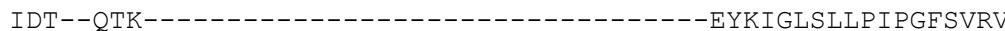
IHS--EQS--------------------------NFKFGLSRLAIPGLS IRV

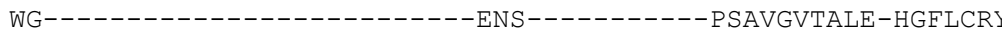
IDP--NAK-------------------------------EYKVGLSALPI PGFTIRI IGK--DLD---------------------------ECKAGLSLLIEGGFTLRI LHE--NST------------------------------DFKIGLSALSVPGFTLRV FP-------------------------NNS----------S SQGGVTRLP-MGLLCRY

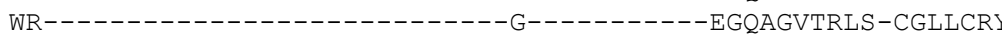

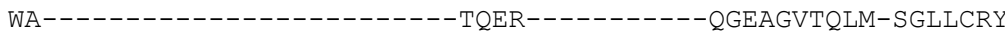
GK--------------------PTLS---------HSQIGVTRLE-HGLLCRY

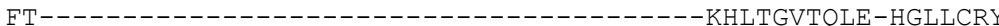

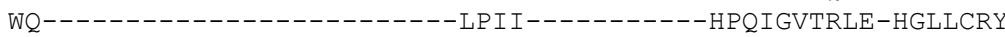

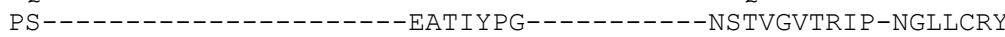
IDM--NSD---------------------------EYKLGLS ILSVPGLTIRV FL---------------------SSTAPNPS F S I P S PQVGVTRLS-CGLLCRY

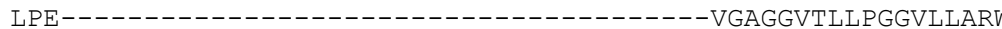

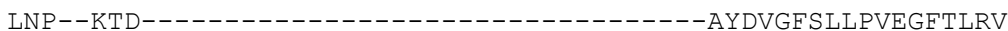
ST----------------------VD---------QGETGVTRLT -TGLLCRY VDG--MEG-----------------------------DFEFGI SRLT I PGFTIRI

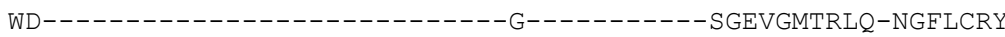

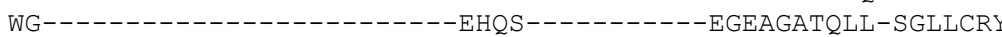

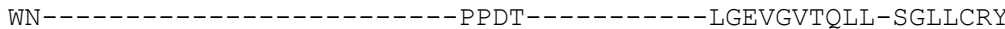
WS---------------------DKQY---------LGEAGVTQTQARGLLCRY

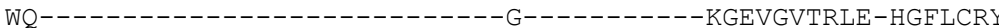

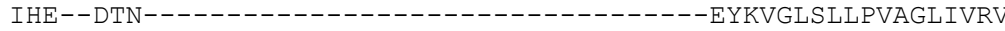

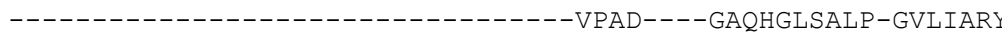

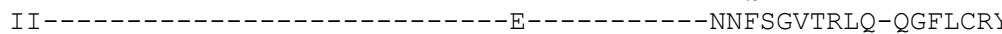


UniRef90 K8GMD3 $12 \quad 265$ UniRef90_A0A0S3ŪB12 16269 UniRef90 A0A0F7D4R9 $4 \quad \overline{2} 65$ UniRef90 AOYQS4 $5 \quad 271$ UniRef90_A0A0Q8 $\bar{R} C \bar{L} 2$ 14_276 UniRef90_UPI0005625009_5 271 UniRef90_UPI000305E365_16_284 UniRef90_UPI0002E38242_11_269 UniRef90 G8Q511 $12 \quad 270$

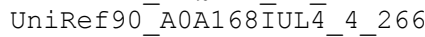

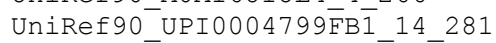
UniRef90 Q3KIS7 $11 \quad 269$ UniRef90_K9XZ09_12_271 UniRef90 A0A090 RU $8 \overline{6} 25288$ UniRef90_A0A0M5LWB1 $11^{-} 269$ UniRef90_A0A0C2I8A1_11_269 UniRef90 H3SNI3 $3 \quad 2 \overline{6} 5$ UniRef90_A0A0Q0XXPTE_11_269 UniRef90 K4ZJ70 $4 \quad 2 \overline{6} 5$ UniRef90 A0A085V̄ $9 \overline{5} 111269$ UniRef90_A0A098SV87_11_271 UniRef90_A0A0A1GEL6 9 _ 267 UniRef90 I 4CP19 $9 \quad 2 \overline{6} 7$ UniRef90_AOAOWOP $2 \overline{\mathrm{S}} 5$ 11_269 UniRef90 C3K5A $6 \quad 11 \quad \overline{2} 69$

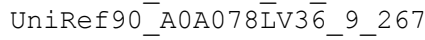
UniRef90 J3GGT8 $11 \quad \overline{2} 6 \overline{9}$ UniRef90 A5L5M9 $32-304$ UniRef90_A0A0J6GEPD 811270 UniRef90_QKJ05 $11 \quad \overline{2} 69$

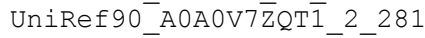
UniRef90_A0A075PF54_11 269 UniRef90 A0A0D5Y774-11-269 UniRef90_A0A0Q5EC30 11_271 UniRef90 I 4N4V9 $11 \quad \overline{2} 69$ UniRef90 D4TUH6 ${ }^{-} 7 \overline{2} 66$ UniRef90_UPI000 $\overline{4} 8 \overline{\mathrm{A}} \mathrm{E} 6 \mathrm{EC}$-1_266

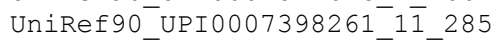
UniRef90-B0C790 $12 \quad 273$ UniRef90 A0A066UMR $726 \quad 298$ UniRef90 A0A0Q9XWI2 $4 \overline{2} 65$ UniRef90_A0A0S7ZTJ9_14 276 UniRef90 A6SZ04 $26 \quad \overline{2} 86$ UniRef90 U3H3U5 $9 \overline{2} 67$ UniRef90_A0A073C̄Y $\overline{5} 2$ 6_272 UniRef90 U6ZYX1 $11 \overline{2} 7 \overline{0}$ UniRef90_UPI000 $67 \mathrm{C} \overline{\mathrm{F}} 5 \mathrm{D} 4 \quad 26 \quad 284$ UniRef90_A0A0K2BGW7_26_288 UniRef90 A0A011QEK6 $40 \quad 302$ UniRef90_G4T117_15_ 272 UniRef90 Q87VP5 $11^{-} 271$ UniRef90_A0A089ȲS3̄̄ 11269 UniRef90_UPI0004174 C9A_9_267 UniRef90 UPI000379F3E4 ${ }^{-} \overline{1} 286$ UniRef90_A4VQU8_9_267 UniRef 90-A0A0M3V $4 \overline{\mathrm{J}} 1 \quad 7 \quad 297$ UniRef90 A0A098ESZ3 4266

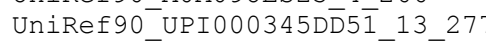
UniRef90_UPI00047D06E7_9_270 UniRef90-I3BUX5 1262 UniRef90_UPI0007800B9AB 11271 UniRef90 UPI000255752 $\mathrm{C}^{-}{ }^{-} 1^{-} 273$ UniRef90-UPI000484E5E1 $11^{-} 269$ UniRef90 A0A0D6AS13 $1 \quad \overline{2} 64$ UniRef90 UPI00034A4 $25 \bar{D} 18281$ UniRef90_UPI00046A7B93_11_269 UniRef90 I3YAM1 6262 UniRef90 A0A0D9ĀT̄7 9267 UniRef90_UPI0003FDB $\overline{5} \bar{F} \overline{5}+4265$ UniRef90 K9SBL5 6267 UniRef90_UPI 000 $40 \bar{A}$ A 544_17_274 UniRef90 A6D6Q9 $31 \quad 296$ UniRef90 B8HW54 $12-274$ UniRef90_A0A0J6H $3 B \bar{B}{ }_{11} 269$
WN------------------------GA----------VGQTGITRLQ-SGILCRY WA-------------------------GT----------SGEIGVTRLP-LGLLCRY VHA--ESG------------------------------DFEFGISKLTVPGFTLRI WN--------------------HSDT---------LGEVGVTQLL-SGFLCRY DVS----------------------------------DGAFGVTQMK-SVIVARY IS-----------------------------SVDS---IALEVGATQVD-GVLVVRV WQ---------------LPITHHPLPIT---------HPQIGVTRLE-HGLLCRY -------------------------------ST----AVRGDLSQLP-GLLVARC

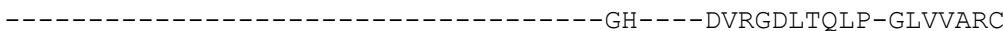
LKC--CTS------------------------------SAHIGLSTLMVPGFSLRV -------------------------------TPGD----GARHGITAPP-GLLIARY ---------------------------------GH----EVRGDLTQLP-GLLVARC RK----------------------TREN----------KGEFGVTELM-SGLLCRY LT---------------NMQQE---------NKKG----AVLIAASQLE-NLLVIRA $-------------------------------P G----P V R A D L T Q L P-G L L V A R C$ -------------------------------PA----RVRGDLTQLP-NLLVARC LDL--NRM-------------------n---n---EGCI GLSELI I PGFGVRM ---------------------------------PN----PVRGDLTQLP-GLLVARC IDG--KYE------------------------------DCRIGLSLLPVSGLMARV --------------------------------PA----QVRGDLTQLP-GLLVARC ------------------------------- AEHS----PVRGDLSQLP-GLI IARC ------------------------------- PN----RVRGDLTQLP-GMLVGRC --------------------------------PS----RVRGDLTQLP-GLVVARC $--------------------------------Q \mathrm{QH}----\mathrm{PVR}$ GDLTQLP-GLLLARC ---------------------------------PH----TVRGDLTQLP-GLLVARC ---------------------------------PG----RVRGDLTQLP-GLLVGRC $---------------------------------P N----D V R G D L T Q L P-G L L V A R C$ LL---------------SITQQASQQSDSSKISSDP----TLILGATQIE-GLIVVRA -------------------------------- PN----PVRGDLTQLP-GLLVARC $----------------------------------A H----$ PVRGDLSQLP-GLLVARC WK---------SNPHMTLSRHAALTPIPNSK-----------SPNQGVTRLN-NGFLCRY ------------------------------ PH----AVRGDLTQLP-GLLVARC -------------------------------GH----AVRGDLTQLP-GLLVARC -------------------------------NMPN----PVRGDLTQLP-GLIVARC $---------------------------------K G----K V R G D L S Q L P-G L L V A R C$ IA--------------------------N----------GWDAGVTRLE-QGILCRY YSE--DDQ------------------------------KYKMGISSLVI PGFSVRI WE-----------ALPEQEVRSQHGVPRNV-----------LTQVGVTRLM-SGLLCRY WQ----------------------PTTD----------GAEMGVTRLP-LGLVCRY LL---------------SITQQASLQPVHFGSSSKS----SLIMGATQIE-GLIVIRA LEQ--MEG----------------------------NFKIGISRLATEGLS IRI T------------------------------AAHT----TALCSATLVD-EVLVCRY SS-----------------------------ALAQ----GGRSGATQMK-QVLVARY

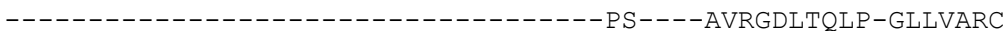
WS---------------------QRET---------SSQAGVTQLI-SGLLCRY

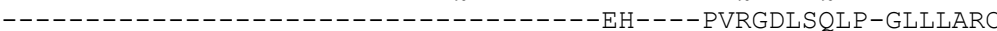
TA-----------------------------VAAE----DGRSGATQMK-QVLVARY TG----------------------------ALTRDS--NDRTGATQMK-QVLVLRY -----------------------------PVAD----GLLTGVTALP-ELLVARC IGE---------------------------------APGRGVTRID-DLLICRA ------------------------------SMPS----PVRGNLTQLP-GLIVARC $--------------------------------T T----R V R G D L S Q L P-G L L V A R C$ -------------------------------DT----PVRGDLTQLP-GLLVARC RT----------PLSLDGSGFGGEAARGV----------HHQAGATRLT-DGLLCRY ---------------------------------PS----RVRGDLTQLP-GLIVARC FTPYLALSEKLRAGVPPVEQTSVTQHSALST----------QHLVGVTQLE-HGLLCRY IQN--KSP------------------------------AAAI GISMLPI PGFTVRI ---------------------------------GLDG----AGKFGVTQMK-GVLSARY CK-----------------------------AFGG----EGYTAPTLLD-DVLVVRY C-----------------------------AEAG----MGTAGATLFN-GVLVVRY ------------------------------AEHS----PVRGDLSQVP-GLI IARC $---------------------------------A A D N R L E L R G D L S Q L P-G I L V A R C$ ---------------------------------DH----PVRGDLTQLP-GLLVARC IE-----------------------SKFT----------NLI ICITTLQ-QGLLCRY VK--------------------TAIKGEM----------QGEFGVTRLE-QGI I CRY -----------------------------------EH----PVRGDLTQLP-GLLVARC A----------------------------ATDS----DILWGATLLD-DLLVARC $--------------------------------S S----R V R G D L T Q L P-G L V I G R C$ IQQ--EAG-----------------------------EFTFGLSKLAVPGFTIRI

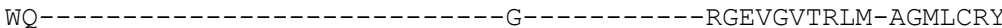
IGD------------------------------------ATGRGVTRMD-DLLVCRA LD-----------------NMQQE----------HNEG----AVLIAASQLE-NLLVIRA WN-------------------- AEKF----------EGETGVTRLM-SGLLCRY ------------------------------ PH----PVRGDLTQLP-GLLVARC 


\section{HpUreD}

UniRef90 A0A0K9H6B6 4266

UniRef90_A0A0K9GXZ4_4_265

UniRef90 A0A0A3IXZ5 4-264

UniRef90 K9ZPz7 $7 \quad 2 \overline{7} 3$

UniRef90_A0AOC1X̄DA $\bar{B} 3$ 13_272

UniRef90 UPI000379D7E3 4266

UniRef90_UPI0002DF3930_1 3 _277

UniRef90 AOAOMOWOK1 1 2 66

UniRef90 UPI000422C $\overline{8} 8 \overline{5} \quad 4 \quad 265$

UniRef90_B4W160_8_270

UniRef90_Q8YQZ4 ${ }^{-} 1 \overline{0} 269$

UniRef90 A0A0P1 $\bar{B} U Z \overline{9} \quad 3269$

UniRef90_A0A0M1 JRC4_17 282

UniRef90 UPI0007108B5C 4266

UniRef90_UPI0006A76A92_4_265

UniRef90 W4ETC9 4265

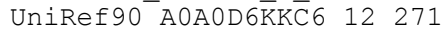

UniRef90_A0A0D8ZYE2_11_271

UniRef90-B2IT63 $10 \quad \overline{2} 69^{-}$

UniRef90_UPI000308766C_11_271

UniRef90_K9R600_10_280

UniRef90-A0A127D̄3L $\overline{2} \quad 4 \quad 264$

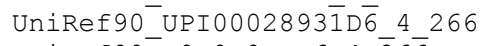

UniRef90 AOAOMOENP $6 \quad 4 \quad \overline{2} 6 \overline{6}$

UniRef90 A0A0S3PHU6 ${ }^{-} 1 \overline{6} \quad 275$

UniRef90_A0A081NYG6_3_ 264

UniRef90 A0A0K9GPB1 ${ }^{-} 266$

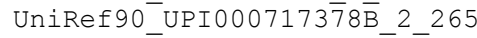

UniRef90_K9W1V1_14_278

UniRef90 K9U4Q1 $17^{-} 272$

UniRef90_A0A0M2SWM $\overline{6}$ 4_265

UniRef90_UPI0003652Ā $4 \overline{8}$ 11_275

UniRef90_UPI00047A812C_16_286

UniRef90_K9TKA4_12_277

UniRef90 M7NKH7 ${ }_{1}^{-}-269$

UniRef90_K6DR39 4 465

UniRef90_A0A0B4 $\overline{\mathrm{R}} \overline{\mathrm{S}} \mathrm{S} 1$ 1_265

UniRef90 A0A168N9T6 $4-266$

UniRef90_A0A139X4D9-7 274

UniRef90-UPI00030AB $\overline{1} 9 \overline{2} 1627$

UniRef90 K7W9HO 9269

UniRef90_UPI000 $34 \overline{\mathrm{A}} 5 \mathrm{E} 0 \mathrm{C} \_10 \_263$

UniRef90 A0AOAOE $403 \quad 4 \quad \overline{2} 65$

UniRef90_UPI0007172 $\overline{6} 3 \overline{\mathrm{C}}$-4_266

UniRef90_K9QPZ4_10_269

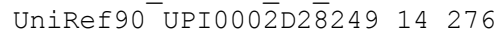

UniRef90_F9DU20_4_266

UniRef90 UPI000̄ $7 \overline{9} 33 \mathrm{CA} 3266$

UniRef90 W7RFE8 4266

UniRef90_UPI00074 $41 \mathrm{C} 40 \_4 \_265$

UniRef90 A0A0T7BRT9 $7 \overline{2} 6 \overline{8}$

UniRef90_UPI0006A78 $\overline{3} 5 \overline{7} \quad 4 \quad 266$

UniRef90 UPI0007C7BB46-4 266

UniRef90 UPI000472611B 4 265

UniRef90_UPI0002ACBA0D_1̄ 270

UniRef90-A0A0C2KR59 $11^{-} 26 \overline{9}$

UniRef90_K9WE93 $4 \quad 2 \overline{7} 7$

UniRef90_AOAOMOSP30 16 277

UniRef90 K9Q9K1 $10 \overline{2} 68$

UniRef90 A0A0S3TTX $\overline{4} \quad 17278$

UniRef90 K9VQF3 $56 \quad \overline{3} 23^{-}$

UniRef90 W1SM28 $4 \quad \overline{2} 65$

UniRef90-A0A0C1 $\bar{N} 9 \overline{3} 5 \quad 15 \quad 285$

UniRef90 A0A139SK67 $11^{-} 275$

UniRef90_UPI00041C7CDC_4_265

UniRef90_K9XHH8_15_275

UniRef90 UPI0002E7D 9014265

UniRef90 A0ZB05 $10 \quad 269^{-}$

UniRef90-D4ZSS4 $5 \overline{2} 70$

UniRef90 A0A0F5ȲFȲ1 6271

UniRef90-K9T9Y9 $59 \overline{3} 2 \overline{2}$

UniRef90-K9VAD2 $10^{-} 273$

UniRef90 ${ }^{-}$W7Z4J7 ${ }_{4}^{-} \overline{2} 65$

UniRef90-Q47G52 $1 \overline{3} 278$

UniRef90_UPI000 $\overline{4} 02 \overline{4} \mathrm{FBO} 33$ _269 $\begin{array}{llll}240 & 250 & 260 & 265\end{array}$

LAKGSEPLLHLREKIARLVTQTTTOKV LANSTQTVERLFTECHRI ISEEWFNKLANKTQTIERLFTECHQI ISEAWFN-LAHSTQLIERIFDNCHRLIKKSWF--RGNSTSEVRNWFTNVWQILRVSLLNRRGSSTSEVRNWFIDVWQLLRMSFSSRQANATQTIERIFNQCHTI ISKKWNHRRGSSTSEVRNWFTAAWQLLRQSLLERQANTTQTIERI INQCHAILSEKWNHRLANKTQTIERIFSECHQLISEDWFN-RGSSTTEVRNWFTQVWQCLRLTYLGRRGASTSEVRNWFTSVWQLLRGEFFSRRGSSTSEVRNWFTSVWELLRVSFLHRRGNSTSEVRSWFIDVWHLLRLSYLG-LANGTQTIERIFSEFHNIISQEWFNKLANSTQLIERI FNNCHRI ISEKWNN-LANSTQLIERIFNSCHKIISEKWTN-RGASSSEVRNWFTSVWOMLRVNFLSRRGSSTTEVRHWFTNVWQLIRSSYLERRGSSTSEVRNWFIDVWQLLRVSFLNRRGSTTSEVRNWFTAVWQLLRQSFLARRGDSTAKVRNWFISVWQLLRISFLNRLANSTOEIEKIFTECHRI I SOEWF--LANNTQA IENIFSEFHHI ISLEWFNKLAHSTQVIER ILDQCQKI ISEKWNNRRGLSTSEVRNWFTVVWOLLRVSFLHRLASSTQDIERLFAACQRLVREQWLG-LANLTQTIEQLFTECHCMISEEWFQKLANSTQLIERIFANCHKDITQKWFG-RGYSTLEARNWF IRVWELLRLAYLGKRGSSS IEVRNWFTSVWO-_-_-_-_-LANSTQI IERIFNDCHKI I SRKLNH-RGHSSSEARRWFLAVWQLIRVSYFQRRGSSTAEVRHWFIGVWQLLRMSFLNRRGSSTPEVRNWFSEVWQLLRLSFIGRLGRSTGRIEKMLNACHKRISEEWLG-LANSTQMIEK I FSE I HQMI SREWFQ-LANSTQVIEKI INECHRI I HERWFG-QANATQTIERI LNQCHTI I SEKWNNRRGSGTTEVRNWFTSAWQLLRQSVLTRRGYSTTEVRNWFIGVWQLLRIFFLSRRGNSTSQVRSWFTNIWQMLRVSCLNRRGDSTSEVRNWFMAVWQMLR-----FANTTQVIERIFSE IHRHISHEWFQ-LANSTQVIERI LNNCHKLISEKWLNRRGASTSEVRHWFTSVWQMLRVDYFKRRGSSTAEVRNWFISVWQLLRVSFLSRV MANYTQVIERI ISACHHVISDEWYQKLANSTQVIEKMFSEFHQI ISQEWFNKLANQTQIVERLFSEFHH I LNQEWFNKLGNSTQLIERIFNQCHKI ISEKWNN-RGNSTSEVRNWF I SVWOLLROS I GNRLAKNTQTIESMFFDFHHI ISQEWFNKLAHSTQKIEELMAACSSFLRKEWYDRLANTTQVIEALFAKCHMIVNKEWYD-RGSSSTEVRNWFTE IWQLLRSPYLNRRGSTTSEVRNWFIGVWQLLRQSFL--RGSSTSEVRNWFTEVWQLLRLSFLGRRGSSTAEVRNWFIGVWQLLRMSELSRRGASTSEVRNWFTAVWQILRTSFLSRRGSSTAEVRNWFIGVWQLLRMSFLNRRGTSTTAARDWFVNIWQLLRLSFSQRLANTTQVIEKLFSEIHRVISQEWFN-RGSGTTEVRNWFTSVWQLLRQSVLARLGPACEPGRAWFARLWAVLRPALSGRA LANSTQI IERIFADCHQMICEEWFG-RGDSTTEVRQWFTEVWHLLRLSSLGKLADKTQLIES IVSACHLAVSEKWHQ-RGASTSEVRNWFTVVWELLRGDFLHRRGPSSQEAIAWFTQIWQLLRPNLSGKRGNTTQEVINWFTTVWQLIRQNHQGRV RGSSTADVRNWFTGVWQLLRLSLMKRRGSGSSEVRNWFTDVWQLLRMSYLHRV LANSTQVIEKI HTKCHH I I YQQFFN-LGNSSEAARLWFAELWTILRPACCGRRGHSISEVRNWFTNIWQSLRINYQNR- 
UniRef90 K8GMD3 $12 \quad 265$

UniRef90 A0A0S3ÜB12 16269

UniRef90 A0A0F7D4R9 $4 \quad \overline{2} 65$

UniRef90 AOYQS4 $5 \quad 271$

UniRef90_A0A0Q8BतCL 2_14_276

UniRef90 UPI0005625009 5271

UniRef90-UPI0 $00305 E 365-16$ _ 284
UniRef90-UPI0 002 E 38242 11_269

11 269 LAGQALHARAWLIELWRLLRPALLGR-

UniRef90_A0A168IUL $\overline{4} 44$ _266

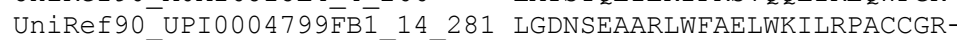

UniRef90 Q3KIS7 $11 \quad 269^{-}$LASEALLARAWLIDLWRLLRPALLGR-

UniRef90_K9XZ09-12_271

UniRef $90^{-}$A0A090 RU $8 \overline{6} \quad 25288$

UniRef90 A0A0M5LWB1 $11^{-} 269$

UniRef90_A0A0C2I8A1_11_269

UniRef90 H3SNI3 $3 \quad 265$

UniRef90_A0A0Q0X̄PTE_11_269

UniRef90_K4ZJ70_4_265

UniRef90 A0A085V̄ $9 \overline{5} 111269$

UniRef90_A0A098SV87_11_271

UniRef90 A0A0A1GEL $6^{-} 9 \overline{2} 67$

UniRef90 I4CP19 $92 \overline{6} 7$

UniRef90_AOAOWO $\overline{\mathrm{P}} 2 \overline{\mathrm{S}} 5$ _11_269

UniRef90 C3K5A6 $11 \quad 269$

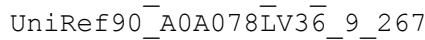

UniRef90 J3GGT8 $11 \quad \overline{2} 6 \overline{9}$

UniRef90 A5L5M9-32 304

UniRef90_A0A0J6GPD 8 _11_270

UniRef90 Q4KJ05 $11 \quad \overline{2} 69$

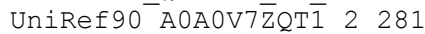

UniRef90_A0A075PF54_1̄ 269

UniRef90 A0A0D5Y774 $11^{-} 269$

UniRef90_A0A0Q5EC30 $11^{-} 271$

UniRef90-I4N4V9 $11 \quad 269^{-}$

UniRef90 D4TUH6 ${ }^{-} 7 \overline{2} 66$

UniRef90_UPI000 $\overline{4} 8 \overline{\mathrm{A}} \mathrm{E} 6 \mathrm{EC} \_1$ 266

UniRef90 UPI0007398261_1̄i_285

UniRef90-B0C790 $12 \quad 273$

UniRef90-A0A066UMR 726298

UniRef90 A0A0Q9XWI2 $4 \overline{2} 65$

UniRef90_AOAOS7ZTJ9_14 276

UniRef90-A6SZ04 $26 \quad 286$

UniRef90-U3H3U5 $9 \overline{2} 67$

UniRef90_A0A073C̄ $\overline{5} 2$ 2_6_272

UniRef90 U6ZYX1 $11 \overline{2} 7 \overline{0}$

UniRef90-UPI000 67 CF5D4 $26 \quad 284$

UniRef90_AOA0K2BGW7_26-28 8

UniRef90 A0A011QEK6 $40 \quad 302$

UniRef90_G4T117 15 272

UniRef90 Q87VP5 $11^{-} 271$

UniRef90 A0A089ȲS3̄ 11269

UniRef90_UPI0004174 C9A_9_267

UniRef90 UPI000379F3E4 $4 \overline{1} 286$

UniRef90-A4VQU8 9267

UniRef90_AOAOM $3 \overline{\mathrm{V}} 4 \overline{\mathrm{J}} 1$ 7297

UniRef90 A0A098ESZ3 ${ }^{-} 266$

UniRef90 UPI00047D06E7 9 270 LGNSTEQAHHLFRKIWLAIRPLVNGRI

UniRef90 I3BUX5 $1262-2^{-}$LGDSTAQAHRLFRSLWQAIRPLLTGRA

UniRef90_UPI000780B9AB_11_271 LADEALHARAWLIELWKLLRPALLGR-

UniRef90 UPI000255752C ${ }^{-} 11^{-} 273$ LAREALHARAWLIQLWQLLRPAVLGR-

UniRef90_UPI000484E5E1_11_269 LASEALLARGWLIALWRLLRPALLGRUniRef90 A0A0D6AS13 $11 \overline{2} 64^{-}$HGNSVSEAKTCLTAIWQLLRAKY---UniRef90 UPI00034A4 $\overline{2} 5 \overline{\mathrm{D}} 18281$ RGASSLEARTWLIAVWQMLRVSFMG-UniRef90-UPI00046A7B93_11_269 LASEALLARAWLIDLWRLLRPALLGRUniRef90 I3YAM1 6262

UniRef90 A0A0D9AITT 9267

UniRef90_UPI0003FDB $\overline{5} \overline{\mathrm{F}} \overline{5}+4{ }_{-} 265$

UniRef90 K9SBL5 6267

UniRef90-UPI000 $\overline{4} 0 \bar{A}$ C544 $17 \quad 274$

UniRef90 A6D6Q9 $31 \quad 296$

UniRef90 B8HW54 $12^{-} 274$

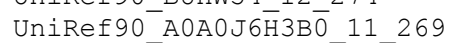

RGHSSTEARRWLIAVWSMVR------RGNTTOEVINWFTNIWOFIRONYQGRV RGYSTTEAKEWLSQVWQILRSEI---LAVEALOARAWLIELWRLLRPALLGRLGNSTOAIETLFGRIANAVRESWFG-I LADEALHARAWLIELWKLLRPALLGRLASEALHARAWLIDLWHLLRPALLGRARGWLIDLWKLLRPVMFGRLASEALLARGWLIDVWRLLRPALLGRSWTEDILOAFGOIWOATRSHLYG-LASEALOARAWLIELWRLLRPALIGRRGNSTAEVRNWF INVWLLLRTSFLSRLASETLIARAWLIDLWRLLRPALIGRLADEALHARAWLIELWRHLRPALLGRRGNSTSWAKKWFTNVWODLROSLLNRRGTSTQEARRWFTTVHLIRWELINRRGPSSQAARQWFI IVWNLLRSTHLGRMANSTOLIERI FTACHHTI SMEWFQ-LGHHGEQAKKVFTSVWSAIRPACVNRMAWQRIRPELMQR RGNSTQEVINWFTDVWQLLRQNYTGKGASALQARAWLMDLWRLLRPALLGRA 作 PLALGKLADEALHARAWLIEIWKRLRPALLGRIADEALHARDWLIOLWTLLRPALLGRLASEALHARAWLIELWRLLRPALLGREVRWFIGVWQLLRQSFWGRLADEALHTRAWLIDLWRLLRPALLGRRGASTSEVRNWFTAVWQILRTSFLSRLAPFAEPARRLFAAIWGILRPRLL--LASEALHARAWLIDLWRLLRPALLGRLANYTQVIERI ISVCHHVISDEWYQ-RGDSTEEARAWMLRVWDLLROALIORLDCRSDRLRVFFERVWAVVRPDCVRRLGNWSEVILACFQKIWQLVRGHWTG-RGFSTOSARNWFMOVWHLLRLHYRHOLAGEAFQARGWLIDLWRLLRPALLGRLATEALQARAWLIELWRLLRPALLGR- 
Table 2-SI. ConSurf analysis of the multiple sequence alignment obtained using PSI-BLAST.

\begin{tabular}{|c|c|c|c|c|c|c|c|c|c|c|c|c|c|c|c|c|c|c|c|c|c|c|}
\hline $\begin{array}{l}\text { HpUreD } \\
\text { sequence } \\
\text { number } \\
\end{array}$ & A & $\mathrm{C}$ & $\mathrm{D}$ & $\mathrm{E}$ & $\mathrm{F}$ & G & $\mathrm{H}$ & $\mathrm{I}$ & $\mathrm{K}$ & $\mathrm{L}$ & M & $\mathrm{N}$ & $\mathrm{P}$ & Q & $\mathrm{R}$ & $\mathrm{S}$ & $\mathrm{T}$ & $\mathrm{V}$ & W & $\mathrm{Y}$ & $\begin{array}{r}\text { Most } \\
\text { conserved } \\
\text { residue }(\%)\end{array}$ & $\begin{array}{r}\text { ConSurf } \\
\text { Grade }\end{array}$ \\
\hline 1 & & & & & & & & 8 & & 8 & 38 & & 23 & & & & & 23 & & & M 38.462 & 6 \\
\hline 2 & 8 & & 4 & & & & & 12 & & & & 31 & & 4 & 4 & 23 & 15 & & & & N 30.769 & 3 \\
\hline 3 & 10 & & 6 & & & 1 & 1 & & 1 & 1 & 4 & 1 & 4 & 4 & 3 & 12 & 48 & 1 & & & Т 47.826 & 3 \\
\hline 4 & 3 & & & & 3 & 1 & 1 & & 4 & & & 4 & 47 & 12 & & 12 & 12 & & & 1 & P 47.368 & 2 \\
\hline 5 & 7 & & 2 & 2 & & 33 & 6 & 1 & & & & 2 & 1 & 3 & 1 & 36 & 6 & & & & S 36.275 & 3 \\
\hline 6 & & & & & & & & & & & & & & 1 & & & & & 99 & & W 99.315 & 9 \\
\hline 7 & & 1 & 1 & 1 & & & 47 & & 3 & 1 & & 2 & & 14 & & & 28 & 1 & & 3 & Н 46.980 & 6 \\
\hline 8 & 35 & & & & & 64 & & & & & & & & & & 1 & & & & & G 64.430 & 9 \\
\hline 9 & 1 & & 1 & 26 & & & & 8 & 18 & 2 & & 7 & & 3 & 9 & 10 & 3 & 11 & & 1 & Е 26.174 & 2 \\
\hline 10 & & & & & & & & 1 & & 99 & & & & & & & & & & & L 99.333 & 9 \\
\hline 11 & 4 & 1 & 10 & 26 & & & 7 & & 1 & & & 21 & & 3 & 13 & 12 & 3 & & & & E 26.000 & 2 \\
\hline 12 & & & & & & & & 1 & & 99 & 1 & & & & & & & & & & L 98.667 & 9 \\
\hline 13 & 9 & & 19 & 3 & & 27 & & 3 & 5 & 1 & & 2 & & 1 & & 3 & 5 & 25 & & & G 26.667 & 1 \\
\hline 14 & 8 & & & & 17 & & & 2 & & 9 & 2 & & & & & & 1 & 6 & & 55 & Y 55.333 & 6 \\
\hline 15 & 52 & 1 & & 30 & & 7 & & 1 & 1 & & & 1 & & 1 & & 2 & 2 & 3 & & & A 52.000 & 6 \\
\hline 16 & & & & & & & & 100 & & & & & & & & & & & & & I 100.000 & 6 \\
\hline 17 & 1 & 4 & 22 & 7 & 1 & 1 & 7 & & 6 & 1 & & 13 & 1 & 6 & 24 & 2 & & 1 & & 2 & R 24.000 & 1 \\
\hline 18 & 2 & 3 & 7 & 1 & 15 & & 3 & 2 & 5 & & & 1 & & 2 & 53 & 2 & 1 & 1 & & 1 & R 52.667 & 3 \\
\hline 19 & 7 & & 5 & 3 & & 26 & 3 & & 7 & 5 & & 12 & 1 & 23 & 4 & 2 & 1 & & & 1 & G 26.000 & 1 \\
\hline 20 & 3 & & 20 & 5 & & 51 & 1 & & 1 & & & 16 & 1 & & & 2 & & & & & G 51.333 & 1 \\
\hline 21 & 8 & 3 & & 2 & & 3 & & 3 & 35 & & & & & 3 & 11 & 17 & 13 & 1 & & & K 35.333 & 2 \\
\hline 22 & & 1 & & & & & & & & & & & & & & 5 & 94 & & & & Т 94.000 & 9 \\
\hline 23 & 4 & & & 1 & & 1 & 1 & 4 & 3 & & & & & 25 & 27 & & 2 & 33 & & 1 & V 32.667 & 6 \\
\hline 24 & 23 & & & & & 1 & & 5 & & 37 & 3 & & 24 & & & 1 & 1 & 5 & & & L 37.333 & 6 \\
\hline 25 & 3 & & 1 & 1 & & 1 & & 26 & 23 & 1 & 1 & 1 & & 1 & 5 & 3 & 11 & 22 & & & I 26.000 & 3 \\
\hline 26 & & & 5 & 9 & 4 & 1 & 15 & & 4 & 13 & 1 & 15 & & 8 & 11 & 5 & 1 & & & 9 & HN 14.667 & 1 \\
\hline 27 & 7 & 1 & 1 & 1 & & & & 2 & 1 & 1 & & 19 & & 2 & 32 & 9 & 1 & 23 & & & R 32.000 & 5 \\
\hline 28 & 1 & & & 1 & 3 & & 11 & & 1 & 2 & & & & 15 & 28 & 5 & 1 & & & 31 & Y 31.333 & 4 \\
\hline 29 & 1 & & & & 25 & 3 & 39 & 1 & & & 3 & 9 & & 7 & 1 & 3 & 1 & 5 & & 2 & Н 39.333 & 5 \\
\hline 30 & 1 & 1 & & 1 & 4 & 1 & 1 & 1 & 9 & 9 & & 1 & & 59 & 5 & 5 & 3 & & & 1 & Q 58.667 & 5 \\
\hline 31 & 36 & & & & & 61 & & & & & & 1 & 1 & & & 1 & 1 & & & & G 61.333 & 9 \\
\hline 32 & 27 & & & & & & & & & & & & 73 & & & & & & & & P 72.667 & 9 \\
\hline 33 & & & & & 19 & & & & & 77 & & & & & & & & & 1 & 3 & L 77.333 & 7 \\
\hline 34 & 5 & & & & & & & & 63 & & & 2 & & & 27 & & 1 & 1 & & & K 63.333 & 9 \\
\hline 35 & & & & & & & & 11 & & 5 & 1 & & & & & & & 84 & & & V 84.000 & 7 \\
\hline 36 & 1 & & & & & & & & & 1 & 25 & & & 72 & & & 1 & & & & Q 72.000 & 9 \\
\hline 37 & 1 & & & & & & & & 29 & & & & 1 & & 69 & 1 & & & & & R 69.333 & 9 \\
\hline 38 & 3 & & & & & & 21 & & & & & & 71 & & & 3 & 1 & & & & P 71.333 & 8 \\
\hline 39 & & & & & 42 & & 1 & 17 & 1 & 31 & & & & & & & & 8 & & & F 42.000 & 7 \\
\hline 40 & & & & & & & 3 & & & & & & & & & & & & & 97 & Y 97.333 & 9 \\
\hline 41 & 20 & & & & 3 & & 17 & & & 4 & & & 55 & & & & 1 & & & & P 55.333 & 7 \\
\hline 42 & & & 25 & 71 & & 1 & & & 1 & & & 2 & 1 & 1 & & & & & & & E 70.667 & 9 \\
\hline 43 & 1 & & 17 & 3 & & 69 & 2 & & 1 & & & 5 & & 1 & 1 & & & & & & G 69.128 & 5 \\
\hline 44 & 8 & & 6 & 28 & & 30 & & & 9 & & & 2 & 1 & 9 & 1 & 5 & 1 & & & & G 30.000 & 1 \\
\hline 45 & & & & & & & 2 & 15 & 2 & 1 & & & 2 & 21 & 1 & & 1 & 53 & & 2 & V 53.333 & 6 \\
\hline 46 & 9 & 72 & & & & & & & & & & & 7 & & & & & 12 & & & C 72.000 & 7 \\
\hline 47 & & 26 & & 1 & & & 51 & & & & & & & 23 & & & & & & & Н 50.667 & 9 \\
\hline 48 & 6 & 1 & & & 1 & 1 & 21 & 1 & & 1 & & 1 & & & & 33 & 5 & 1 & & 27 & S 33.333 & 7 \\
\hline 49 & 1 & & & & 1 & & & 29 & & 1 & 1 & & & & & & & 35 & & 33 & V 34.667 & 8 \\
\hline 50 & 1 & & & & & & & 64 & & 23 & 1 & & & & & & & 10 & & & I 64.000 & 6 \\
\hline 51 & & & & & & & & 1 & & 71 & 3 & & & & & & & 25 & & & L 70.667 & 8 \\
\hline 52 & 1 & & & & & & 72 & & & & & 27 & & & & 1 & & & & & H 72.000 & 9 \\
\hline 53 & & & & & 1 & & & & & & & & 61 & & & & 37 & 1 & & & P 61.333 & 9 \\
\hline 54 & 36 & & & & & 29 & & & & & & & 35 & & & 1 & & & & & A 36.000 & 9 \\
\hline 55 & 1 & & & & & 97 & & & & & & & 1 & & & 1 & & & & & G 97.333 & 9 \\
\hline 56 & & & & & & 100 & & & & & & & & & & & & & & & G 100.000 & 9 \\
\hline 57 & & & & & & & & 42 & & 1 & 4 & & & & & & & 26 & & 27 & I 42.000 & 7 \\
\hline 58 & 23 & & & & & & & & & 26 & 1 & & & & & & & 50 & & & V 50.000 & 9 \\
\hline 59 & 2 & & 25 & 1 & & 71 & & & & & & 1 & & & 1 & & & & & & G 70.667 & 8 \\
\hline 60 & & & & & & 99 & & & & & & & & & & 1 & & & & & G 99.333 & 9 \\
\hline 61 & & & 100 & & & & & & & & & & & & & & & & & & D 100.000 & 9 \\
\hline 62 & 1 & 1 & & 2 & & & 3 & 1 & 2 & & & & & 3 & 78 & 4 & 5 & 1 & & & R 78.000 & 6 \\
\hline 63 & & & & & & & & & & 71 & & 1 & & 1 & & & & & & 27 & L 70.667 & 9 \\
\hline 64 & 7 & 1 & 15 & 1 & 1 & 1 & 3 & 1 & 7 & 2 & & 5 & & 9 & 11 & 32 & 4 & & & & S 32.000 & 4 \\
\hline 65 & 1 & 4 & & & 2 & 1 & & 35 & & 13 & 21 & & & 7 & & 7 & 2 & 1 & & 7 & I 35.333 & 5 \\
\hline 66 & 1 & 1 & 13 & 11 & & & 5 & & 14 & & & 18 & & 7 & 5 & 18 & 5 & & & & NS 18.000 & 1 \\
\hline 67 & 23 & & & & 19 & & & 35 & & 8 & & & & & & & & 16 & & & I 34.667 & 3 \\
\hline 68 & 4 & & 2 & 3 & & 1 & 35 & & 1 & 1 & & 5 & & 4 & 9 & 25 & 10 & & & & Н 35.333 & 1 \\
\hline 69 & 11 & & & & & & & 1 & & 57 & & & & & & 1 & & 30 & & & L 57.333 & 7 \\
\hline 70 & 8 & 1 & 11 & 18 & & 23 & 1 & 1 & 3 & 1 & & 1 & & 30 & 1 & 2 & & & & & Q 30.000 & 2 \\
\hline 71 & 10 & & 5 & 25 & & & 1 & & 6 & & & 1 & 35 & 3 & 4 & 6 & 3 & & & & P 35.333 & 1 \\
\hline
\end{tabular}




\begin{tabular}{|c|c|c|c|c|c|c|c|c|c|c|c|c|c|c|c|c|c|c|c|c|c|c|}
\hline 72 & 2 & & 15 & 5 & & 25 & 7 & & 4 & & & 25 & & 15 & 3 & & & & & & N 25.333 & 1 \\
\hline 73 & 67 & 1 & & & & & & & & & & & & & & 20 & 12 & & & & A 67.333 & 7 \\
\hline 74 & & & 1 & 2 & & 1 & 17 & & 18 & & 1 & 2 & & 27 & 10 & 1 & & & 21 & & Q 26.667 & 4 \\
\hline 75 & 61 & & & & & & & & & 15 & 2 & & & & & 3 & 3 & 16 & & & A 60.667 & 6 \\
\hline 76 & & & & & 1 & & & 1 & & 49 & & & & 23 & 1 & & 23 & 2 & & & L 49.333 & 8 \\
\hline 77 & & & & & & & & 40 & & 58 & 1 & & & & & & & 1 & & & L 58.000 & 7 \\
\hline 78 & & & & & & & & & & & & & & & & & 100 & & & & T 100.000 & 9 \\
\hline 79 & & & & & & & & & & & & & & 1 & & 23 & 76 & & & & T 76.000 & 9 \\
\hline 80 & 33 & & & & & & & & & & & & 37 & 28 & & 1 & 1 & & & & P 37.333 & 9 \\
\hline 81 & 35 & & & & & 36 & & & & & & & & & & 25 & 4 & & & & G 36.000 & 8 \\
\hline 82 & 96 & & & & 1 & & & & & & & & & & & 3 & & & & & A 96.000 & 9 \\
\hline 83 & 23 & & & 1 & & 18 & & & & & & 1 & & & & 23 & 33 & & & & Т 33.333 & 7 \\
\hline 84 & & & & & & & & & 99 & & & & & & 1 & & & & & & K 99.333 & 9 \\
\hline 85 & & & & & 7 & & & 40 & & 1 & & & & & & & & 25 & 27 & & I 40.000 & 7 \\
\hline 86 & & & & & & & 1 & & & & & & & & & & & & & 99 & Y 99.333 & 9 \\
\hline 87 & & & & & & 1 & & & 27 & & & 1 & & & 71 & & & & & & R 71.333 & 8 \\
\hline 88 & 24 & & & & & & & & & & & & & & & 43 & 33 & & & & S 43.333 & 8 \\
\hline 89 & 14 & & 1 & 3 & & 5 & & 1 & 1 & 1 & & 37 & 26 & 1 & 1 & 5 & 4 & 1 & & & N 37.333 & 5 \\
\hline 90 & 1 & & 1 & 1 & & 65 & 1 & & 10 & & & 11 & & 1 & 1 & 5 & 3 & 1 & & 1 & G 64.667 & 4 \\
\hline 91 & 3 & & 4 & 2 & 1 & 3 & 1 & & 11 & 17 & 3 & 4 & 23 & 5 & 6 & 9 & 6 & & 1 & 1 & P 22.667 & 1 \\
\hline 92 & 2 & 1 & & 11 & 5 & 1 & 14 & 3 & 1 & 8 & & 1 & 8 & 19 & 2 & 3 & 4 & 3 & & 13 & Q 19.492 & 1 \\
\hline 93 & 88 & & & & & & & & & & & & 1 & & & 5 & & 7 & & & A 88.000 & 8 \\
\hline 94 & 1 & & & 1 & 7 & 1 & 3 & 1 & 14 & 1 & 1 & 1 & & 7 & 17 & 8 & 2 & 1 & & 36 & Y 36.000 & 2 \\
\hline 95 & & & & & & & 1 & & & 1 & & 1 & & 96 & 1 & 1 & & & & & Q 96.000 & 9 \\
\hline 96 & & & 5 & 28 & & & 1 & 6 & 5 & 1 & 1 & 9 & & 8 & 3 & 7 & 23 & 1 & & 1 & E 28.000 & 2 \\
\hline 97 & 3 & & & & & & & 25 & & 19 & 3 & 1 & & 7 & & 3 & 19 & 20 & & & I 24.667 & 5 \\
\hline 98 & 3 & & 9 & 36 & & & 4 & 3 & 3 & 1 & 1 & 13 & & 9 & 4 & 5 & 9 & 1 & & 1 & E 36.000 & 1 \\
\hline 99 & & 1 & & & 9 & & & 54 & & 30 & 3 & & & & & & & 3 & & & I 54.000 & 7 \\
\hline 100 & 1 & 1 & 2 & 3 & 3 & & 11 & 2 & 15 & 1 & & 7 & & 19 & 11 & 10 & 11 & 2 & & 1 & Q 19.333 & 1 \\
\hline 101 & 3 & & & & & & & 16 & & 29 & 3 & & & & & & & 49 & & & V 48.667 & 5 \\
\hline 102 & 21 & & 25 & 19 & & 7 & & & 21 & & & 1 & & 5 & 1 & 1 & 1 & & & & D 24.667 & 3 \\
\hline 103 & 35 & & 5 & 11 & & 1 & & & 20 & & & 3 & 10 & 2 & 1 & 8 & 4 & & & & A 34.667 & 1 \\
\hline 104 & 1 & & 7 & 1 & & 78 & 4 & & & & & 8 & & 1 & 1 & 1 & & & & & G 78.000 & 3 \\
\hline 105 & 64 & 1 & & & & 5 & & & & & & & & & & 30 & 1 & & & & A 64.430 & 8 \\
\hline 106 & 3 & 29 & & & 2 & & 1 & 2 & & 1 & 1 & 1 & & & 3 & 2 & 25 & 3 & 1 & 28 & C 28.667 & 3 \\
\hline 107 & & 3 & & & & & & & & 95 & & & & & & & & 2 & & & L 95.333 & 8 \\
\hline 108 & & & 1 & 99 & & & & & & & & & & & & & & & & & E 99.333 & 9 \\
\hline 109 & & & & & 3 & & & & & 1 & & & & & & & & & 62 & 33 & W 62.000 & 6 \\
\hline 110 & 1 & & & & 3 & & & 11 & & 79 & 4 & & & & & & & 2 & & & L 79.333 & 6 \\
\hline 111 & & & & & & & & & & & & & 98 & & & 1 & 1 & & & & P 98.000 & 9 \\
\hline 112 & & & 27 & & 1 & & & & & 2 & & & & 67 & 3 & & & & & & Q 66.667 & 9 \\
\hline 113 & 2 & & 2 & 69 & & 1 & & & & & & & 25 & & & 1 & & & & & E 69.333 & 9 \\
\hline 114 & 1 & & & & & & & 3 & & 25 & & 6 & & & & 4 & 61 & 1 & & & T 60.667 & 7 \\
\hline 115 & & & & & & & & 99 & & 1 & & & & & & & & & & & I 99.333 & 9 \\
\hline 116 & 21 & & & & 8 & 5 & & 8 & & 9 & 2 & & 1 & & & & & 47 & & & V 46.667 & 6 \\
\hline 117 & & & & & 64 & & & & & & & & & & & & & & & 36 & F 64.000 & 8 \\
\hline 118 & 2 & 1 & 11 & 9 & & & & & 5 & & & 31 & 5 & 9 & 7 & 21 & & & & & N 31.333 & 5 \\
\hline 119 & 17 & & 18 & 3 & & 34 & 5 & & 1 & & & 13 & & 5 & & 5 & & & & & G 34.000 & 2 \\
\hline 120 & 95 & 1 & & & & 2 & & & & & & & & & & 1 & 1 & & & & A 95.333 & 9 \\
\hline 121 & 1 & 1 & 5 & 3 & & & 13 & 21 & 7 & 5 & & 4 & & 21 & 15 & 2 & & 1 & & & IQ 21.333 & 2 \\
\hline 122 & 25 & 1 & & & 5 & 1 & & & & 1 & & & 1 & & & & & 7 & & 61 & Y 60.667 & 7 \\
\hline 123 & 1 & & & 21 & & 1 & 1 & 1 & 20 & 2 & & 1 & & 5 & 41 & 2 & 1 & 2 & & 1 & R 41.333 & 6 \\
\hline 124 & 1 & & & & & 1 & & 1 & & 28 & 3 & & & 65 & & 1 & & & & & Q 65.333 & 9 \\
\hline 125 & 1 & & 35 & 7 & & & 1 & & 26 & & & 5 & & 4 & 2 & 7 & 10 & 1 & & 1 & D 34.667 & 2 \\
\hline 126 & & & & & & & 2 & 1 & & 30 & 3 & 22 & & 1 & & 1 & 37 & 3 & & & T 36.667 & 7 \\
\hline 127 & 1 & 3 & 1 & 3 & & & 3 & 8 & 2 & & 1 & 3 & & 8 & 41 & 5 & 5 & 17 & & 1 & R 40.667 & 1 \\
\hline 128 & & & & & 1 & & & 49 & & & & & & & & & & 51 & & & V 50.667 & 6 \\
\hline 129 & 1 & & 10 & 42 & & & 15 & & 4 & & & 7 & & 1 & 11 & 1 & 2 & 1 & 1 & 3 & E 42.000 & 2 \\
\hline 130 & & & & & & & & 3 & & 73 & 24 & & & & & & & 1 & & & L 72.667 & 8 \\
\hline 131 & 35 & & 5 & 36 & & 4 & 6 & 1 & & & & 1 & & 9 & 1 & 1 & 1 & & & & E 36.000 & 4 \\
\hline 132 & 7 & 1 & 2 & 3 & & 19 & & & 15 & & & 1 & 20 & 3 & 5 & 7 & 16 & 1 & & & P 20.000 & 2 \\
\hline 133 & 1 & & 31 & 3 & & 48 & & & 3 & & & 7 & & 1 & & 2 & 4 & & & & G 48.000 & 3 \\
\hline 134 & 85 & 1 & & & & 3 & & & & & & & & & & 10 & 1 & & & & A 85.333 & 8 \\
\hline 135 & 3 & 3 & & 1 & & & 1 & 1 & 2 & 2 & & 7 & & 4 & 27 & 19 & 30 & 1 & 1 & & T 30.000 & 4 \\
\hline 136 & & & & & 32 & & & 1 & & 35 & 1 & & & & & & & 1 & 18 & 13 & L 34.667 & 4 \\
\hline 137 & & 5 & & & 19 & & & 22 & & 47 & 3 & & & & & & 1 & 2 & 1 & & L 47.333 & 2 \\
\hline 138 & 3 & & & & 1 & 45 & & 1 & & 2 & & & & & & 1 & & & & 47 & Y 46.667 & 6 \\
\hline 139 & 1 & 1 & & & & 3 & & & & & & & & & & 16 & 11 & 1 & 68 & & W 68.000 & 8 \\
\hline 140 & & & 50 & 50 & & & & & & & & & & & & & & & & & DE 50.000 & 9 \\
\hline 141 & & & & & & & & 77 & & 2 & 9 & & & & & & & 11 & & & I 77.333 & 8 \\
\hline 142 & 1 & 1 & & & & & 4 & 14 & & 21 & 1 & 3 & & 1 & & 1 & 31 & 23 & & & T 31.333 & 5 \\
\hline 143 & 22 & 11 & & & & & & & & & & & & & 37 & 1 & 27 & 1 & & & R 37.333 & 9 \\
\hline 144 & 1 & 1 & & & 37 & & & & & 33 & & & 26 & & & 1 & & 1 & & 1 & F 36.667 & 6 \\
\hline 145 & & & & & & 100 & & & & & & & & & & & & & & & G 100.000 & 9 \\
\hline 146 & & & & & & & & & & & & & & & 73 & & & & 27 & & R 72.667 & 9 \\
\hline 147 & 1 & & & & & & & & & 1 & 1 & & 26 & 1 & 1 & 52 & 17 & 1 & & & S 52.000 & 7 \\
\hline
\end{tabular}




\begin{tabular}{|c|c|c|c|c|c|c|c|c|c|c|c|c|c|c|c|c|c|c|c|c|c|c|}
\hline 148 & 71 & & & & & & & & & & & & 27 & & & & 1 & 1 & & & A 70.667 & 9 \\
\hline 149 & 5 & 1 & 9 & 7 & & 1 & & 1 & 1 & 1 & & 5 & & 1 & 37 & 30 & & & & & R 37.333 & 6 \\
\hline 150 & 1 & & 4 & & & 88 & & & 1 & & & 5 & & 1 & & & 1 & & & & G 88.000 & 6 \\
\hline 151 & & & 3 & 87 & & 1 & & & 5 & & & & & & 1 & 1 & 1 & & & & E 87.333 & 8 \\
\hline 152 & 1 & & & 1 & & 3 & 3 & 2 & 33 & 3 & & 2 & 1 & 8 & 35 & 3 & 3 & & 1 & & R 35.333 & 2 \\
\hline 153 & & & & & 98 & & & & & 1 & & & & & & & & & & 1 & F 98.000 & 9 \\
\hline 154 & 6 & 1 & 16 & 9 & 1 & 1 & & 1 & 1 & 19 & 1 & 2 & & & 2 & 25 & 6 & 7 & & 3 & S 24.667 & 1 \\
\hline 155 & 7 & 1 & 1 & 5 & 1 & 1 & 7 & 1 & 1 & 6 & & & & 27 & 3 & 7 & 3 & & & 27 & QY 27.333 & 2 \\
\hline 156 & & & 18 & 1 & & 72 & 2 & & 1 & & & 3 & & 1 & & 1 & 1 & & & & G 72.000 & 6 \\
\hline 157 & 1 & & 3 & 26 & 1 & & 21 & 1 & 5 & 3 & 4 & 7 & & 3 & 7 & 4 & 13 & & & 3 & E 26.000 & 2 \\
\hline 158 & 3 & & & & 23 & & & 8 & & 19 & 3 & & & & & & & 11 & 33 & & W 33.333 & 5 \\
\hline 159 & 3 & & 3 & 1 & & 1 & 2 & & 3 & 4 & & & & 41 & 40 & 1 & 1 & 2 & & & Q 41.333 & 6 \\
\hline 160 & 11 & & & & 3 & 3 & & 1 & & 27 & 1 & 2 & & 4 & & 46 & 1 & 1 & & & S 46.000 & 6 \\
\hline 161 & 1 & 3 & 1 & 1 & 1 & & 37 & 9 & 13 & 3 & 2 & 3 & & 9 & 9 & 1 & & 5 & & 3 & Н 36.667 & 2 \\
\hline 162 & & 1 & & & 1 & & & 1 & & 23 & & 16 & & & & 2 & 56 & & 1 & & Т 56.000 & 8 \\
\hline 163 & 1 & & 18 & 66 & & & 1 & & 1 & & 1 & 3 & & 4 & 3 & 3 & & & & & E 66.000 & 7 \\
\hline 164 & & & & & & & & 79 & & 3 & & & & & & & & 18 & & & I 79.333 & 7 \\
\hline 165 & & & & 2 & 1 & & 1 & & & 1 & & 1 & & 1 & 23 & 1 & 1 & 1 & 36 & 32 & W 36.000 & 6 \\
\hline 166 & & 1 & & & & & 1 & 1 & 1 & 12 & 13 & & & 35 & 31 & & & 4 & 2 & 1 & Q 34.667 & 7 \\
\hline 167 & 3 & & 50 & 8 & & 3 & 1 & & 1 & 1 & 1 & 9 & & 22 & 1 & 1 & & & & & D 50.000 & 5 \\
\hline 168 & & & 13 & 4 & & 71 & & & 1 & & & 9 & & 1 & & 1 & & & & & G 70.667 & 3 \\
\hline 169 & 1 & 1 & 3 & 19 & & & 1 & 3 & 25 & 1 & & & & 17 & 15 & 1 & 2 & 11 & & & K 25.333 & 1 \\
\hline 170 & 1 & & & & & & & 1 & 1 & 47 & & & 47 & & 2 & & 1 & & 1 & & P 47.333 & 6 \\
\hline 171 & 5 & & & & 1 & 7 & & 7 & & 63 & & & & 1 & & & & 17 & & & L 63.333 & 6 \\
\hline 172 & 2 & & & & 1 & & & 1 & & 7 & 2 & & & & & 1 & & 21 & 64 & 2 & W 64.000 & 6 \\
\hline 173 & & & & & 19 & & 21 & 39 & 1 & 5 & & & & & & & 3 & 1 & 1 & 11 & I 38.667 & 6 \\
\hline 174 & & & 67 & 33 & & & & & & & & & & & & & & & & & D 67.333 & 9 \\
\hline 175 & & & & & & 3 & 27 & & & & & 1 & 1 & 5 & 63 & & & & & & R 63.333 & 8 \\
\hline 176 & 1 & & & & 1 & 6 & & 21 & & 10 & & & & 59 & & & 1 & 1 & & & Q 58.667 & 8 \\
\hline 177 & 1 & 1 & 1 & & 1 & 1 & 3 & 3 & 23 & 3 & 1 & 2 & & 3 & 28 & 1 & 1 & 1 & 23 & 3 & R 28.000 & 3 \\
\hline 178 & & & & & 3 & & & 18 & & 67 & 1 & & & & & & 1 & 11 & & & L 67.333 & 5 \\
\hline 179 & 5 & 1 & 5 & 4 & 1 & 1 & 4 & 3 & 2 & 1 & 1 & 7 & 31 & 5 & 5 & 7 & 5 & 13 & & & P 30.667 & 1 \\
\hline 180 & 9 & & & & & 61 & & & & & & 1 & 29 & & & & & & & & G 61.333 & 7 \\
\hline 181 & 15 & 1 & 8 & 7 & & 25 & 1 & & 3 & 1 & & 13 & 1 & 2 & 4 & 19 & 1 & & & & G 25.170 & 1 \\
\hline 182 & 3 & & 28 & 32 & & 1 & 1 & 1 & 4 & 1 & 1 & 3 & 2 & 6 & 2 & 7 & 5 & 3 & 1 & & E 31.757 & 1 \\
\hline 183 & 10 & & 7 & 21 & & 21 & 1 & & 6 & & & 3 & 2 & 22 & 1 & 3 & 3 & 1 & & & Q 22.000 & 3 \\
\hline 184 & 4 & & 5 & & & 1 & 1 & 12 & 1 & 28 & 4 & 13 & 2 & & 1 & 5 & 5 & 16 & 1 & & L 27.891 & 1 \\
\hline 185 & & & & & 25 & & & 16 & & 41 & 15 & & & & & & & 3 & 1 & & L 40.667 & 4 \\
\hline 186 & 4 & & 27 & 9 & & 2 & 21 & 2 & 3 & & & 10 & & 2 & 3 & 7 & 7 & & & 3 & D 26.667 & 1 \\
\hline 187 & 6 & & 1 & 1 & & 20 & & & 1 & 1 & & 3 & & & & 66 & 1 & & & & S 66.000 & 7 \\
\hline 188 & 3 & & & & 1 & & 2 & 9 & & 21 & 1 & 1 & 58 & & 1 & 1 & & 1 & & 1 & Р 58.219 & 4 \\
\hline 189 & 4 & 1 & & & & 27 & 33 & 19 & 1 & 4 & 2 & 3 & 1 & & 1 & 1 & & 3 & 2 & & Н 33.333 & 6 \\
\hline 190 & 4 & & 1 & & 20 & 65 & 1 & & & 5 & 1 & & & & 1 & 2 & & & & 1 & G 65.333 & 6 \\
\hline 191 & & & & & 1 & & & & & 73 & 25 & & & & & & & & 1 & & L 72.667 & 9 \\
\hline 192 & 33 & & 19 & 27 & 1 & 4 & 1 & & 1 & 3 & & 4 & & 1 & 3 & 3 & & & & & A 32.667 & 5 \\
\hline 193 & & & 1 & & & 93 & & & & & & 3 & & & 1 & 1 & & & & & G 93.333 & 7 \\
\hline 194 & 1 & 3 & 1 & 1 & 11 & & 9 & & 11 & 1 & & 6 & & 27 & 1 & & & & 1 & 29 & Y 29.333 & 1 \\
\hline 195 & 5 & & & & & & & & & & & & 53 & 1 & & 15 & 26 & & & & P 52.667 & 6 \\
\hline 196 & 1 & & & & & & 28 & 19 & & 3 & 3 & & & & & 1 & & 45 & & & V 45.333 & 8 \\
\hline 197 & 5 & 5 & & & 23 & & & 7 & & 24 & 4 & & & 1 & & 1 & 3 & 27 & & 1 & V 26.667 & 4 \\
\hline 198 & 36 & & & & & 63 & & & & 1 & & & & & & & & & & & G 63.333 & 6 \\
\hline 199 & & & & & & & & & & & & 3 & & & & 53 & 44 & & & & S 52.667 & 8 \\
\hline 200 & & & & & 15 & & & & & 61 & 24 & & & & & & & 1 & & & L 60.667 & 6 \\
\hline 201 & 10 & & & & 4 & & & 35 & & 23 & 3 & & & & & 1 & 3 & 17 & 1 & 3 & I 35.333 & 4 \\
\hline 202 & 18 & 2 & & & 2 & 1 & & 3 & & 5 & 1 & & & & & & & 37 & 22 & 9 & V 37.333 & 3 \\
\hline 203 & 1 & & & & & & & 27 & & 6 & 1 & & & & & 6 & 20 & 37 & & 2 & V 36.667 & 3 \\
\hline 204 & 3 & 1 & 2 & & 1 & 73 & & 1 & 1 & & & 1 & 4 & 1 & & 11 & & & & & G 73.333 & 4 \\
\hline 205 & 1 & 1 & 10 & 42 & 1 & 3 & 3 & & 9 & 1 & & 3 & 3 & 15 & 1 & 5 & 1 & 1 & & & E 41.667 & 2 \\
\hline 206 & 7 & & 2 & 11 & & 1 & & & 9 & 2 & & 3 & 23 & 23 & 2 & 5 & 6 & 5 & & 2 & PQ 23.148 & 1 \\
\hline 207 & 8 & & & & & & & 27 & & 3 & 6 & & & & & 3 & 15 & 36 & 1 & & V 36.301 & 3 \\
\hline 208 & 2 & 1 & 26 & 7 & & 2 & & & & & & 16 & 3 & & & 33 & 10 & & & & S 33.333 & 2 \\
\hline 209 & 19 & & 4 & 7 & & 3 & 3 & & 7 & 1 & 1 & 7 & 24 & 5 & 3 & 13 & 3 & 1 & & & P 24.000 & 1 \\
\hline 210 & 11 & & 21 & 54 & & 1 & 1 & & & & & 1 & & 4 & & 5 & & 1 & & & E 54.000 & 3 \\
\hline 211 & 2 & 1 & 2 & & 11 & 1 & & 17 & & 56 & 4 & & & & 1 & & 2 & 3 & 1 & 1 & L 56.000 & 2 \\
\hline 212 & & & & & & & & 18 & & 57 & 4 & & & & 1 & & & 19 & & 1 & L 56.667 & 5 \\
\hline 213 & 7 & & 28 & 49 & & & 3 & & 2 & & & 3 & & 5 & 1 & 1 & 2 & & & & E 48.667 & 5 \\
\hline 214 & 6 & & & 13 & & & 3 & 2 & 24 & 5 & 1 & 1 & & 13 & 24 & 2 & 5 & 1 & & & KR 24.000 & 1 \\
\hline 215 & 26 & 25 & & & & & & 7 & & 30 & & & & & & 1 & 1 & 11 & & & L 30.000 & 5 \\
\hline 216 & 1 & 1 & & & & 1 & 3 & 1 & 1 & & & 1 & & 5 & 66 & 1 & & & & 21 & R 66.000 & 7 \\
\hline 217 & 9 & & 6 & 23 & & 3 & 1 & & 1 & 2 & 1 & 13 & & 9 & & 26 & 4 & 1 & & 1 & S 26.000 & 1 \\
\hline 218 & 12 & 1 & & 4 & 1 & 1 & 1 & 5 & 1 & 59 & 3 & & & 1 & & 3 & 5 & 5 & & 1 & L 58.667 & 1 \\
\hline 219 & 1 & 2 & 1 & & 6 & 2 & & 26 & & 12 & 4 & & 1 & & 2 & 3 & 4 & 5 & 31 & 1 & W 30.702 & 1 \\
\hline 220 & 5 & 2 & 13 & 5 & & 5 & 7 & 3 & 7 & 5 & 1 & 10 & 3 & 15 & 2 & 7 & 7 & 1 & & 2 & Q 15.315 & 1 \\
\hline 221 & 9 & & 13 & 15 & & 5 & 5 & 1 & 5 & 3 & 1 & 7 & 11 & 7 & 6 & 8 & 3 & 2 & & & E 15.333 & 1 \\
\hline 222 & 5 & 3 & 1 & & 11 & 25 & 2 & 1 & & 4 & & 1 & 4 & & & 7 & 2 & 24 & 1 & 11 & G 24.667 & 1 \\
\hline 223 & 3 & 1 & 3 & 21 & 1 & 1 & 1 & 2 & 17 & 7 & & 1 & & 9 & 27 & 3 & 3 & & & 1 & R 26.667 & 1 \\
\hline
\end{tabular}




\begin{tabular}{|c|c|c|c|c|c|c|c|c|c|c|c|c|c|c|c|c|c|c|c|c|c|c|}
\hline 224 & 12 & 1 & & & 14 & 23 & 1 & 15 & & 1 & 3 & & & 1 & 1 & 3 & 7 & 17 & 1 & 1 & G 22.667 & 1 \\
\hline 225 & 3 & 1 & 21 & & & 75 & & & & & & 1 & & & & 1 & & & & & G 74.667 & 8 \\
\hline 226 & 10 & & & & 1 & & & 11 & & 40 & 1 & & 1 & & & & & 37 & & & L 40.000 & 6 \\
\hline 227 & & & & & & & & & & & & & & & & 37 & 63 & & & & T 62.667 & 8 \\
\hline 228 & 4 & & & 3 & 1 & & 1 & 1 & 4 & 11 & 3 & 1 & & 35 & 33 & 2 & 2 & & & & Q 35.333 & 4 \\
\hline 229 & & & & & 1 & & & 4 & & 86 & 4 & & 1 & & & & 2 & 3 & & & L 86.000 & 7 \\
\hline 230 & 9 & & 4 & 15 & & & & 2 & 3 & 3 & 4 & 1 & 37 & 7 & & 9 & 4 & 1 & & & P 36.667 & 2 \\
\hline 231 & 4 & & & 2 & & 2 & & 33 & & & & & & & & 2 & 2 & 53 & & & V 53.333 & 5 \\
\hline 232 & 1 & 3 & 3 & 3 & & 27 & 11 & 1 & 2 & 1 & 1 & 9 & 19 & 5 & 1 & 11 & 1 & & & & G 26.667 & 1 \\
\hline 233 & & & & & & 65 & 1 & 1 & & 26 & 1 & & & & & & & 7 & & & G 64.667 & 7 \\
\hline 234 & & & & & 33 & & & 7 & & 57 & 1 & & & & & & & 2 & & & L 56.667 & 5 \\
\hline 235 & & 2 & & & & 1 & & 5 & & 37 & 1 & & & & & 11 & 13 & 29 & & & L 37.333 & 6 \\
\hline 236 & 27 & 39 & & & & 2 & & 17 & & 6 & & & & & & & & 9 & & & C 39.333 & 6 \\
\hline 237 & & & & & & & & & 1 & & & & & & 99 & & & & & & R 99.333 & 9 \\
\hline 238 & 5 & 23 & & & & & & 13 & & & 1 & & & & & & & 14 & 1 & 44 & Y 44.000 & 7 \\
\hline 239 & & & & & 1 & & 1 & 1 & & 57 & 2 & & & 2 & 37 & & & & & & L 57.333 & 8 \\
\hline 240 & 48 & & 1 & & & 50 & & & & & & & & & & 1 & & & & & G 50.000 & 8 \\
\hline 241 & 5 & 1 & 11 & & 1 & 3 & 11 & & 1 & 1 & & 32 & 3 & 1 & 1 & 23 & 2 & 1 & & 3 & N 32.000 & 2 \\
\hline 242 & 2 & & 1 & 21 & 1 & 4 & 1 & & 3 & 1 & & 2 & & 1 & 2 & 53 & 5 & & 3 & 1 & S 52.667 & 6 \\
\hline 243 & 21 & 1 & & & & 1 & & 1 & & & & & & & & 15 & 61 & 1 & & & T 60.667 & 7 \\
\hline 244 & 6 & & 1 & 11 & 1 & 1 & & 1 & & 22 & & & 1 & 33 & & 17 & 7 & & & & Q 32.667 & 6 \\
\hline 245 & 6 & & 3 & 34 & & & 12 & 2 & 2 & 9 & 1 & & 2 & 8 & 1 & 2 & 9 & 9 & 1 & & E 34.000 & 2 \\
\hline 246 & 38 & & & & & 1 & & 29 & & 2 & & & & & & & 1 & 29 & & & A 38.000 & 8 \\
\hline 247 & & & & 27 & & & 1 & 3 & 3 & 4 & & & & & 62 & & & & & & R 62.000 & 8 \\
\hline 248 & 19 & & 3 & 2 & & 5 & 4 & & 7 & 2 & & 26 & & 4 & 21 & 3 & 2 & 1 & & & N 26.000 & 2 \\
\hline 249 & 1 & 2 & & & 1 & & & 18 & & 10 & 2 & & & & & & & 3 & 63 & & W 62.667 & 5 \\
\hline 250 & & & & & 63 & & 1 & 3 & & 27 & 5 & & & & 1 & & 1 & 1 & & & F 62.667 & 6 \\
\hline 251 & 7 & & 1 & 1 & 1 & 2 & & 33 & & 2 & 3 & 8 & & 1 & 3 & 9 & 27 & 1 & & & I 33.333 & 3 \\
\hline 252 & 15 & 1 & 15 & 23 & & 6 & 1 & & 3 & & & 8 & & 11 & 5 & 9 & 1 & 2 & & 1 & E 22.667 & 1 \\
\hline 253 & 3 & 19 & & & 3 & & & 13 & & 23 & & & & & & & 1 & 37 & & 1 & V 36.667 & 6 \\
\hline 254 & 1 & & & & & & 24 & & & & & & & 2 & & 1 & & & 72 & & W 72.000 & 8 \\
\hline 255 & 3 & 1 & 1 & 2 & & 1 & 9 & & 9 & 2 & 1 & 2 & & 43 & 21 & 2 & 3 & & & & Q 43.333 & 4 \\
\hline 256 & 5 & 1 & 1 & & 2 & & 1 & 18 & & 52 & 6 & & & 1 & 5 & 1 & 1 & 4 & & & L 52.027 & 2 \\
\hline 257 & 1 & & & & & & & 30 & & 61 & & & & & & & 1 & 6 & & & L 61.486 & 7 \\
\hline 258 & & 1 & & & & & 1 & & 1 & & & 2 & & & 75 & 19 & 1 & & & 1 & R 75.000 & 8 \\
\hline 259 & 1 & & 1 & 14 & & 2 & 1 & 2 & 3 & 7 & 5 & & 33 & 15 & 2 & 4 & 2 & 7 & 1 & & P 32.877 & 1 \\
\hline 260 & 25 & & 3 & 21 & 1 & & 3 & & 8 & 2 & & 4 & 1 & 2 & 1 & 25 & 2 & 1 & & & AS 24.658 & 4 \\
\hline 261 & 1 & 3 & & & 17 & & 1 & 3 & & 32 & 1 & & & & & 1 & 1 & 3 & 27 & 9 & L 32.192 & 1 \\
\hline 262 & & 2 & & & 19 & 1 & 1 & 1 & & 50 & 3 & 6 & & 3 & 1 & 3 & 5 & 2 & 1 & 3 & L 49.650 & 1 \\
\hline 263 & 1 & & 2 & 3 & & 45 & 6 & & 1 & & & 22 & & 11 & 1 & 7 & 1 & & & & G 44.928 & 1 \\
\hline 264 & & & & & & & & & 16 & & & & & 1 & 83 & & & & & & R 82.727 & 8 \\
\hline 265 & 45 & & & & & & & & & 9 & & & & & & & & 45 & & & AV 45.455 & 7 \\
\hline
\end{tabular}




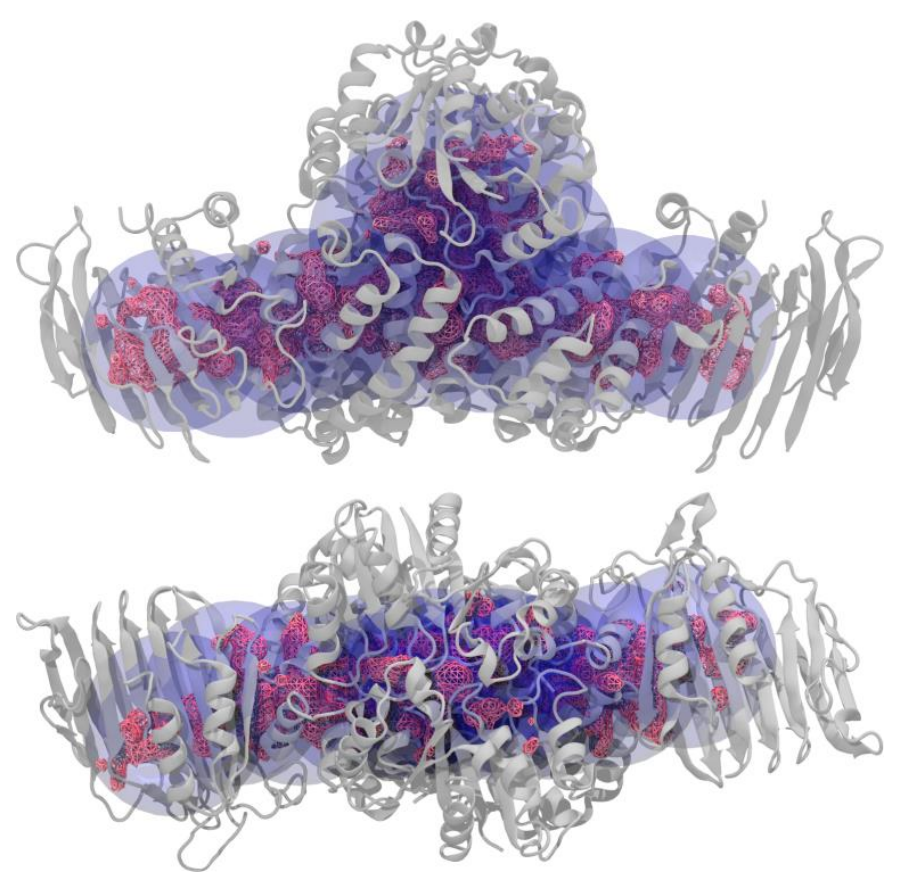

Figure 12-SI. Density isosurface of the water molecules found inside the $H p U$ reDFG tunnels contoured at 0.025 oxygen atom $\AA^{-3}$ (purple mesh) superimposed on the fourteen spheres (light blue) used to discriminate the time frames in which selected waters lied inside or outside the tunnels. The $H p \mathrm{UreDFG}$ complex is reported as white ribbons. In the bottom panel, the $H p \mathrm{UreDFG}$ complex is rotated by $90^{\circ}$ around the horizontal axis with respect to the orientation in the top panel.

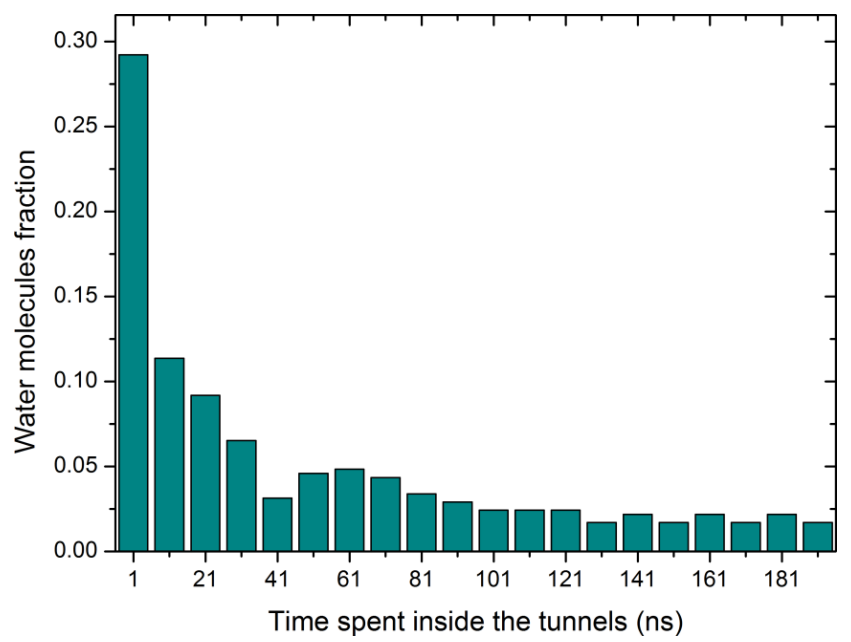

Figure 13-SI. Distribution of the time spent inside the tunnels of the 370 water molecules that are able to enter in the tunnels from the bulk of the solvent or that escape from the tunnels during the course of the simulation (see main text for details). 
Figure 14-SI (part one). Trajectory of selected water molecules inside the HpUreDFG tunnels (see main text for details). In each frame, the water molecule is reported as a sphere colored from red to green and finally to blue, accordingly to the simulation time. The starting frame is indicated by a red sphere of larger radius with respect to the others and a black arrow. The $H p$ UreDFG complex is reported as white ribbons and GDP is depicted as balls-and-sticks.
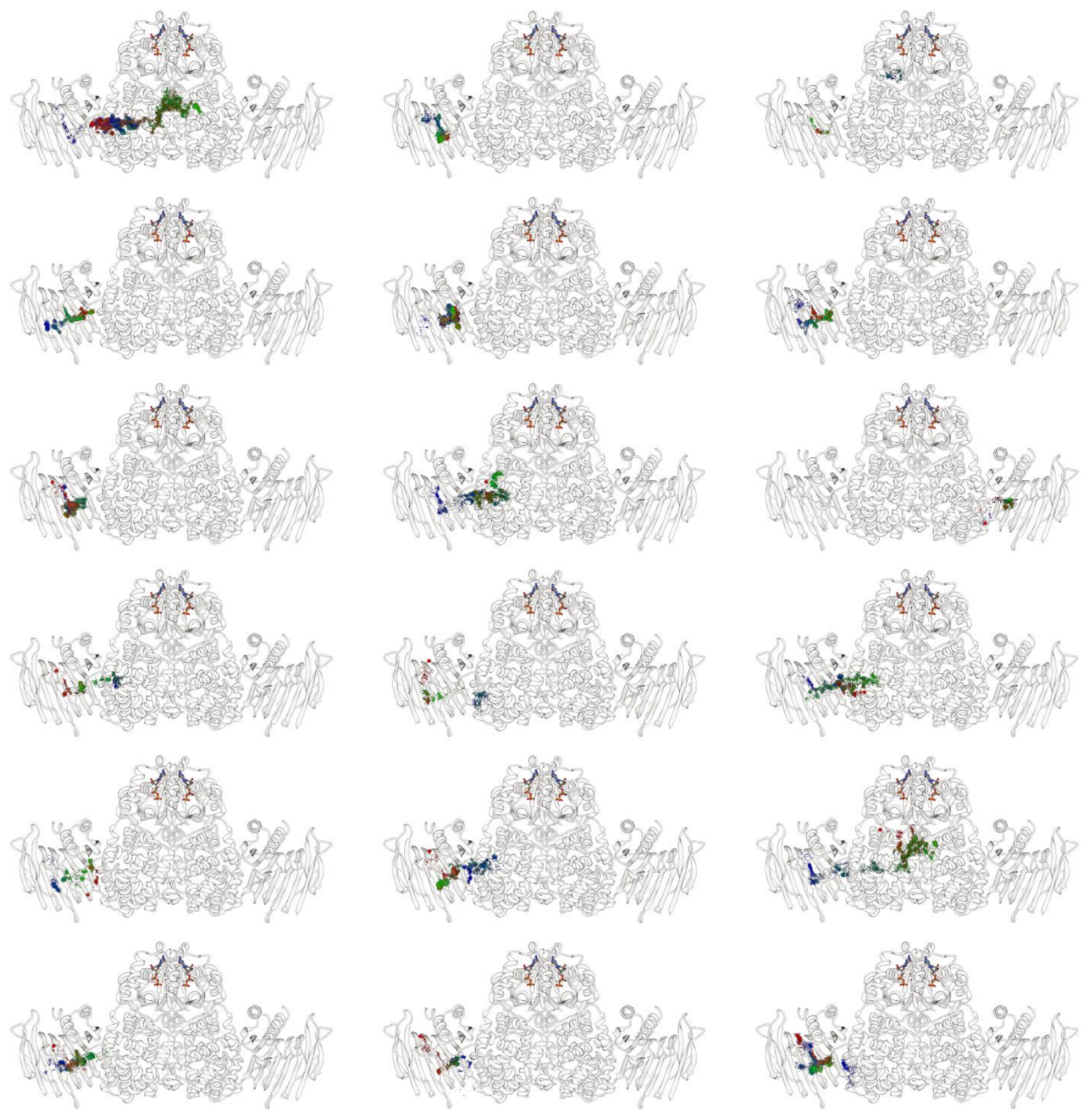
Figure 14-SI (part two).
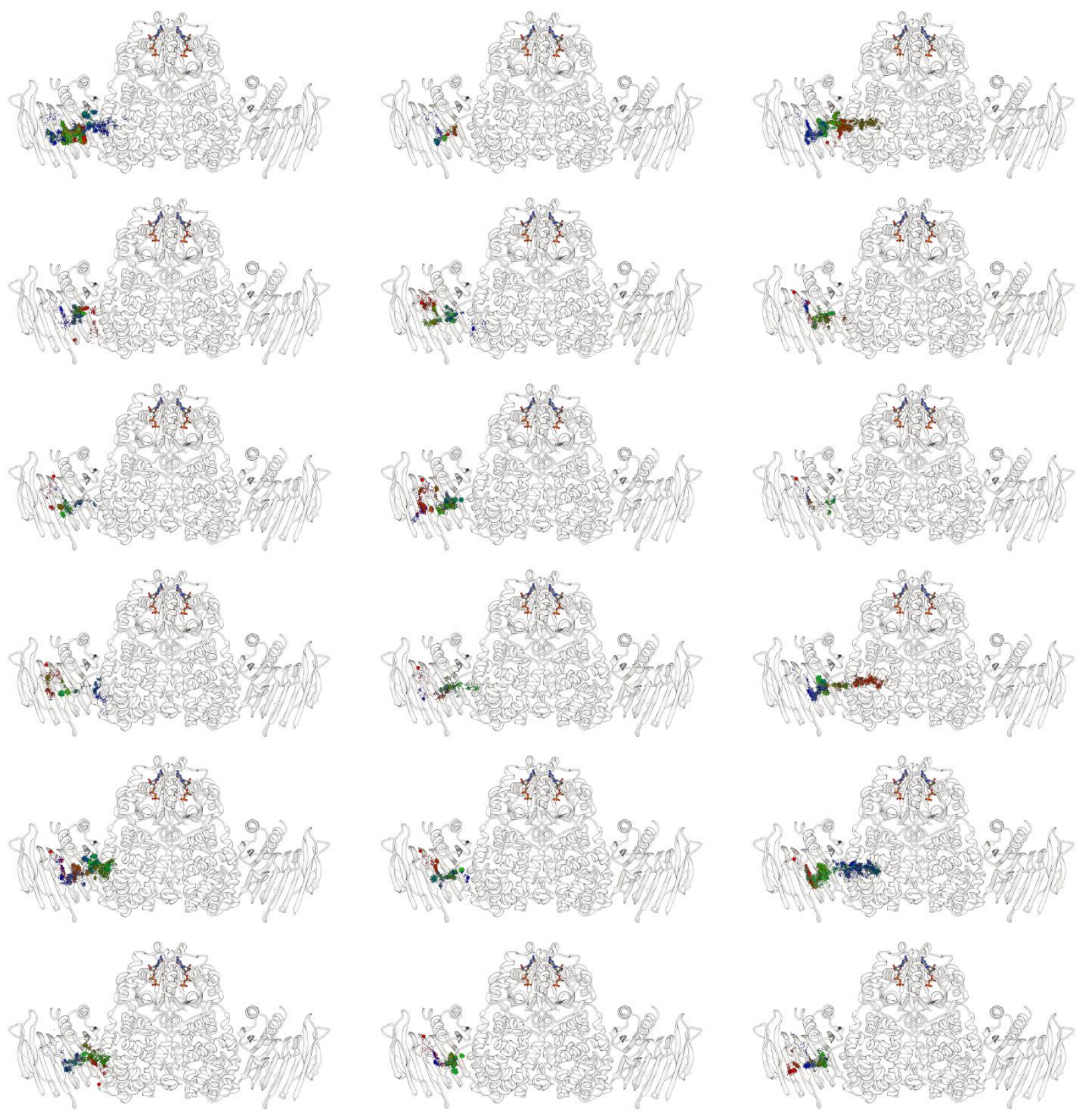


\section{Figure 14-SI (part three).}
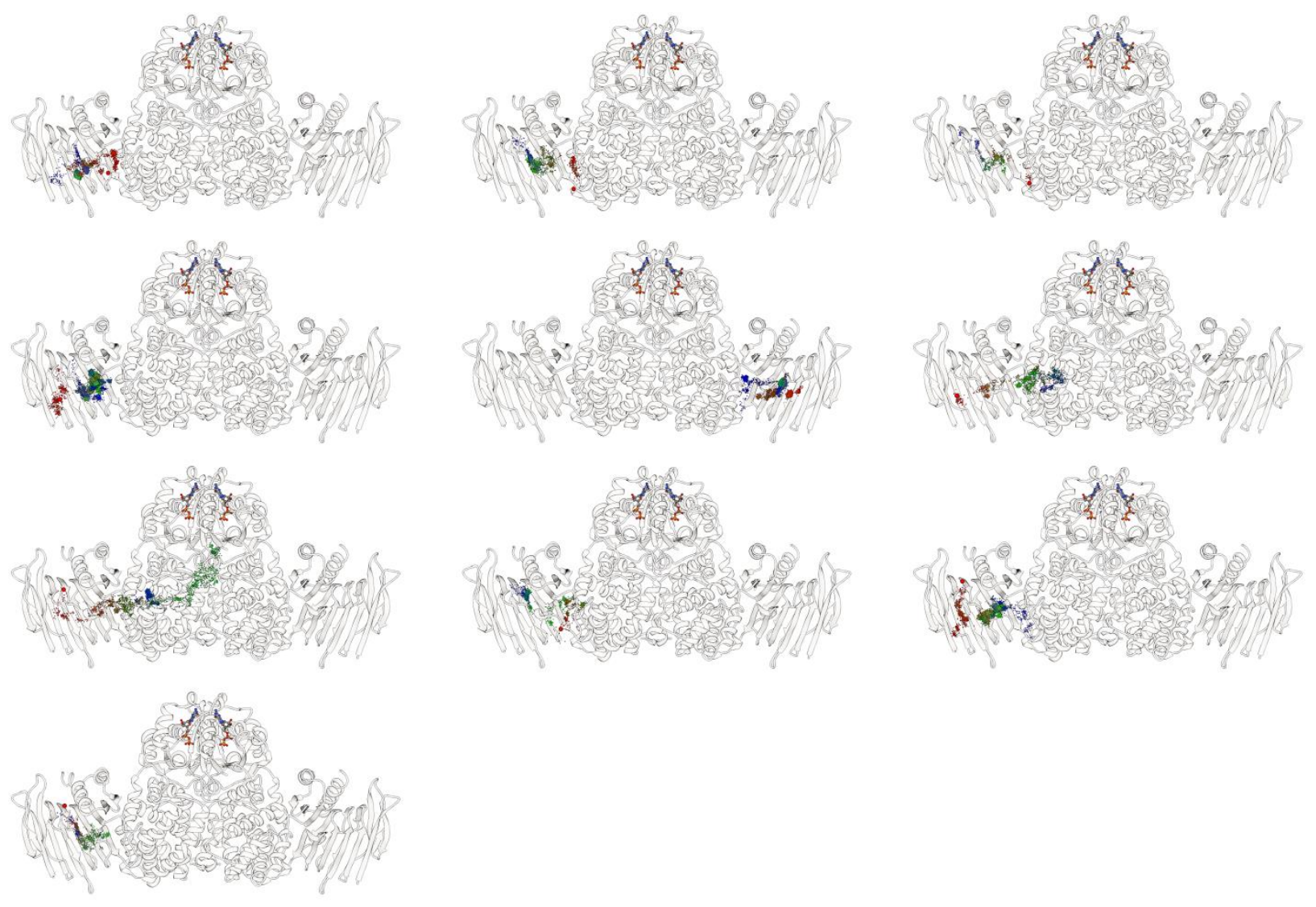

\section{REFERENCES}

1. Musiani, F., Ippoliti, E., Micheletti, C., Carloni, P., and Ciurli, S. (2013) Conformational fluctuations of UreG, an intrinsically disordered enzyme, Biochemistry 52, 2949-2954.

2. Celniker, G., Nimrod, G., Ashkenazy, H., Glaser, F., Martz, E., Mayrose, I., Pupko, T., and Ben-Tal, N. (2013) ConSurf: Using Evolutionary Data to Raise Testable Hypotheses about Protein Function, Isr. J. Chem. 53, 199-206. 